\title{
Depressão puerperal em adolescentes cadastradas na Estratégia Saúde da Família do município de Embu Guaçu - SP
}

Elisabeth Octaviano Kogima

Tese apresentada ao Programa de PósGraduação em Saúde Pública da Faculdade de Saúde Pública da Universidade de São Paulo para obtenção do título de Doutor em Saúde Pública.

Área de concentração: Saúde, ciclos de vida e sociedade

Orientador: Prof. Dr. Alberto Olavo Advincula Reis

São Paulo 
É expressamente proibida a comercialização deste documento, tanto na sua forma impressa como eletrônica. Sua reprodução total ou parcial é permitida exclusivamente para fins acadêmicos e científicos, desde que na reprodução figure a identificação do autor, título, instituição e ano da tese. 


\section{Agradecimentos}

A meu Deus, que, me conhecendo tão bem, guiou todos os meus caminhos, aliviou meus fardos, abriu as portas necessárias, não achando nenhuma das minhas angústias pequenas demais a ponto de não se importar com elas nem encontrando obstáculos grandes demais que $\mathrm{O}$ impedissem de me ajudar.

Ao Prof. Dr. Alberto Olavo Advincula Reis que me suportou em todos os momentos, acreditou no meu trabalho e me mostrou o tempo certo que os caminhos necessitam para que sejam percorridos na sua totalidade.

Aos meus mui amados pais que desde a meninice me ensinaram que as sagradas letras devem preceder o conhecimento, sempre me amparando em todos os desvios e retornos deste percurso acadêmico.

Ao meu marido Toyoji e meus filhos Richard e Rudolph, que transformaram muitas vezes a escuridão em claridade e luz que eles emanavam simplesmente por existirem.

Ao meu eternamente amado filhinho William que transformou meus caminhos durante o curto tempo que passou comigo.

Às minhas estimadas e mui queridas alunas Glaucia Moreno e Bruna de Moraes que percorreram muitos quilômetros comigo entre São Paulo e Embu Guaçu me ajudando a desvendar aquele município tão cheio de particularidades.

A todas as ESF que me receberam calorosamente e abraçaram esta pesquisa comigo, fazendo com que eu me sentisse parte de sua realidade.

Ao pessoal do Departamento Saúde, ciclos da vida e sociedade, que sempre presente, vem me apoiando em todas as minhas necessidades nestes últimos quatro anos. 
Kogima, E.O. Depressão puerperal em adolescentes cadastradas na Estratégia Saúde da Família do município de Embu Guaçu - SP São Paulo; 2010. [Tese de Doutorado - Faculdade de Saúde Pública da USP].

\section{Resumo}

A depressão maior tem sido considerada comum, recorrente e debilitante principalmente durante a adolescência. Quando nesta fase do ciclo da vida, a menina adolescente engravida e se torna mãe, a situação se configura um problema de Saúde Pública. Em si, a adolescência já é um processo de mudança tanto física, como psicológica, quanto mais se neste período uma gravidez for vivenciada. Ter um bebê é uma decisão bastante difícil e a complexidade dos fatores envolvidos torna de grande importância o apoio das famílias envolvidas. Desta forma, a maternidade pode se apresentar como fator relevante no desenvolvimento da depressão feminina muitas vezes relacionada ao estresse que o evento pode provocar. Objetivo: Determinar a prevalência do transtorno depressivo em puérperas adolescentes que são atendidas nas Unidades de Estratégia de Saúde da Família do Município de Embu Guaçu e caracterizar as puérperas adolescentes com grande probabilidade de desenvolverem transtorno depressivo. Método: Foram rastreadas as puérperas adolescentes com grande probabilidade de transtorno depressivo a fim de determinar a prevalência do transtorno depressivo pós-parto através da EPDS e do Questionário socioeconômico e obstétrico elaborado pela pesquisadora. Análise dos resultados: As variáveis quantitativas foram descritas por meio de medidas de tendências centrais, de variabilidades e intervalo de confiança. As qualitativas foram apresentadas por frequências e proporções. Resultados: $39 \%(n=18)$ das adolescentes apresentaram sintomas de depressão pós-parto, com pontuação maior ou igual a doze, com IC95\% (25; 54). $15,21 \%$ (7) das puérperas adolescentes obtiveram pontuação maior ou igual a 9 e menor que 12, o que representa moderada possibilidade de desenvolver um quadro depressivo. As adolescentes parecem ser mais novas do que os seus parceiros, têm filhos com cerca de 5 meses, moram 
juntos com parceiros, são brancas, com ensino médio incompleto. Pouco mais da metade tem renda de até oitocentos reais, a maioria usa algum tipo de medicamento e não utiliza drogas ou substâncias ilícitas.

Descritores: Adolescente; Puérpera; Gravidez e/ou gestação; Depressão.

Kogima, E.O. Postpartum depression in adolescents enrolled at Family Health Strategy in the city of Embu Guaçu/ Depressão puerperal em adolescentes cadastradas na Estratégia Saúde da Família do município de Embu Guaçu - SP São Paulo, 2010. [Doctorade Thesis - Faculdade de Saúde Pública da USP,

\section{Summary}

Major Depression has been considered common, recurrent and debilitating, especially in adolescence. When adolescent girls become pregnant at this stage of the life cycle, situation becomes a public health problem. Adolescence itself is already a changing process, physical and psychological, much more when a pregnancy is experienced. It's a very difficult decision having a baby, with complexes factors involved, what suggests the need of support from the families involved. Motherhood presents itself as a relevant factor in the development of female depression, often related to stress. Objective: To set the prevalence of depressive disorder in post partum adolescents who are enrolled at Family Health Strategy and characterize those who have great probability of developing depressive disorders. Methods: Post partum adolescents were screened through EPDS and characterized by a Socioeconomic and obstetric questionnaire constructed by the researcher. Analysis: Quantitative variables were described by measures of central tendency, and variability of the confidence interval. Qualitative variables were presented as frequencies and proportions. Results: $39 \%(n=18)$ of adolescents had postpartum depression symptoms, with scores greater than or equal to twelve, with CI95\% $(25,54) .15 .21 \%(7)$ of the adolescent mothers scored higher than or equal to 9 and less than 12 , 
which represents moderate possibility of developing a depressive disorder. The teenagers seem to be younger than their partners, their babies have about five months, most of them live together with partners, are white, with incomplete secondary education. Slightly more than half have incomes of up to 400 dollars, most use some kind of medication and does not use drugs or illegal

substances.

Descriptors: Adolescents; post partum; pregnancy; depression. 


\section{ÍNDICE}

1 INTRODUÇÃO 10

2 TRANSTORNO DO HUMOR - DEPRESSÃO 13

2.1 Histórico 13

2.2 Epidemiologia 16

3 DEPRESSÃO PUERPERAL 19

3.1 Caracterização 19

3.2 Classificação e critérios 25

3.3 Epidemiologia 32

3.4 Etiologia $\quad 36$

3.5 Implicações para o bebê $\quad 40$

3.6 Depressão puerperal em homens $\quad 45$

3.7 Diagnóstico, prevenção e tratamento precoce $\quad 49$

3.8 Recomendações de tratamento 55

4 ADOLESCÊNCIA

4.1 Aspectos políticos $\quad 59$

4.2 Gravidez na adolescência $\quad 64$

4.3 Gravidez, depressão e suicídio 68

4.4 Depressão pós-parto na adolescência 81

5 OBJETIVOS 85

6 FINALIDADES $\quad 86$

7 MÉTODO 87

7.1 DESCRIÇÃO DO LOCAL DA PESQUISA

7.2 SUJEITOS DO ESTUDO 89

7.3 PROCEDIMENTOS PARA A COLETA DE DADOS 89

7.4 ASPECTOS ÉTICOS E LEGAIS 92

7.5 ANÁLISE DOS DADOS 92

8 RESULTADOS E DISCUSSÃO 93

9 CONCLUSÃO 133

10 REFERÊNCIAS BIBLIOGRÁFICAS 142

11 CURRÍCULO LATTES 162 


\section{ANEXOS}

Anexo 1 - Escala de Depressão pós-parto de Edimburgo (EPDS)

Anexo 2 - Questionário socioeconômico e obstétrico

Anexo 3 - Termo de consentimento livre e esclarecido

Anexo 4 - Variáveis utilizadas

Anexo 5 - Resultado do exame de qualificação 


\section{Lista de Tabelas}

Tabela 1 - Distribuição em frequências e porcentagens da EPDS das adolescentes puérperas atendidas na Estratégia de Saúde da Família do Município de Embu Guaçu com pontuação maior ou igual a 12 segundo a EPDS. 2008/2009 p.95

Tabela 2 - Prevalência do transtorno depressivo em adolescentes puérperas atendidas na Estratégia de Saúde da Família do Município de Embu Guaçu com pontuação maior ou igual a 12 segundo a EPDS. 2008/2009.

Tabela 3 - Características sociodemográficas das adolescentes puérperas atendidas na Estratégia de Saúde da Família do Município de Embu Guaçu, com pontuação maior ou igual a 12 segundo a EPDS. 2008/2009. p.102

Tabela 4 - Características de aspetos relacionados à moradia das adolescentes puérperas atendidas na Estratégia de Saúde da Família do Município de Embu Guaçu, com pontuação maior ou igual a 12 segundo a EPDS. 2008/2009.

Tabela 5 - Características dos aspectos relacionados à maternidade das adolescentes puérperas atendidas na Estratégia de Saúde da Família do Município de Embu Guaçu, com pontuação maior ou igual a 12 e com pontuação menor que 12 segundo a EPDS. 2008/2009.

p.113

Tabela 6 - Características dos aspectos relacionados à Estratégia da Saúde da Família do Município de Embu Guaçu percebidas pelas adolescentes puérperas com pontuação maior ou igual a 12 segundo a EPDS. 2008/2009. 


\title{
1 INTRODUÇÃO
}

\author{
O SOFRIMENTO MENTAL
}

O mero correr dos olhos na temática desta pesquisa já se remete à complexidade que a compõe. São necessários novos olhares destituídos de velhos conceitos a fim de tornar-se possível a compreensão deste momento de vida da mulher adolescente.

Os portadores de sintomas depressivos podem ser identificados em diversos espaços como na comunidade, escolas, clínicas, hospitais e nos centros de saúde mental (SILVA; FUREGATO; COSTA JÚNIOR, 2003), inclusive nas maternidades ou nos domicílios de mães com crianças de colo.

$\mathrm{O}$ portador de transtorno mental é facilmente percebido devido às suas diferenças de comportamento estipuladas pela sociedade como fora do normal. Devido a não compreensão da sociedade acerca do sofrimento psíquico, o portador acaba sofrendo com a exclusão social, não sendo aceito pelos padrões normais do grupo em que convive (SPADINI; SOUZA, 2006).

Os transtornos mentais são comuns em todos os países e causam imenso sofrimento. Pessoas com esses transtornos possuem um baixo nível de qualidade de vida e estão sujeitas à crescente mortalidade. Um quarto dos clientes que procura serviços de saúde possui pelo menos uma desordem mental, neurológica ou comportamental que, na maioria das vezes, não seria diagnosticada nem tratada (STEFANELLI; FUKUDA; ARANTES, 2008).

No início da era psiquiátrica a família do portador de transtorno mental não participava do tratamento, não o acompanhando e sendo totalmente ausente e sem interesse na vida que o familiar enfrentava. $O$ afastamento da família era levado em conta pelos preceitos estipulados pela sociedade com relação à exclusão do doente. Esse afastamento era compreendido como uma forma de tratamento da doença, o que é diferente nos dias de hoje. A participação da família no tratamento é fundamental para uma boa recuperação. Essa visão da presença do familiar começou a mudar com o Movimento da Reforma Psiquiátrica, onde princípios foram mudados e evoluíram com o decorrer da história (SPADINI; SOUZA, 2006). 
É possível notar que a forma como o portador de transtorno mental é tratado ainda reflete as linhas duras que a história e a cultura colocaram ao longo do tempo e que nos induzem a subjugar e encarcerar o louco e a loucura (CAMPOS; ROMAGNOLI, 2007).

Tal processo acaba por minar a confiança de que os transtornos mentais são doenças passíveis de serem tratadas. Elas levam um conceito de cronicidade que acaba limitando a socialização dos portadores, como, por exemplo, ao recusar-Ihes oportunidades de emprego, de trabalho ou de moradia (FIORATI; SAEKI, 2008; GRAHAM et al., 2007).

Quaisquer ações de saúde necessitam sempre ter em vista o trabalho de resgate e recuperação do sujeito, da capacidade de produção material e simbólica da vida, para que esses usuários possam inscrever sua marca pessoal na cultura (FIORATI; SAEKI, 2008).

GRAHAM et al. (2007) salientam a importância da pesquisa para identificar meios de intervenção que reduzam as variadas formas de estigmatização e discriminação da doença mental. Para que os portadores não se sintam discriminados é importante "praticar a solidariedade que engloba múltiplos elementos da vida de cada pessoa, no caso, reabilitador e reabilitado, promovendo a valorização de pequenas coisas, gestos ou afetos" (FERREIRA et al., 2005).

É compreensível a percepção de que é difícil conviver com um portador de transtorno mental devido, muitas vezes, às atitudes de agressividade, ausência de afeto, imprevisibilidade e mesmo ao isolamento social (SPADINI; SOUZA, 2006). Tal dificuldade pode ser vivenciada não apenas pelos familiares que o cercam, mas também pelos profissionais de saúde que o assistem. $O$ agente comunitário de saúde é um dos elementos da ESF (Estratégia da Saúde da Família) que desenvolve um elo de maior intimidade e muitas vezes de cumplicidade com os familiares e com o individuo em sofrimento psíquico. No entanto, nem sempre este profissional se sente preparado para lidar com tais situações e muitas vezes não possui recursos próprios de empatia ou comunicação terapêutica.

As famílias que possuem menor poder aquisitivo, além de se incomodarem com os sintomas da doença, tendem a esperar atitudes das instituições, acompanhando passivamente as mudanças do familiar enfermo (CAMPOS; ROMAGNOLI, 2007). 
Os agentes comunitários de saúde (ACS) podem atuar como elos capazes de unir a comunidade aos serviços de saúde. CAMPOS e ROMAGNOLI (2007) acrescentam que para esta prática ser efetiva seria necessária uma capacitação e participação dos ACS em grupos oferecidos pelos CAPS (Centro de Atenção Psicossocial) de modo a conhecerem e construírem novas formas de relacionamento com o portador de transtorno mental.

Nos últimos 20 anos tem havido uma percepção mais evidente e crescente de que para algumas mulheres a gravidez pode ser acompanhada por transtornos do humor, em particular da depressão. É patente que essa percepção segue no sentido contrário ao de uma crença popular amplamente difundida de que a gravidez é um período de alegria para todas as mulheres. Os transtornos do humor durante a gravidez colocam as mulheres em risco de terem depressão pósparto (DP). Recentemente tem havido um deslocamento na literatura, de um foco voltado para os sintomas e tratamento da DP instalada para um foco no tratamento da depressão ou ansiedade durante a gravidez, a fim de evitar uma piora dos sintomas durante o período pós-parto (ZINGA; PHILIPS; BORN, 2005).

O avanço do conhecimento científico na obstetrícia tem oportunizado habilidades fundamentais aos profissionais de saúde que prestam assistência ao ciclo gravídico puerperal das mulheres. Contudo muitas vezes esta assistência mantém invisíveis os aspectos emocionais que interferem nesta etapa da vida. Se especificamente a mulher ainda estiver no período da adolescência, alem da sobrecarga emocional que implica uma gestação, estará vivenciando as transformações físicas e psicossociais que esta fase do ciclo da vida impõe.

O profissional de saúde definitivamente necessita compreender que a importância de uma avaliação clinica da mulher só se torna completa se aliada ao conhecimento e reconhecimento de seus sentimentos, medos, ansiedades e preocupações. 


\section{TRANSTORNO DO HUMOR - DEPRESSÃO}

\subsection{HISTÓRICO}

A depressão é um transtorno psiquiátrico antigo e prevalente. Em 1.500 A.C foi encontrado um papiro egípcio com inscrições acerca de um discurso sobre a velhice que dizia: "o coração torna-se pesado e não recorda o passado". O Velho Testamento registra uma síndrome depressiva do Rei Saul, com oscilação do humor entre a excitação e a depressão. Hipócrates (460-375? A.C.) conhecia os sintomas depressivos e ensinava que era um excesso de bile negra chamada de melancholi que significa "humor negro" (TAYLOR, 1992).

Moses Maimonides, médico judeu que viveu no século XVIII, classificava a melancolia como uma entidade patológica distinta. Em 1686, Bonet reconheceu um transtorno mental identificando-o como maníaca-melancholicus. Jules Fabret, em 1854 descreveu uma condição chamada de folie circulaire, em que o paciente sofreu humores intercalados de depressão e mania. Na mesma época, o psiquiatra francês Julis Baillarger demonstrou a condição folie à double forme na quais pacientes profundamente deprimidos se recuperam eventualmente. Em 1882 o alemão Karl Kahlbaum apresentou a mania e a depressão como estágios da mesma doença (SADOCK; SADOCK, 2007).

A WHO (World Health Organization, 2010) reconhece a depressão como um transtorno mental comum, caracterizado por tristeza, perda de prazer ou interesse, sentimentos de culpa ou baixa autoestima, distúrbios no sono ou no apetite, pouca energia e concentração prejudicada. Tais distúrbios podem se tornar crônicos ou recorrentes, extremamente incapacitantes quanto à habilidade de lidar com a vida diária. Conforme o grau de severidade, a depressão pode levar ao suicídio, uma fatalidade trágica associada à perda de 850.000 vidas cada ano. A maioria dos casos de depressão pode ser tratada através de medicamentos ou de psicoterapia.

No entanto, é preciso atenção, uma vez que isoladamente a palavra depressão pode se referir a um sinal, um sintoma, uma síndrome, um estado emocional, uma reação, uma doença ou uma entidade clínica (STUART; LARAIA, 2001). Frequentemente é associada a reações normais diante de determinados sofrimentos e sentimentos de perda. 
Recentemente a WHO (2010) lançou um projeto sobre depressão na saúde pública. O projeto tem como objetivo reduzir o impacto da depressão eliminando as lacunas existentes entre o custo efetivo dos tratamentos e o grande número de pessoas que não recebem este tratamento ao redor do mundo. A WHO objetiva: oferecer educação sobre o tema aos pacientes, familiares, "cuidadores" e políticos; reduzir o estigma relacionado à depressão; treinar profissionais da atenção primária no diagnóstico e manejo da depressão; incrementar a capacidade dos países em criar políticas de apoio para a melhoria dos cuidados na depressão e um gerenciamento efetivo e concreto na atenção primária.

Enquanto um estado afetivo ou uma doença, a depressão caracteriza-se como um transtorno que afeta biológica e psicologicamente os seres humanos, suscitando, portanto, o interesse pela elaboração de teorias científicas e do senso comum que auxiliem na busca da sua compreensão e explicação (COUTINHO; SARAIVA, 2008a).

Segundo STUART e LARAIA (2001), a depressão pode apresentar níveis leves, moderados e graves, com ou sem aspectos psicóticos.

Os sintomas de depressão leve são identificados através das associações com pesar normal, como por exemplo, raiva, negação de sentimentos, ansiedade, culpa, impotência, desespero, inquietação, agitação, insônia, cefaleia e dores nas costas (TOWNSEND, 2002).

A depressão moderada constitui um distúrbio mais problemático, uma vez que permanece subdiagnosticada muitas vezes. Tem como principais sintomas associados: sentimento de tristeza, desânimo, desesperança, desespero, movimentos físicos mais lentos, postura largada, fala mais lenta e os processos de pensamento retardados (TOWNSEND, 2002).

A depressão grave se caracteriza por intensificação dos sintomas descritos para depressão moderada. Os exemplos de depressão grave incluem o distúrbio depressivo maior e a depressão bipolar (TOWNSEND, 2002).

Em face de sua alta prevalência e custos sociais elevados, nos dias atuais vem sendo percebida com um problema para a saúde pública (CRUZ; SIMÕES; FAISALCURY, 2005; HORIMOTO; AYACHE; SOUZA, 2005). 
Segundo classificação do DSM-IVTR (APA, Diagnostic and Statistical Manual of Mental Disorders Text Revised, 2000) e da OMS, no CID-10 (Classificação Internacional das Doenças, 2009), os sintomas clínicos da depressão são: humor depressivo, tristeza, perda de interesse ou prazer, perda ou ganho de peso significativo, insônia (no inicio, na metade ou no final do sono) ou hipersonia, agitação ou retardo psicomotor, fadiga ou perda de energia, sentimento de inutilidade ou culpa excessiva e/ou inadequada, indecisão ou capacidade diminuída de pensar ou concentrar-se e pensamentos de morte recorrente.

O principal elemento do comportamento que se deve avaliar é a mudança que ocorre nas respostas habituais cotidianas. O choro ocorre com freqüência, pois faz parte dos sinais de humor deprimido: o individuo passa por sensação de tristeza, de chateação, de estar "na fossa", de infelicidade e/ou incapacidade de curtir a vida. A ansiedade é outro humor que vem acompanhado da depressão. Os indivíduos deprimidos encontram uma variada gama de queixas somáticas, entre elas: aflição gastrointestinal, dor intermitente ou crônica, irritabilidade, palpitações, tonturas, mudanças no apetite, falta de energia, alteração no impulso sexual ou perturbação do sono (STUART; LARAIA, 2001).

LIPPINCOTT e WILKINS (2005) apresentam as causas mais frequentes que desencadeiam esse transtorno: frequência maior em familiares de primeiro grau; problemas com neurotransmissores como norepinefrina, dopamina, acetilcolina e serotonina; doença decorrente da sensação de impotência e falta de controle diante dos eventos da vida e superego muito duro.

Diversos estudos epidemiológicos têm demonstrado diferenças de gênero na incidência, prevalência e curso de transtornos mentais e do comportamento. Mulheres apresentam maiores taxas de prevalência de transtornos de ansiedade e do humor que homens, enquanto estes apresentam maior prevalência de transtornos associados ao uso de substâncias psicoativas, incluindo álcool, transtornos de personalidade antissocial e esquizotípica, transtornos do controle de impulsos e de déficit de atenção e hiperatividade na infância e na vida adulta. Mesmo nos transtornos cuja prevalência é semelhante em homens e mulheres, são observadas diferenças na idade de início, perfil sintomatológico e resposta ao tratamento. Têm, ainda, sido identificados diferentes padrões de comorbidade psiquiátrica e física em mulheres e homens (ANDRADE et al., 2006). 
É bastante conhecida e documentada a diferença de prevalência na depressão em mulheres e em homens. Essa diferença tem sido observada em várias regiões do mundo, mediante a aplicação de diferentes instrumentos de avaliação e critérios diagnósticos operacionais. A razão entre as taxas de prevalência em mulheres e homens tem variado entre 1,5 e 3,0, com uma média de 2 mulheres para cada homem (ANDRADE et al., 2006)

Continuando com os achados de ANDRADE et al. (2006), revisões sistemáticas têm falhado em identificar associações entre fatores hormonais e taxas mais elevadas de depressão maior em mulheres. O efeito da gravidez na incidência e recorrência de depressão não tem se mostrado significativo. A única exceção parece ser o período pós-parto, associado a um aumento substancial das taxas de depressão. Episódios depressivos que se manifestam pela primeira vez nesse período ocorrem com maior frequência em mulheres que têm forte história familiar de depressão.

Existe outra teoria que procura explicar as diferenças de gênero na prevalência da depressão maior. Esta sugere que a maior persistência dos episódios depressivos em mulheres que em homens pode ser resultante das pressões sociais, estresse crônico e baixo nível de satisfação associado ao desempenho de papéis tradicionalmente femininos, ou pela forma diferencial entre gêneros de lidar com problemas e buscar soluções. Outro argumento amplamente divulgado infere que mulheres podem ter maior facilidade de identificar sintomas, admitir que estejam deprimidas e de buscar ajuda que os homens. A evidência disponível, no entanto, não permite tal conclusão. Mulheres apresentam como comorbidade maiores taxas de ansiedade associada à depressão e homens mostrando maior abuso de substâncias psicoativas e transtornos de conduta, reforçando a diferença de gênero (ANDRADE et al., 2006).

\subsection{EPIDEMIOLOGIA DA DEPRESSÃO}

A depressão é a causa principal de incapacidade ao redor do mundo e foi a quarta principal contribuinte para a carga global de doenças em 2000. É estimado que em 2020 a doença alcance o segundo lugar no ranking em todas as idades e em ambos os sexos. Atualmente a doença já está em segundo lugar se relacionada à categoria idade entre 15 e 44 anos em ambos os sexos (WHO, 2010). 
A magnitude epidemiológica dos transtornos mentais das populações no mundo é preocupante, sendo considerada a depressão um dos transtornos mentais mais incapacitantes em razão da duração, recorrência e multiplicidade de indicadores de disfunção e sofrimento (MENDES; LOUREIRO; CRIPPA, 2008).

Relatos mais recentes e alarmantes colocam que a depressão atinge pessoas de todos os gêneros, idades e experiências, sendo um transtorno comum que afeta 121 milhões de pessoas ao redor do mundo. Apesar da sua magnitude, pode ser seguramente diagnosticada e tratada na atenção primária à saúde. Mesmo assim, menos de $25 \%$ dos portadores tem acesso a tratamentos efetivos (WHO, 2010).

A prevalência de depressão na população em geral apresenta uma ampla variação. Estudos constatam índices da doença entre 3,7\% e 6,7\% ao longo da vida, e de sintomas depressivos entre $13 \%$ e $20 \%$. Mulheres e adolescentes do sexo feminino desenvolvem duas a três vezes mais depressão do que homens e adolescentes do sexo masculino (HETEM; GRAFF, 2004).

STUART e LARAIA (2001) já estimavam a predisposição do transtorno depressivo em mulheres entre 20 e $30 \%$ e em homens de 7 a 12\%. Cerca de um em cada oito adultos está predisposto a vivenciar um episódio depressivo no decorrer da vida, sendo que 11,5 milhões de pessoas em 2001 foram afetadas a cada ano, com $71 \%$ sendo mulheres. Aproximadamente $15 \%$ dos indivíduos com essa patologia comete suicídio, entre outras complicações como dificuldades conjugais, com os pais, sociais e ocupacionais. Apenas um terço de todas as pessoas com depressão recebe diagnóstico correto e recorrem a tratamentos adequados.

Segundo TOWNSEND (2002), as estimativas já sugeriam que 10 a 14 milhões de norte-americanos são afetados por alguma forma de distúrbio afetivo maior; aproximadamente $20 \%$ da população vai ter um episódio de doença depressiva pelo menos uma vez em sua vida e algumas estimativas colocam o risco em $30 \%$.

A WHO (2010) revela dados preocupantes para as próximas duas décadas um aumento vertiginoso para o número de novos deprimidos. Em 2020 a depressão representará a segunda afecção que mais perpassará os anos de vida útil da população mundial, podendo mesmo até ultrapassar o número de afetados por doenças cardiovasculares. Pode se tornar um problema crônico ou recorrente que impossibilite ao sujeito cuidar de si mesmo e de suas atividades diárias. 
Os problemas de saúde mental, particularmente a depressão, são a maior causa de incapacidade em mulheres de todas as idades. A despeito das causas da saúde-doença mental serem passíveis de variações de um indivíduo para outro, nas mulheres são considerados fatores favoráveis o status rebaixado da mulher na sociedade, sua carga de trabalho e situações de violência vivenciadas. Uma vez que a adolescência é um período de mudanças sociais, emocionais e físicas, não é de se surpreender que estas jovens mulheres estejam em risco significativo quanto a problemas mentais relacionados a transtornos depressivos unipolares, esquizofrenia e transtornos bipolares (WHO, 2010).

É estimado que 73 milhões de mulheres adultas ao redor do mundo apresentem um episódio de depressão maior a cada ano. Transtornos que sucedem o parto, inclusive a depressão pós-parto, têm afetado em torno de 13\% de mulheres no primeiro ano de vida do bebê (WHO, 2010).

$\mathrm{O}$ tratamento com medicamentos antidepressivos e psicoterapia breve e estruturada é eficaz para 60 a $80 \%$ dos portadores e pode ser operacionalizado na atenção primária à saúde. Em alguns países, menos de 10\% recebem estes tratamentos. As barreiras para tornar o tratamento viável estão relacionadas à falta de recursos, profissionais treinados e muitas vezes ao estigma associado aos transtornos mentais (WHO, 2010). 


\section{DEPRESSÃO PUERPERAL}

\subsection{CARACTERIZAÇÃO}

Tem-se observado a presença de produções sobre depressão pós-parto nos cinco continentes. A predominância dos continentes europeu e americano é evidente, destacando-se a Inglaterra. É possível que essa produção científica seja devida à maior cobrança pela Organização Mundial de Saúde para que os paísesmembros possam alcançar ou manter metas mais amplas e abrangentes na atenção à saúde da mulher. A predominância das pesquisas são as abordagens quantitativas, possivelmente pelo fato da maioria desses estudos utilizarem como instrumento de coleta de dados escalas para detecção da depressão pós-parto, e também por terem como objetivo predominante a identificação de incidência e prevalência da doença (SANTOS JÚNIOR; SILVEIRA; GUALDA, 2009).

Esses indicativos apontam para a importância de os profissionais adquirirem informações clínicas e socioculturais acerca das mulheres, buscando compreender sua realidade, estabelecendo relação empática de confiança mútua e respeito, proporcionando escuta acolhedora, onde sentimentos conflitantes possam aparecer. A partir deste vínculo que proporciona mais liberdade para relatos pessoais a avaliação do estado psíquico da puérpera se torna mais completa. Logo, é fundamental que se tenha em mente a importância da atenção precoce na DP, tendo em vista a possibilidade de intervenções profissionais que proporcionem às puérperas o apoio de que necessitam para enfrentar os desafios de ser mãe, sem perder sua identidade, inserção social, relação parental, entre tantos (SANTOS JÚNIOR, SILVEIRA, GUALDA, 2009).

A gestação é um período de transição que faz parte do processo normal do desenvolvimento humano no qual ocorrem grandes transformações, não só no organismo da mulher, mas no seu bem-estar, alterando seu psiquismo e o seu papel sócio-familiar (FALCONE et al., 2005).

Apesar de a gestação ser tipicamente considerada um período de bemestar emocional e de se esperar que a chegada da maternidade seja um momento jubiloso na vida da mulher, o período perinatal não a protege dos transtornos do humor. 
"O que teria a depressão a ver com a festa que cerca o nascimento de um bebê? Como entender que este momento considerado normal e tão comum ao ciclo vital de qualquer ser humano se transforme em um momento depressivo, com a mãe se sentindo angustiada, insegura, sensível demais, entristecida e chorando desesperadamente?" (AZEVEDO; ARRAIS, 2006).

As experiências de mães que vivem a depressão pós-natal têm como exemplo de sentimentos a solidão, ansiedade, desesperança e perda do controle, exatamente num momento em que se antecipam expectativas de felicidade (LEAHY-WARREN; MCCARTHY, 2007).

Muitas vezes atribuindo seu insucesso a um cansaço transitório, as mães não identificam o cerne de suas dificuldades. MASLACH, SCHAUFELI E LEITER (2001) descrevem que, considerando as várias definições do "burnout" (sentimento de fracasso e exaustão causados por um excessivo desgaste de energia e de recursos), são encontrados elementos comuns: predominância de sintomas relacionados à exaustão mental e emocional, fadiga e depressão; ênfase nos sintomas comportamentais e mentais e não nos sintomas físicos; sintomas relacionados ao trabalho, no caso da mãe e os cuidados com o bebê; manifestação em pessoas "normais" que não sofriam de distúrbios psicopatológicos; diminuição da efetividade e desempenho no trabalho e cuidados com a casa e o bebê.

Tais características são muito presentes em mulheres que acabaram de ter um bebê. À medida que o tempo passa, a fadiga materna aumenta, muitas vezes devido não só apenas a exaustão mental e física mas também pela privação do sono tão comum nesse período. A sobreposição de situações traz dificuldades no cumprimento do seu "dever de mãe" de modo a favorecer a diminuição da autoestima e o desencadeamento de sintomas depressivos.

AZEVEDO e ARRAIS (2006) entendem que desde a infância as meninas treinam o papel de boa mãe, segundo o qual a mulher deve ser capaz fazer muitos sacrifícios, entre eles ser amável, tranquila, compreensiva, terna, equilibrada, acolhedora, feminina em tempo integral! O modelo pronto e esperado é de uma mãe "perfeita". Nessa fantasia de contos de fadas acerca da maternidade não sobra nenhum espaço para dúvidas quanto aos sentimentos de alegria e felicidade. No entanto, na ocasião do nascimento de um filho, a maioria das mulheres experimenta sentimentos contraditórios e inconciliáveis com a imagem idealizada de maternidade ditada pela cultura. 
Emerge um cruel conflito entre o ideal que se espera da mulher e a realidade. Instaura-se assim um sofrimento psíquico que pode se configurar como uma base para a depressão após o parto (AZEVEDO; ARRAIS,2006).

De maneira geral, as crenças sobre a maternidade são divulgadas como se fossem tradicionais e naturais, e por serem concebidas assim, essas crenças se tornam inatacáveis. Contudo, é possível verificar na história da humanidade que essas ideias têm poucas centenas de anos. A boa mãe, tal qual conhecemos hoje, com sua propensão natural ao sacrifício, seu amor universal e automático pelos filhos e sua completa satisfação nas tarefas da maternidade, não foi sempre assim. Acreditamos que esta insistência em que certo estilo de maternidade seja "natural", entra em choque com a vivência da maternagem, o que leva ao sentimento de "mãe desnaturada" e muito sofrimento. Mas também tem levado muitas mulheres, na atualidade, a questionarem cada aspecto do que fazem, pensam, sentem, e a avaliar suas próprias experiências, buscando tornar mais flexível o padrão rígido e determinista cultuado socialmente (AZEVEDO; ARRAIS, 2006).

O puerpério é considerado um estado de alteração emocional essencial, provisório, em que existe maior vulnerabilidade psíquica e que, por certo grau de identificação, permite às mães se ligarem intensamente ao recém-nascido, se adaptando ao contato com ele e atendendo às suas necessidades básicas. Quando a gravidez se dá na adolescência a vulnerabilidade da nova mãe é maior ainda, necessitando de atenção especial nesta etapa. A relação inicial mãe/bebê ainda é pouco estruturada, com o predomínio de uma comunicação não verbal e, por isso, intensamente emocional e mobilizadora. Com a chegada do bebê, 0 imaginário materno desperta muitas ansiedades e os sintomas depressivos são comuns. $O$ bebê deixa de ser idealizado e passa a ser vivenciado como um ser real e diferente da mãe, que posterga suas necessidades em função das necessidades do bebê. Apesar de todo esse esvaziamento de si em prol do recém-nascido, a mulher continua a precisar de amparo e proteção, assim como ao longo da gravidez (BRASIL, 2006). 
Ainda hoje algumas questões sobre esta manifestação que ocorre no puerpério permanecem em debate: os transtornos puerperais poderiam ser manifestação de um transtorno prévio não adequadamente tratado? A gestação ou o puerpério seriam fatores protetores ou de risco para o desencadeamento de transtornos psiquiátricos? As alterações hormonais que ocorrem nesse período poderiam estar envolvidas na sua etiologia? Quais seriam os principais fatores de risco? Em quais situações seria adequado usar psicofármacos como medida de tratamento (CAMACHO et al., 2006).

De qualquer forma, o profissional de saúde deve acrescentar à sua avaliação clínica uma avaliação da história de vida da mulher, seus sentimentos, ansiedades e desejos. Hoje, os aspectos emocionais da gravidez, do parto e do puerpério são amplamente reconhecidos e a maioria dos estudos converge para a ideia de que esse período é um tempo de grandes transformações psíquicas, no qual acontece uma importante transição existencial (BRASIL, 2006).

Nos últimos 40 anos estudos têm sido unânimes em concluir que a presença de antecedentes psiquiátricos pós-parto ou em outros períodos da vida aponta para um alto risco de recorrência após o próximo parto. Igualmente, é preocupante o fato de que esses dados tenham causado um impacto tão reduzido nas práticas psiquiátricas e obstétricas. Único dentre os antecedentes de doença psiquiátrica, o nascimento de um bebê é como um aviso 9 meses antes, dando tempo suficiente para a detecção do risco de depressão e para se estabelecer um plano de ação. Na Inglaterra, a autora refere que metade das mulheres que morriam após o parto sofria de transtornos mentais severos. Essas mortes poderiam ser evitadas em $50 \%$ dos casos se houvessem sistemas de prevenção incluindo a identificação precoce de sua história psiquiátrica pregressa nos prontuários e implantação de medidas preventivas (OATES, 2003).

A maternidade se apresenta como fator relevante no desenvolvimento da depressão feminina muitas vezes relacionada ao estresse que pode provocar (BAPTISTA; BAPTISTA; TORRES, 2006).

Tem-se dado importância cada vez maior ao tem, e estudos atuais têm visado delinear os fatores de risco para os transtornos psiquiátricos nessas fases da vida, a fim de se realizarem diagnóstico e tratamento o mais precocemente possível (CAMACHO, 2006). 
A gravidez e o pós-parto estão associados a profundas mudanças físicas e emocionais. Também se relacionam a sintomas psíquicos e transtornos mentais de nível leve ao psicótico (BROCKINGTON, 2004).

A gestação e o puerpério são considerados períodos de elevado risco para o surgimento de transtornos psiquiátricos. De acordo com VESGA-LÓPEZ et al. (2008) entre $15 \%$ e $29 \%$ das mulheres durante estas fases manifestam alguma psicopatologia. Durante a gestação, RENNÓ e SOARES (2007) identificaram 80\% das mulheres com sintomas depressivos. DA SILVA et al. (2010) encontraram uma prevalência de depressão na gestação de 21,2\% em Pelotas, RS, Brasil.

COUTINHO e SARAIVA (2008a) publicaram um artigo com o objetivo de apresentar uma análise teórica acerca da depressão pós-parto enquanto manifestação biopsicossocial, de modo a possibilitar ao profissional da saúde uma reflexão sobre este sofrimento psíquico, que acomete muitas mães após o nascimento de um bebê, com importantes implicações psicoafetivas.

Para entender a depressão no puerpério é necessário entender o sofrimento psíquico como um mal-estar moderno amplamente identificado em vários perfis humanos. A depressão feminina fica particularmente enfocada no sofrimento materno após o nascimento de um bebê, incluindo seus principais sintomas e fatores associados, a indicação da sua prevalência, os instrumentos para o diagnóstico deste transtorno psicoafetivo, com ênfase nas repercussões da dor psíquica na vida familiar (COUTINHO; SARAIVA, 2008a).

DA SILVA et al. (2010) admitem associações entre ter planejado a gravidez e depressão. Acredita-se que este fato possa ser consequência das expectativas quanto à maternidade e aos medos intrínsecos durante a gestação.

A literatura científica é vasta e compreende bem as causas da depressão maior na população em geral. Contudo, são escassas as evidências acerca dos preditores da depressão em mulheres nos períodos pré e pós-natal. Sendo considerados os prováveis efeitos adversos da depressão em gestantes, é necessário conhecer a prevalência da depressão e que fatores a ela se associam desde a gravidez. 
Transtornos mentais associados ao período puerperal também foram incluídos no CID-10 (OMS, 2009) no capítulo de síndromes comportamentais associadas a distúrbios fisiológicos e fatores físicos (F50 a F59). Inclui qualquer transtorno que tenha início até a sexta semana após o parto. Também estão classificados como doenças mentais ou doenças do sistema nervoso central complicando o puerpério (O99.3).

No DSM-IVRT (APA, 2000), o especificador "com início no pós-parto" foi incorporado ao capítulo de transtornos do humor e deve ser utilizado para caracterizar qualquer episódio que tenha início até a quarta semana após o parto, podendo também ser utilizado para especificar transtornos psicóticos breves. Os transtornos puerperais, tanto psicóticos como depressivos e de ansiedade, não foram diferenciados do ponto de vista sintomatológico, daqueles que não ocorrem no período pós-parto.

A manifestação do quadro de depressão pós-parto acontece, na maioria dos casos, a partir das primeiras quatro semanas após o parto, alcançando habitualmente sua intensidade máxima nos seis primeiros meses. Os sintomas mais comuns são desânimo persistente, sentimentos de culpa, alterações do sono, ideias suicidas, temor de machucar o filho, diminuição do apetite e da libido, diminuição do nível de funcionamento mental e presença de ideias obsessivas ou supervalorizadas (MORAES et al., 2006).

\subsection{CLASSIFICAÇÕES E CRITÉRIOS}

O Manual diagnóstico e estatístico de transtornos mentais (DSM-IVTR, 2000) não distingue os transtornos do humor do pós-parto dos que acontecem em outros períodos, exceto como especificador "com início no pós-parto", que limita o início dos sintomas às quatro primeiras semanas após o parto (CANTILINO, 2003). A limitação em quatro semanas após o parto tem se revelado um viés para os pesquisadores. Muitas mulheres durante este prazo ainda nem se apresentaram para a primeira consulta após o nascimento do bebê. 
A DP não é menos incidente no sexto mês ou um ano após o parto que nas primeiras semanas ou meses (ENKIN et al., 2005). Uma ampliação do período de início da manifestação da doença tem sido usada por diversos pesquisadores encontrando-se aceitação de até um ano após o parto para definição da depressão como puerperal (MORAES et al., 2006).

Apesar da diferenciação entre a DP e a depressão em geral ser estabelecida apenas pelo período temporal em que decorre, existem estudos que mostram que a vulnerabilidade para perturbações depressivas persiste, pelo menos, durante 6 meses após o parto, tendo um pico imediatamente após o nascimento da criança (LEAHY-WARREN; MCCARTHY, 2007).

A revisão de LEAHY-WARREN e MCCARTHY (2007) ressalta que esta temática é importantíssima no âmbito dos cuidados de enfermagem a este transtorno mal compreendido, pouco assistido e muito frequentemente pobremente tratado.

Alguns autores classificam os transtornos mentais no puerpério de acordo com seu grau de severidade. Os quadros considerados mais severos são compreendidos como uma emergência médica, conhecidos por psicose puerperal.

BLOCH; DALY e RUBINOW (2003), entre muitos outros autores, consideram a psicose puerperal um quadro mais raro, e relatam a incidência encontrada entre 1,1 e 4 para cada 1.000 nascimentos. A sua manifestação apresenta um curso inconstante, que varia rapidamente ao longo do dia e ao longo do período pós-parto (SADOCK; SADOCK, 2007).

ANDRADE et al. (2006) também identificam os quadros de psicose puerperal como ocorrendo mais raramente ( 1 caso em 500 a 1.000 nascimentos) e tendo início nos primeiros dias após o parto, sendo compostos por episódios depressivos ou maníacos, recorrentes ou não, com sintomas psicóticos de maior gravidade e episódios psicóticos transitórios. Ressaltam o grave prejuízo da capacidade funcional que acomete a puérpera, o impacto familiar e o efeito deletério na relação mãe-bebê. Podem ser manifestadas ideações suicidas ou infanticidas, geralmente associadas a perturbações da senso-percepção, com comandos para matar o bebê. O risco para episódios psicóticos no pós-parto é maior em mulheres que já tiveram manifestações puerperais de transtornos do humor ou história pregressa de transtorno afetivo não puerperal. Estima-se que o risco de recorrência de psicose puerperal seja de $30 \%$ a $50 \%$ a cada parto subsequente. 
As queixas da mulher no período prodrômico se configuram em fadiga, insônia e episódios de choro fácil ou labilidade emocional. Posteriormente podem se tornar confusas, incoerentes, com discurso irracional, déficits cognitivos graves e preocupação obsessiva em relação à saúde e bem estar da criança. Queixas relacionadas com a incapacidade de se mover, manter-se de pé ou andar são também frequentes. Em $50 \%$ dos casos registram delírios, sendo que o conteúdo do material psicótico gira, quase invariavelmente, em torno da recente gravidez ou maternidade. Muitas vezes os delírios consistem na convicção de que a criança tem algum tipo de deficiência ou está morta. Podem negar a maternidade, defendendo a ideia de que não são casadas, ou não consumaram o matrimônio. Sentem-se perseguidas, influenciadas ou pervertidas. As alucinações, sobretudo visuais e auditivas, estão presentes em cerca de $25 \%$ das situações (SADOCK e SADOCK, 2007).

A psicose puerperal também se configura como um risco para a mãe e materno e para seu bebê. Sua reincidência em gestações subsequentes é comum, bem como o fato de poder acarretar futuros episódios psicóticos em períodos não gestacionais (NEWPORT et al., 2002).

A psicose puerperal também é conhecida como depressão psicótica pósparto. É considerada por muitos como uma urgência psiquiátrica, com manifestações alucinatórias, delirantes, com ideação de infanticídio e suicídio. Manifesta-se nos três primeiros dias pós-parto e tem prevalência de um para 500 a 1000 nascimentos (SADOCK; SADOCK, 2007; FONTANA; FONTANA, 2005; RENNÓ; SOARES, 2005).

Muitos autores sugerem que o episódio psicótico no período pós-parto não é mais do que a recorrência de uma eventual perturbação do humor subjacente. No entanto, há uma tendência expressa no CID-10 de considerá-la juntamente com a depressão pós-parto, como um tipo de perturbação de humor, iniciada ou precipitada pelo puerpério (OMS, 2010).

Como qualquer outro transtorno psicótico, não se pode excluir a possibilidade de uma causa médica geral, como o hipotireoidismo, síndrome de Cushing, toxemia, neoplasias ou psicose induzida por substâncias como anti hipertensores durante a gravidez ou medicação para a dor como a pentazocina (SADOCK; SADOCK, 2007). 
Mais amena que a psicose puerperal, a depressão pós-parto também possui graus diferentes de severidades. Quando moderada à grave apresenta um grau de severidade mais acentuado, podendo se manifestar através de sintomas como fadiga excessiva sintomas normais da privação do sono e ideação suicida.

Sua manifestação geralmente se dá a partir das primeiras quatro semanas após o parto, alcançando habitualmente sua intensidade máxima nos seis primeiros meses (STEFANELLI; FUKUDA; ARANTES, 2008; MORAES et al., 2006).

É sabido que o transtorno depressivo puerperal apresenta um quadro clínico muito semelhante ao da depressão em outros momentos da vida da mulher. No entanto, existem especificidades relativas à maternidade em si e ao desempenho do papel de mãe que não ocorrerão em nenhum outro período de sua vida. Sentimentos negativos, desinteresse pelo bebê e culpa por não conseguir cuidar dele são frequentes e podem resultar em um desenvolvimento insatisfatório da interação mãe-bebê (ANDRADE et al., 2006).

O Ministério da Saúde também encara a depressão no pós-parto como menos frequente que a psicose puerperal, manifestando-se em 10 a $15 \%$ das puérperas. Relaciona os sintomas associados como perturbação do apetite, do sono, decréscimo de energia, sentimento de desvalia ou culpa excessiva, pensamentos recorrentes de morte e ideação suicida, sentimento de inadequação e de rejeição ao bebê (BRASIL, 2006).

No início, a depressão pós-parto pode se assemelhar ao quadro da tristeza pós-parto, com tristeza acentuada, choro fácil, insônia, fadiga, ansiedade e irritabilidade. Contudo, na DP estes sintomas se prolongam por mais tempo e/ou são mais graves. A ansiedade das puérperas deprimidas é bastante mais acentuada do que na tristeza pós-parto. Pode se observar uma preocupação excessiva em relação à saúde e bem estar da criança. Um dos riscos principais desta condição relaciona-se com os pensamentos frequentes em torno da morte ou suicídio, e em um nível mais grave da depressão, a vontade de prejudicar a criança, com pensamentos obsessivos envolvendo violência contra a criança e agitação psicomotora intensa. Sintomas psicóticos, especialmente delírios, também podem ocorrer e, geralmente, envolvem o recém-nascido (SMITH; JAFFE, 2007, ANDRADE et al., 2006). 
CARIFETE (2009) explica que as mulheres que acabaram de dar à luz sentem-se frequentemente apavoradas quanto a acharem que o bebê não está engordando o suficiente ou quanto a um aumento da temperatura poder ser sinal de uma simples constipação ou de uma possível meningite. Estes receios podem oprimir as mães deprimidas e as mesmas podem experimentar ataques de pânico clássicos, com sentimentos de pavor, palpitações dificuldades em respirar e tremores. O autor conclui que o quadro clínico da depressão pós-parto reflete predominantemente uma perturbação do humor, mas também acentuada desregulação fisiológica.

Em relação às diferenças culturais e sua associação à depressão pós-parto materna e paterna, se acredita que a maneira como diferentes culturas vivem 0 nascimento de um filho e interpretam as repercussões deste evento pode ter impacto também distinto sobre a saúde emocional de pais e mães e influenciar a prevalência da depressão pós-parto. Além disso, uma vez que estudos têm apontado a relação entre dificuldades socioeconômicas e a ocorrência de depressão, é possível que países em desenvolvimento, com grande parte da população vivendo com baixa renda, apresentem percentuais mais elevados de depressão (RUSCHI et al., 2007; MORAES et al., 2006).

A não aceitação da gravidez (MORAES et al., 2006), bem como a falta de suporte oferecido pelo companheiro (CRUZ et al., 2005), também têm se mostrado associados à ocorrência de depressão pós-parto.

A terapia pode ajudar a paciente a aceitar e encarar com harmonia o papel de ser mãe. Também devem ser consideradas alterações em fatores ambientais, como um maior apoio por parte do marido e da família, que podem contribuir para a redução do estresse da paciente. O prognóstico é relativamente bom se for feita uma detecção precoce e tratamento adequado (CARIFETE, 2009).

Ainda são considerados transtornos emocionais no puerpério vividos na transição gravidez-maternidade: a perda do corpo gravídico e não retorno imediato do corpo original; a separação mãe/bebê; a amamentação e o medo de ficar eternamente ligada ao bebê; a preocupação com a estética das mamas. Tais dificuldades iniciais podem ser sentidas como incapacidades (BRASIL, 2006). 
Estudo de RONDÓ e SOUZA (2007) reconheceu que qualquer preocupação materna fora do habitual após o parto deve ser valorizada. Os autores detectaram uma associação negativa entre as mulheres que estavam mais preocupadas com as mudanças de seu corpo sendo que estas pretendiam amamentar seus bebês por menos tempo que as mães que não se incomodavam com esta questão.

Tais preocupações alertam os profissionais a estarem atentos a sintomas que se configurem como mais desestruturantes e que fujam da adaptação "normal" característica do puerpério. Há de se levar em consideração a importância do acompanhamento no pós-parto imediato e no puerpério, prestando o apoio necessário à mulher no seu processo de reorganização psíquica quanto ao vínculo com o seu bebê, nas mudanças corporais e na retomada do planejamento familiar (BRASIL, 2006).

Por fim, conhecida por diversas nomenclaturas semelhantes, a tristeza materna se manifesta por volta do terceiro dia pós-parto e costuma ter remissão espontânea em torno do décimo dia. Em torno de 50 a 85\% das mulheres podem apresentar alterações emocionais e cognitivas, manifestando tristeza, disforia, choro frequente e dependência, caracterizando uma sintomatologia pós-parto leve também conhecida como blues puerperais, tristeza materna, disforia pós-parto, síndrome depressiva transitória, melancolia pós-parto ou "maternity blues" (SADOCK e SADOCK, 2007; RENNÓ e SOARES, 2005; IACONELLI, 2005; CANTILINO, 2003).

O que distingue a depressão pós-parto da "tristeza materna" é a gravidade do quadro e o que ele tem de incapacitante, afetando a funcionalidade da mãe e pondo em perigo seu bem-estar e o do bebê. É também um importante problema de saúde pública (MORAES et al., 2006).

O manual técnico "Pré-natal e puerpério: atenção e qualificada e humanizada" publicado pelo Ministério da Saúde coloca que o "baby blues" acomete de 50 a $70 \%$ das puérperas. É definido como estado depressivo mais brando, transitório, que aparece em geral no terceiro dia do pós-parto e tem duração aproximada de duas semanas. Caracteriza-se por fragilidade, hiperemotividade, falta de confiança em si própria, sentimentos de incapacidade, irritabilidade fácil, depressão, labilidade emocional, insônia e choro fácil. (CANTILINO, 2003; BRASIL, 2006). 
Acredita-se que, devido a diversos tabus, preconceitos e medos que impedem as mulheres de admitirem estar vivenciando sentimentos de tristeza após o parto em um momento culturalmente rotulado como de felicidade, a disforia pós-parto possa ter sua incidência subestimada.

A disforia no pós-parto ou "maternity blues" inclui sintomas depressivos leves e foi identificada por CANTILINO (2003) em $50 \%$ a $85 \%$ das puérperas. $O$ autor enfatiza que as estatísticas dependem dos critérios diagnósticos utilizados. Outro estudo realizado com 1.558 mulheres detectou $17 \%$ das gestantes com sintomas significativos para depressão na gestação tardia, 18\% no puerpério imediato e $13 \%$ entre a sexta e a oitava semanas do puerpério. O mesmo valor (13\%) foi encontrado no sexto mês do puerpério (JOSEFSSON et al., 2001).

Este período que precede o nascimento é considerado um momento de normalidade para a puérpera, desde que não se expanda por um período maior evoluindo para uma depressão puerperal. Portanto, não deve ser menosprezado, pois representa um aumento significativo de risco para uma futura depressão puerperal (SADOCK e SADOCK, 2007; IACONELLI, 2005; NEWPORT et al., 2002).

Das mulheres que preenchem critérios para um quadro depressão pósparto, cerca de dois terços vivenciou previamente a tristeza materna. Por isso, a intervenção clínica deve incluir além da psicoterapia a monitorização cuidadosa de um possível agravamento dos sintomas (SADOCK; SADOCK, 2007).

WHITE (2006) oportuniza uma abordagem bastante atual ao enfatizar que a grande maioria de pesquisas e serviços de saúde que tem como enfoque o bem-estar emocional da mulher após o parto tem direcionado sua atenção apenas para transtornos do humor, em especial a depressão pós-parto (DP).

Recentemente, porém, foi percebida a necessidade de ser considerada também a crescente ocorrência dos transtornos ansiosos neste período de vida das mulheres. Um dos transtornos ansiosos que despertou a atenção dos pesquisadores é o Transtorno do Estresse Pós-traumático (TEPT) pós-parto, cuja prevalência tem sido estimada entre 2 a 7\% após 6 semanas do parto (AYERS, 2007; VAN SON et al., 2005; SOET; BRACK; DILORIO, 2003; CREEDY; SOCHET; HORSEFALL, 2000; CZARNOCKA; SLADE, 2000). Tem-se demonstrado uma comorbidade substancial entre depressão e transtornos ansiosos tais como o TEPT. 
Achados de CZARNOCKA e SLADE (2000) demonstram que $75 \%$ das mulheres que preencheram o critério do DSMIV-TR (2000) para TEPT também pontuaram 13 ou mais na Escala de Depressão Pós-parto de Edimburgo (EPDS), considerando-se muito provável o diagnóstico de depressão pós-parto.

De acordo com WHITE (2006) o desdobramento da questão sugestiva que as mulheres com TEPT pós-parto estejam também deprimidas pode assegurar uma série de implicações clínicas. Existe um alto grau de sobreposição de sintomas entre as duas condições, podendo o diagnóstico de DP ser favorecido em detrimento ao TEPT. A autora ressalta ainda o fato de que a depressão seja um transtorno mais amplamente reconhecido e que a inclusão da TEPT como uma categoria diagnóstica no DSMIV-TR (2000) seja comparativamente recente, a percepção de um transtorno se configura mais facilitada que a do outro.

Para gestantes com hiperemese idiopática, contrações precoces ou síndrome do estresse pós-traumático a psicofarmacologia e intervenções psicológicas para estresse pós-traumático podem proporcionar alívio em curto espaço de tempo. Tratamentos em saúde mental para as mulheres antes do parto também tem benefícios para o bem-estar de seu infante. Os achados sugerem que mulheres que sofrem de TEPT podem apresentar maior risco para problemas físicos durante a gestação, previstos com base nas sequelas comportamentais e neuroendócrinas, incluindo gravidez ectópica, aborto espontâneo e aumento do crescimento fetal (SENG et al., 2001).

Quando o estresse traumático ocorre antes de um evento, este é percebido como ameaçador ou temível. O estresse traumático e o medo no parto apresentam correlação significativa. Atenção especial deve ser dispensada a mulheres que evidenciem sinais de depressão concomitantemente com altos níveis de ansiedade, com história de aconselhamento psiquiátrico ou psicológico relacionado ao nascimento por vir e que relatem problemas psicológicos (SODERQUIST; WIJMA; WIJMA, 2004).

Mulheres que esperam sentir mais dor durante o trabalho de parto e parto são mais susceptíveis a perceber o parto como traumático. Mulheres com experiências piores do que imaginavam também tendem a considerar a experiência do parto como traumática (SOET; BRACK; DILORIO, 2003). 
Neste pensamento, pode-se perceber que muitas mulheres estão sujeitas a receber não só o diagnóstico, mas também o tratamento apenas direcionado a DP devido à falta de informação nos serviços de saúde acerca das diferenças entre a DP e o TEPT. Mostra-se premente a necessidade de conhecimento associado às condições emocionais das mulheres após o parto bem como um incremento no grau de percepção dos serviços de saúde quanto à existência também de transtornos ansiosos no puerpério.

Tendo em vista uma abordagem holística da saúde, onde são considerados os diversos planos da saúde, percebe-se a necessidade de serem despertadas discussões e debates acerca da depressão puerperal, transtorno psiquiátrico do puerpério frequentemente ignorado nos serviços de atendimento primário à saúde (CANTILINO et al., 2006), bem como do Transtorno do Estresse Pós-traumático após o parto.

\subsection{EPIDEMIOLOGIA}

A depressão no decorrer do ciclo gravídico puerperal muitas vezes se manifesta não apenas após o parto, mas também no transcorrer da gravidez. CRUZ; SIMÕES e FAISAL-CURY (2005) testificam que um suporte social satisfatório do marido está diretamente associado a menores índices de prevalência da depressão no pós-parto.

A depressão no decorrer do ciclo gravídico puerperal muitas vezes se manifesta não apenas após o parto, mas também no transcorrer da gravidez. CRUZ; SIMÕES e FAISAL-CURY (2005) testificam que um suporte social satisfatório do marido está diretamente associado a menores índices de prevalência da depressão no pós-parto.

Há evidências de que a ocorrência da depressão já durante a gravidez esteja associada aos indicadores de pobreza, sobretudo ao desemprego e à baixa escolaridade. Os autores levantam a importância de políticas públicas e programas na área social que invistam em educação e na geração de empregos para minimizar os sintomas depressivos deste período (PEREIRA e LOVISI, 2008). 
Pesquisa de BENNETTI et al. (2004) estimou uma prevalência de depressão na gravidez da ordem de 7,4\% no primeiro, 12,8\% no segundo e $12 \%$ no terceiro trimestre. JOSEFSSON et al. (2001) estudaram 1.558 mulheres e detectaram $17 \%$ das gestantes com sintomas significativos para depressão na gestação tardia. No Reino Unido, através do uso da EPDS, observou-se que 9,8\% das mulheres apresentavam-se deprimida durante a gestação (JOHANSON, 2000).

CARIFETE (2009) confirma que a prevalência média da depressão pósparto entre 10 a 15\%, mencionada por vários autores, não seja representativa da prevalência global atual e da magnitude do problema.

Nos países em desenvolvimento, incluindo o Brasil, a prevalência do transtorno depressivo pós-parto é mais alta que nos países desenvolvidos, respectivamente, $20 \%$ e $15 \%$. Apesar de ser uma importante questão de saúde pública, os autores ainda consideram que há poucos estudos sobre o tema no Brasil (PEREIRA; LOVISI, 2007).

LEAHY-WARREN e MCCARTHY (2007) concordam que os índices de prevalência da DP nas mães sofrem grandes variações, indo de $4.4 \%$ a $73.7 \%$ nos achados dos autores. Sugere-se que um índice de $13 \%$ já seja indicador da necessidade de um planejamento sério da enfermagem a fim de prover cuidados pós-natal a estas mulheres.

Apesar de o período pós-natal ser tradicionalmente definido como as 6-8 semanas após o parto, falta evidência necessária para apoiar o porquê de esse período ter sido selecionado. Essa limitação temporal se mostra um tanto arbitrária, especialmente quando se espera que a mulher esteja completamente recuperada, tanto fisiológica quanto psicologicamente, da sua gravidez e parto (BICK; BASTOS; DINIZ, 2008).

Após o parto as manifestações de depressão podem se iniciar em variados espaços de tempo, inclusive até um ano após o parto. BOYCE e HICKEY (2005) constataram valores oscilando entre $8,6 \%$ e 10,1\% para o diagnóstico de depressão entre a $6^{\mathrm{a}}$ e a $24^{\mathrm{a}}$ semanas do puerpério.

JOSEFSSON et al. (2001) estudaram 1.558 mulheres e detectaram $18 \%$ no puerpério imediato e $13 \%$ entre a sexta e a oitava semanas do puerpério. $O$ mesmo valor (13\%) foi encontrado no sexto mês do puerpério. 
Foi encontrada uma a prevalência de $37,1 \%$.quanto à DP e Transtornos Mentais Comuns (TMC) nas puérperas atendidas nas Unidades Básicas de Saúde do Programa de Saúde da Família (CRUZ; SIMÕES; FAISAL-CURY, 2005).

Outro estudo constatou valores oscilando entre $8,6 \%$ e 10,1\% para o diagnóstico de depressão entre a $6^{\underline{a}}$ e a $24^{a}$ semanas do puerpério (BOYCE; HICKEY, 2005). Estudo brasileiro de base populacional indicou a prevalência de DP em 19,1\% dos sujeitos do estudo, o que corresponde a quase uma puérpera em cada cinco (MORAES et al., 2006). A prevalência de DP encontrada em Belo Horizonte $(26,9 \%)$ esteve dentro da margem frequentemente encontrada na literatura atual (FIGUEIRA et al., 2009).

Em estudo transversal no Brasil, com aplicação da EPDS em 292 mulheres que se encontravam entre 31 e 180 dias após o parto, 39,4\% foram consideradas deprimidas, com escore maior que 12 (RUSCHI et al., 2007).

Apesar de no Brasil o número de estudos publicados sobre a DP ainda seja pequeno, a prevalência encontrada demonstra altos índices, acima da média nacional e internacional. Os fatores associados são semelhantes aos encontrados nos demais estudos de países em desenvolvimento (PEREIRA; LOVISI, 2008).

COSTA; PACHECO e FIGUEIREDO (2007) realizaram pesquisa em cidade portuguesa e obtiveram um total de $12,4 \%$ das mulheres consideradas deprimidas na primeira semana pós-parto e 13,7\% três meses após o parto.

WENDER et al. (2002) constatam a depressão puerperal afetando mundialmente em torno de 10 a $15 \%$ das mulheres, com prevalências relatadas entre 3,5 e $33 \%$, trazendo impactos também sobre o recém-nascido (JOSEFSSON et al., 2001; ZLOTNICK et. al, 2001; NEWPORT et al., 2002). No Brasil, observa-se uma prevalência variando entre 6,8 e $37,1 \%$ ou mais (TANNOUS; GIGANTE; BUSNELO, 2001; CRUZ et al., 2005; MORAES et al., 2006).

O estudo de FONSECA; SILVA e OTTA (2010) encontrou $28 \%$ das puérperas com escores indicativos de depressão pós-parto bastante acima da média mundial (10\% a 15\%) e próxima às taxas mais altas referidas para o Brasil. 
COUTINHO e SARAIVA (2008b) realizaram um estudo entre mulheres após o parto com sintomas depressivos e sem sintomas depressivos. As participantes com sintomatologia de depressão pós-parto apresentaram pontuações que variavam entre 11 e 21 pontos segundo a EPDS. As mães sem sintomatologia depressiva obtiveram entre 0 e 9 pontos na escala. Os resultados constatam que os sintomas mais prevalentes nas mães deprimidas concentraramse naqueles denotativos da perda de prazer diante das atividades rotineiras, sentimento de culpa sem motivo aparente, distúrbios do sono e humor deprimido com a manifestação de choro, além de ideação suicida. As mães com sintomatologia de depressão pós-parto se expressaram com falas como: "ser mãe é difícil", "ser mãe é inexplicável" (COUTINHO; SARAIVA, 2008b).

ZAMBALDI; CANTILINO e SOLGEY (2008) também concordam que a depressão pós-parto (DP) seja o transtorno afetivo mais frequente no puerpério. Os autores citam estudos realizados no Brasil com uma taxa de prevalência que pode variar entre 12 e $37,1 \%$. Neste estudo, os sintomas depressivos se iniciaram entre 10 dias e 4 semanas após o parto. Em muitas pacientes também são manifestados sintomas obsessivo compulsivos, por vezes antes dos sintomas depressivos e por vezes após. Também foram identificadas exacerbação de obsessões e compulsões preexistentes.

No Reino Unido, através do uso da EPDS foram encontradas 7,4\% das mulheres deprimidas aos três meses após o parto. Houve significativa associação entre depressão ante natal e pós-natal, considerando ambas frequentemente ignoradas durante as consultas de rotina (JOHANSON et al., 2000).

Pesquisa de CARIFETE (2009) resultou em 15,3\% de mulheres angolanas clinicamente deprimidas após o parto, com pontuação igual ou superior a 10 na EPDS.

De acordo com o DSM-IVTR (2000), o critério para os transtornos pósparto são os mesmos que de alguns transtornos do Eixo I, com especificador de tempo. Muitos estudos tem seu foco apenas na DP sem mesmo examinar depressão ansiosa, variações de depressões atípicas, irritabilidade ou outras síndromes como o TEPT. Transtornos que combinem sintomas físicos e mentais também permanecem sem atenção (HALBREICH; KARUN, 2006). 
É importante a lembrança constante que sintomas, queixas ou ausência de queixas podem variar de acordo com a cultura. A percepção de "normalidade" deve sempre considerar os aspectos culturais. O nascimento de um bebê, especialmente o primeiro filho, é um evento importante em qualquer cultura. Está associado a importantes alterações hormonais, mudanças socioeconômicas, mudanças no estilo de vida e na carga de trabalho da mãe e de sua família imediata (HALBREICH; KARUN, 2006).

\subsection{ETIOLOGIA}

A despeito de diversos estudos estarem sendo direcionados para fatores causais específicos da doença ainda existe uma lacuna nesta associação epidemiológica necessária para a consolidação do conceito diagnóstico (BROCKINGTON, 2004).

Segundo CAMACHO (2006), a etiologia da depressão puerperal ainda não é completamente conhecida, mas se acredita que fatores hormonais e hereditários ou familiares também estejam envolvidos.

A literatura não sustenta de forma consistente qualquer causa orgânica que por si só seja causadora da depressão puerperal, sendo os estudos negativos ou contraditórios para a maioria das variáveis biológicas. Até a própria visão negativa que a mulher possa ter acerca do mundo e de si própria pode contribuir para uma baixa autoestima que poderá se traduzir em um quadro depressivo. Outra associação também é observada entre o cessar da amamentação e o surgimento da depressão pós-parto (CARIFETE, 2009).

ANDRADE et al. (2006) identificaram como fatores de risco para depressão pós-parto: história pregressa de depressão, presença de sintomas depressivos na gravidez e história familiar de transtornos do humor e de ansiedade. Em sua pesquisa de avaliação de mulheres com alterações do humor no pós-parto, identificou-se a presença de algum transtorno psiquiátrico em parentes de primeiro grau em $71 \%$ dos casos, com a ocorrência de transtornos do humor em $48 \%$ e alcoolismo em $30 \%$. Estas taxas bem mais elevadas do que na população geral indicam um componente genético ou familiar na determinação desses transtornos. 
Também se fizeram evidentes fatores de risco psicossociais como alterações psicológicas e sintomas depressivos durante a gestação, eventos adversos durante a gestação e o parto, ausência de suporte social e/ou familiar, relacionamento conjugal deficiente ou tempestuoso, ausência de parceiro, gravidez indesejada, relacionamento parental conturbado na infância, dificuldades no desempenho de papéis maternais por falta de experiência prévia ou por experiências interpessoais negativas com a própria mãe, autoestima limitada, instabilidade financeira ou ocupacional, entre outros (ANDRADE et al., 2006).

O apoio social durante a gestação age de forma protetora, estando associado a sintomas depressivos menos intensos no puerpério. A negativa desta afirmação também deve apontar para a importância de se estabelecer definitivamente a gestação e o puerpério como momentos críticos para o desenvolvimento do infante, merecendo atenção especial nos programas e políticas de saúde (FONSECA; DA SILVA; OTTA, 2010).

$\mathrm{Na}$ gestação, os níveis de estrógeno e progesterona são superiores àqueles vistos nas mulheres fora do período gestacional e esse fator pode estar envolvido nas alterações do humor que ocorrem no puerpério. A queda brusca desses hormônios no pós-parto poderia estar envolvida na etiologia da depressão puerperal. BLOCH et al. (2003) realizaram uma revisão da literatura a fim de correlacionarem os fatores endócrinos e hereditários com a etiologia desse transtorno, porem não se constatou relação genética diferente daquela já esperada em quadros não puerperais. Levantou-se a hipótese de que algumas mulheres seriam mais sensíveis a variações hormonais em qualquer momento de suas vidas, incluindo-se período pré-menstrual, menarca, gestação, puerpério, menopausa e até mesmo durante o uso de anticoncepcionais.

A literatura não identifica um único elemento biológico associado à etiologia da doença mental após o parto, não sendo disponibilizadas evidências convincentes que apoiem as explicações tradicionais da DP, nem bioquímicas nem psicanalíticas. Acredita-se em fortes evidências de uma relação com condições sociais como as expectativas sociais sobre o que deve ser a vida feminina normal e a maternidade normal (NEWPORT et al., 2002; ENKIN et al., 2005). A fadiga materna e o padrão de sono do bebê também se demonstram fortemente associados com o início de sintomas depressivos após o parto (DENNIS; CREEDY, 2006). 
Circunstâncias relativas à saúde física, à experiência emocional de parto e ao primeiro contato com o bebê podem predizer a sintomatologia depressiva na primeira semana do puerpério. Em consequência, a sintomatologia depressiva na primeira semana após o parto e a experiência emocional negativa de parto predizem a sintomatologia depressiva três meses após o parto (COSTA et al., 2007). As autoras constatam que apesar de os sintomas serem diferentes na primeira e na duodécima semana após o parto, a experiência emocional de parto tem impacto, quer a curto quer em longo prazo no nível da saúde mental materna.

BAPTISTA; BAPTISTA e TORRES (2006) colocam como fatores desencadeantes da depressão no puerpério antecedentes psiquiátricos, descontentamento com a gestação, negativismo com relação a eventos vitais, baixo apoio emocional, viver sozinha, ser menor de idade, solteira, ter baixo nível educacional e socioeconômico, histórico de abortos anteriores, partos problemáticos e atitudes negativas.

Para AZEVEDO e ARRAIS (2006), a maneira pela qual a maternidade vem sendo concebida até nossos dias, tem influência direta no aparecimento da depressão no pós-parto. As pressões culturais que a maternidade impõe, associadas ao sentimento de incapacidade em adequar-se a uma visão romanceada desse estado, acabam por deixar as mães ansiosas e culpadas, suscitando dessa maneira conflitos que predispõe a depressão pós-parto. É possível que a mulher com depressão pós-parto estivesse apenas expressando seu choque e desapontamento por não conseguir se sentir emocionada e feliz como difundido nos filmes, comerciais, revistas, igrejas e histórias contadas por outras mulheres.

PEREIRA e LOVISI (2008) observaram fatores de risco parecidos com os achados de outros autores. Os mais frequentes foram: antecedentes psiquiátricos, principalmente história anterior de depressão; fatores relacionados à pobreza como baixa renda, dificuldades financeiras, baixa escolaridade, desemprego; carência de suporte social, familiar ou marital, instabilidade nos relacionamentos; eventos de vida estressantes; gravidez não desejada.

Segundo CARIFETE (2009), é possível afirmar que os transtornos do pósparto são determinados mais pela interação de fatores do que propriamente por uma patologia ou quadro pré-existente da mulher Os principais fatores de risco para a depressão pós-parto foram sintetizados pelo autor da seguinte forma:

. História prévia de depressão; 
. História anterior de depressão pós-parto;

. História familiar de doença psiquiátrica;

. Depressão pré-natal ou durante a gravidez;

. Ansiedade pré-natal;

. Tristeza pós-parto;

. Gravidez não desejada;

. Baixa autoestima;

. Relação conjugal desestruturada;

. Fraco suporte social;

. Sensibilidade a estados associados a flutuações hormonais;

. Baixo estatuto socioeconômico;

. Mães solteiras com deserção ou ausência paterna

. Baixo nível educacional;

. Complicações no parto;

. Idade jovem;

. Multiparidade;

. Aleitamento por fórmula artificial.

CARIFETE (2009) conclui considerando o pós-parto como incontestavelmente um período de adaptações e novos desafios, não apenas de ordem fisiológica como também psicológica. A mulher passa a ter uma nova rotina, mudando seus hábitos de vida, lidando com a responsabilidade da maternidade e todas as tarefas que cercam este novo mundo, sofrendo muitas vezes a pressão instituída socialmente para ser uma "boa mãe". É frequente sentirem-se sobrecarregadas e ansiosas em relação à sua capacidade de criar um filho e ao fato de terem que se adaptar a uma identidade totalmente nova e bastante ruim.

O vínculo da mãe com seu bebê depende do compromisso psicológico da mãe para os cuidados, para a amamentação e para a proteção da criança. Após o nascimento as mães são especialmente solicitadas pelas necessidades do recémnascido e a conexão tanto física como psicológica entre a mãe e o infante continuam por um período significativo ao longo de suas vidas (CARIFETE, 2009). 


\subsection{IMPLICAÇÕES PARA O BEBÊ}

Já é muito difundido que dentre as psicopatologias mais presentes no ciclo gravídico puerperal, a depressão puerperal seja o transtorno psiquiátrico mais frequente após o nascimento do bebê, muitas vezes devido à ausência de suporte social e psicológico durante os dias e semanas após o parto (BROCKINGTON, 2004; ENKIN et al., 2005). Muitas vezes confundida com a 'tristeza materna' ou 'blues puerperais', apresenta-se como mais grave e disfuncional, pondo em perigo seu próprio bem-estar e o do bebê.

Pensamentos agressivos contra o bebê foi o tema mais comum entre as mães deprimidas. As mulheres relataram temor de estar com o recém-nascido. Foi observado que as mulheres demoraram a procurar o ambulatório de 2 a 12 semanas após o início dos sintomas (ZAMBALDI; CANTILINO; SOLGEY, 2008). Muitas puérperas não revelam seus sintomas de depressão devido a sentimentos de culpa e receio de ser vítima de preconceito, já que é socialmente esperado delas que estejam felizes com o nascimento do bebê. Também podem vivenciar sentimentos de medo de serem afastadas de seus bebês caso exteriorizem seus sentimentos.

A associação entre a DP e suas consequências ao nível do comportamento da criança é complexa e ainda não se encontra totalmente estabelecida (CARIFETE, 2009).

Culturalmente, é esperado que as mães sejam sempre ternas, acolhedoras, férteis e disponíveis. Não faz parte do imaginário social vê-las demonstrar sentimentos de tristeza, afinal, tudo isso está ligado ao milagre da vida que presume um instinto materno, uma predisposição inata para o sacrifício, como se o sofrimento fosse algo normal. Desta forma, existem motivos concretos que levam as mães na modernidade a vivenciar sentimentos de culpa, frustração e conflitos de identidade. As mães estão habituadas a uma cultura que proíbe a discussão plena da ambivalência materna, da coexistência de sentimentos ambivalentes natural em todas as mães. A sociedade cristaliza a ideia de que 0 sacrifício e o amor irrestrito são inerentes a todas as puérperas. Alem da maneira de exercer a maternidade vir se tornando cada dia mais idealizada, as tarefas diárias ainda se tornam mais numerosas tanto no ambiente doméstico como no local de trabalho (AZEVEDO; ARRAIS, 2006). 
As autoras acrescentam a ideia de que o amor materno é um sentimento construído paulatinamente, não um puro instinto. Esse sentimento está sujeito a imperfeições, mudanças e transformações.

Estudos de SCHMIDT; PICCOLOTO e MÜLLER (2005) indicam que a depressão pós-parto tem etiologia multifatorial, atingindo um significativo número de mulheres no pós-parto. O fato de a DP dificultar o estabelecimento de vínculo afetivo favorável entre mãe e filho pode interferir na qualidade dos laços emocionais futuros. Há evidências de associação entre a DP e prejuízo no desenvolvimento emocional, social e cognitivo dos infantes. Durante a gestação é importante que se percebam os sentimentos da mulher e especialmente como estes se manifestam após o parto. A disponibilidade de uma rede social de apoio às mudanças psíquicas vividas com o nascimento de um bebê bem como 0 reconhecimento do estado depressivo da mãe são fundamentais.

Em razão das queixas psicossomáticas que podem sugerir somente problemas orgânicos, o diagnóstico materno fica mais nebuloso. É necessário que esta experiência, vivida subjetivamente pela mulher, possa ser detectada. A detecção precoce dos fatores de risco envolvidos na DP, realizada mediante o acompanhamento das gestantes, se mostra como um fator importante para a prevenção da própria DP e das repercussões na interação mãe-filho. Com isto se abre a possibilidade de auxílio à mulher e à sua família, principalmente durante a gestação e o puerpério (SCHMIDT; PICCOLOTO; MÜLLER, 2005).

O relacionamento mãe-filho demonstrou estar prejudicado ao serem avaliadas 507 mães e seus filhos, aos 3 meses de idade. Os filhos de mães que apresentaram diagnóstico de depressão pós-parto tinham dificuldades para dormir e se alimentar. Apresentavam também prejuízos de interação corporal com o ambiente e sorriso social diminuído. Essas pacientes queixavam-se com muita frequência de cansaço excessivo, o que acabava refletindo de forma negativa no relacionamento com seus filhos e, por consequência, no desenvolvimento deles (RIGHETTI-VELTEMA et al., 2002). 
A disponibilidade emocional também mantém associações com a depressão puerperal. Através da Escala de Disponibilidade Emocional, foi avaliada a qualidade de interação entre a mãe e a criança aos quatro meses de idade. Percebeu-se que quanto mais a mãe se sente amparada afetiva e materialmente pelo ambiente social, mais ela se torna apta de lidar com a criança em termos de organização de atividades da criança, de estabelecer regras e favorecer estímulos de acordo com a faixa etária do bebê. A responsividade do bebê também apresenta correlação positiva, ainda que fraca, com o apoio emocional, de informação e material percebido pela mãe (FONSECA; DA SILVA; OTTA, 2010).

Um número considerável de estudos tem evidenciado que a DP está associada a resultados cognitivos e socioemocionais adversos em crianças (BROCKINGTON, 2004). SCHWENGBER e PICCININI (2003) investigaram a experiência da maternidade no contexto da depressão materna no final do primeiro ano de vida do bebê. Os resultados encontrados apoiam a ideia de que mães com indicadores de depressão apresentariam mais acentuadamente impressões e sentimentos negativos em relação aos bebês e sobre a maternidade do que aquelas sem indicadores de depressão. Embora tenham sido também encontradas similaridades entre os dois grupos, mães com indicadores de depressão mostraram-se menos satisfeitas com o desenvolvimento do bebê, com o desempenho do papel materno e com o apoio recebido do companheiro e de outras pessoas com as quais conviviam. Além disso, essas mães assinalaram que, em algum momento do primeiro ano de vida de seus filhos, sentiram-se estressadas por terem de se separar deles em função do trabalho, assim como haviam se sentido estressadas devido a conflitos familiares e conjugais, dificuldades no manejo com o bebê e dificuldades financeiras.

Ao estudarem crianças de sete anos de idade cujas mães apresentavam sintomas depressivos e os pais demonstravam um envolvimento empobrecido, os autores verificaram que sintomas mais severos foram encontrados. As crianças apresentavam habilidades autorregulatórias pobres - pouca capacidade de regular sua resposta emocional frente a estímulos do ambiente - e temperamento desinibido (BOYCE et al., 2006). 
A depressão materna também tem um impacto negativo para a saúde mental dos filhos na idade escolar. Evidenciam-se problemas comportamentais, psicopatologia, rebaixamento cognitivo, prejuízo no autoconceito, no desempenho social e na regulação emocional, independentemente do momento de primeira exposição à depressão materna. A depressão da mãe acaba se configurando como um fator de risco ao desenvolvimento da criança (MENDES; LOUREIRO; CRIPPA, 2008).

A associação o entre as consequências no comportamento da criança e a DP é complexa e ainda não se encontra totalmente estabelecida. Variações no momento de eclosão, duração e gravidade do quadro depressivo, bem como a presença ou ausência de agentes estressantes externos e suporte social adequado, contribuem para as diferenças nas manifestações encontradas no comportamento e desenvolvimento dos filhos de mães deprimidas no período pós-natal. As crianças que vivenciam uma relação mãe-filho desestruturada podem apresentar respostas afetivas diminuídas, interação social prejudicada com estranhos, perturbações do sono, ansiedade de separação, perturbações gastrointestinais, falta de apetite ou episódios constantes de vômitos (CARIFETE, 2009).

Um excesso de atribuições e carga de trabalho pode levar a puérpera à severa fadiga. Associa-se a horas de trabalho prolongadas, particularmente nas primeiras horas da manhã e nas últimas horas da noite, desregulando o ciclo circadiano do sono e repouso. Esta situação é especialmente problemática em ocupações com alta demanda emocional como é o caso das puérperas (ROGERS; GRUNSTEIN, 2005).

De um modo geral, as principais repercussões da DP no desenvolvimento infantil podem ser sintetizadas da seguinte forma:

a) Problemas comportamentais - os filhos de mães deprimidas são mais propensos a perturbações de sono, ataques de raiva, atitudes agressivas, déficits de atenção e hiperatividade.

b) Atraso no desenvolvimento cognitvo - as crianças podem aprender a falar e a andar mais tarde que o habitual bem como dificuldades no nível da aprendizagem escolar.

c) Problemas de socialização - as crianças podem revelar dificuldade em estabelecer relações afetivas estáveis, com dificuldade em fazer amigos na escola e podem mesmo vítima de exclusão social. 
d) Problemas emocionais - estas crianças tendem a ter uma baixa autoestima, são mais ansiosas e medrosas, passivas e dependentes.

e) Depressão - o risco de desenvolver um episódio depressivo major cedo na vida é particularmente alto para os filhos de mães com depressão pós-parto (CARIFETE, 2009).

O infanticídio e o suicídio estão entre as complicações mais graves decorrentes de transtornos puerperais sem intervenção adequada. No entanto, a existência de transtornos psiquiátricos não só no puerpério, mas também na gestação, pode levar a outras graves consequências (CARIFETE, 2006).

Mulheres com diagnóstico de esquizofrenia ou depressão maior apresentaram elevado risco para complicações na gravidez, trabalho de parto e período neonatal. Entre essas complicações, há anormalidades placentárias, hemorragias e sofrimento fetal. Mulheres com esquizofrenia apresentam risco elevado para descolamento prematuro de placenta e, mais frequentemente, tiveram filhos com baixo peso ao nascer. Essas crianças também apresentaram malformações cardiovasculares e menor circunferência encefálica do que os filhos de mães saudáveis (JABLENSKY, et al., 2005).

Há alguns anos atrás, "...o obstetra olhava para a grávida como a sua parturiente, a quem tinha que libertar, nas melhores condições possíveis, do conteúdo uterino já maduro; o pediatra agarrava o recém-nascido, para, depois de uma sequência de manobras, se convencer que o deixava preparado para enfrentar o mundo". Atualmente é completamente reconhecida e aceita a ideia da díade mãe-bebê. Intrincados, um no outro, mãe e filho, realizam uma "dança a dois, em que, para alem do ritmo próprio de cada um, apresentam uma coreografia própria, ao sabor de uma música ancestral de geração para geração, transmitida de mãe para filho, que vai sobrevivendo às mudanças inexoráveis dos estilos de vida e às tentativas da ciência para torná-la objeto do seu estudo" (CARIFETE, 2009).

Algumas mães alem de passarem pelo trabalho de parto, parto e puerpério ainda se deparam com um novo estressor: o nascimento de um bebê pré-termo ou adoentado que necessita ficar por mais tempo no hospital que a mãe. Assim vão se somando angústias e apreensões, quem sabe culpa e pensamentos autocondenatórios que são refletidos na autoestima diminuída e nos sentimentos de prazer que a mulher não consegue vivenciar. 
A adaptação de mães de bebês que nascem doentes ou com problemas é mais difícil, especialmente se o quadro for grave, acarretando grande frustração. Tal situação destrói todas as expectativas relacionadas ao desempenho de maternidade e trazem mudanças na estrutura familiar (PEROSA et al., 2009).

Durante a internação do bebê em unidades de cuidados intensivos, $44 \%$ das mães apresentaram escores indicativos de sintomas clínicos de ansiedade, disforia e/ou depressão. Tais sintomas indicam problemas emocionais que demandam cuidados dispensados a essa clientela na área de saúde mental. Após a alta hospitalar dos bebês houve uma redução significativa do número de mães que apresentaram escores indicativos de sintomas clínicos de ansiedade, disforia e/ou depressão. Destaca-se a importância de se avaliar e fornecer suporte aos sentimentos maternos, no percurso entre o nascimento do bebê pré-termo e a alta hospitalar. Uma avaliação clínica possibilita a identificação de mães com maior dificuldade no enfrentamento adaptativo da situação de estresse psicológico, possibilitando um planejamento e execução adequada intervenções psicológicas preventivas (PADOVANI et al., 2004).

Não se pode dizer que as mães adolescentes oferecem sempre piores condições de cuidado à criança do que as mães adultas. Foi constatada uma considerável variabilidade nos padrões de interação das mães adolescentes com seus bebês e observado como algumas mães adolescentes são capazes de se relacionar até mais adequadamente do que certas mães adultas (FIGUEIREDO, 2000).

A atuação preventiva das equipes multidisciplinares nesse período pode proporcionar à nova mãe o apoio que necessita para enfrentar os eventuais episódios de depressão. É urgente o desenvolvimento de estratégias precoces de intervenção que considerem as particularidades dos quadros depressivos observados a partir do nascimento de um bebê (SCHWENGBER; PICCININI, 2003) 
Ainda há de se considerar a hipótese de um ato suicida materno após o nascimento do bebê. Apesar de raro, os índices encontrados são maiores do que se imaginava. $\mathrm{O}$ autor considera o suicídio como a principal causa da morte materna na cidade de Nottingham, Inglaterra, e lembra que morbidades psiquiátricas são comuns durante a gravidez e o pós-parto, algumas delas sendo bastante severas e outras previsíveis e dignas de prevenção. No entanto, algumas mulheres ainda morrem apesar de uma assistência exemplar. Segundo o autor, um quarto dos suicídios poderia ser evitado se 0 alto índice de recorrência da DP tivesse sido identificado e bem manejado (OATES, 2003).

A DP se torna responsabilidade da atenção primária e da saúde mental especialmente por desencadear efeitos deletérios na saúde da mãe bem como na saúde e no desenvolvimento de seu bebê (HALBREICH; KARKUN, 2006).

Sem intervenções, as crianças de mães deprimidas ficam expostas a uma maior probabilidade no desenvolvimento de psicopatologias futuras. Apesar da existência de teorias e técnicas cientificamente comprovadas como eficientes no atendimento da díade mãe-bebê, fica o desafio de informar e sensibilizar os profissionais de saúde de modo a identificarem e atenderem as necessidades afetivas deste binômio (BRUM, 2006).

Deve-se, portanto, avaliar cada caso com especial atenção, a fim de ser estabelecida a melhor estratégia de tratamento para cada situação em particular, da maneira mais precoce possível (CAMACHO, 2006).

\subsection{DEPRESSÃO PUERPERAL EM HOMENS}

Como pode ser evidenciado na análise da literatura revisada de SILVA e PICCININI (2009), a participação do pai nas famílias em que a mãe apresenta depressão tem sido apontada como de fundamental importância, fornecendo apoio emocional e material à mãe e protegendo a saúde do bebê. No entanto, ainda existem poucos estudos focalizando a paternidade no contexto da depressão materna. Os maridos de mães com depressão se tornam uma população de risco em termos de sua saúde emocional, sendo também frequente a depressão paterna no período puerperal. 
Alguns aspectos da paternidade parecem associar-se à depressão materna, sendo percebida uma influência mútua entre os papéis de pai e mãe neste contexto. $\mathrm{O}$ envolvimento do pai com o bebê pode atenuar os sintomas depressivos da mulher, enquanto estes sintomas podem afetar negativamente 0 exercício da paternidade do pai (SILVA; PICCININI, 2009).

Pesquisa da literatura entre 1980 e 2002 identificou vinte estudos que incluíam a incidência de depressão paterna durante o primeiro ano após o parto. A incidência variou de $1,2 \%$ a $25,5 \%$ na população geral. Entre os homens que tinham suas companheiras com depressão pós-parto, este índice subiu para uma variação entre $24 \%$ a $50 \%$ (GOODMAN, 2004).

A DP na mulher é identificada como o mais forte preditor de depressão paterna no período pós-parto. Esta forte correlação tem importantes implicações no bem-estar da família. O problema da depressão puerperal na mulher tem sido alvo de consistente atenção. Contudo, não é mais possível se ignorar que os homens também vivenciam sentimentos depressivos após o nascimento do bebê e que esta tem correlação com a depressão materna (CARIFETE, 2009; GOODMAN, 2004).

SILVA e PICCININI (2009) concordam com a associação existente entre a entre depressão materna e dificuldades no relacionamento conjugal, consistentemente evidenciada pela literatura. Tal associação ainda necessita maiores aprofundamentos a fim de responder alguns questionamentos: as dificuldades no relacionamento conjugal estariam na origem da depressão materna, especialmente da depressão puerperal, ou o humor deprimido da mãe traria dificuldades no funcionamento familiar e, deste modo, prejudicaria a qualidade do relacionamento conjugal? As autoras entendem que pode haver "feedback" de modo que em famílias onde existem dificuldades no relacionamento conjugal, estas tendem a ser agravadas pelo desencadeamento de uma depressão materna, e vice-versa.

MORAES et al. (2006) também enfatizam a forte associação negativa entre depressão pós-parto materna e qualidade do relacionamento conjugal, apoio emocional oferecido pelo pai e seu envolvimento nos cuidados do bebê e no trabalho doméstico. Também revela que o pai pode diminuir o impacto da depressão materna sobre os filhos, caso mostre-se envolvido e mentalmente saudável. 
A literatura aponta que maridos de mulheres com depressão encontram-se em situação de risco para o desenvolvimento de psicopatologias, o que sugere que as intervenções clínicas neste contexto devem focalizar também as relações familiares. Pai e mãe se defrontam com uma série de tarefas psicológicas no puerpério (MORAES et al., 2006).

MORAES et al. (2006) focalizam a paternidade em famílias em que a mãe apresenta depressão investigam basicamente quatro questões: o papel que o pai exerceria protegendo a saúde mental da mãe e diminuindo a probabilidade do desenvolvimento de um quadro depressivo; o papel do pai em proteger a saúde mental do bebê, agindo como um moderador dos efeitos da depressão materna sobre o desenvolvimento infantil; as relações entre a depressão materna e a saúde mental do pai; e o modo como se dá a participação do pai nas famílias em que a mãe apresenta depressão.

Para BURKE (2003), o apoio emocional do marido pode proteger mulheres com histórico de depressão de serem reincidentes no período puerperal. $\mathrm{O}$ autor afirma que um pai não deprimido e que atue como cuidador, auxiliaria nos cuidados ao bebê e estimularia adequadamente suas necessidades, diminuindo os efeitos negativos da interação com uma mãe pouco responsiva ou intrusiva.

É inegável que a depressão pós-parto em homens seja uma temática relevante e demonstre forte correlação com a depressão materna. Considerando a depressão nas novas mães assim como nos novos pais e também considerando a coocorrência da depressão nos casais, o próximo passo a ser dado é mais pesquisas sobre a temática e praticas assistências que envolvam a família com bebês recém-nascidos (GOODMAN, 2004).

Não se pode perder de vista a importância de novas investigações sobre esse assunto, especificamente quanto à maneira que o pai exerce e vivencia o seu papel neste momento. Desta maneira será possível a elaboração intervenções clínicas focalizando as relações familiares. A inclusão do bebê e do marido no tratamento da depressão pós-parto pode reduzir o estresse da mãe e apoiar o desenvolvimento da competência do casal nos papéis de pais e cônjuges (SILVA; PICCININI, 2009). 


\subsection{DIAGNÓSTICO, PREVENÇAO E TRATAMENTO PRECOCES}

Com a identificação dos fatores de risco da depressão pós-parto, a ciência testemunhou uma maior quantidade de pesquisas sobre estratégias preventivas, com estratégias psicossocial, psicofarmacológica e hormonal. Para atender as necessidades crescentes decorrentes do aumento deste tipo de depressão entre as mulheres, quanto mais precocemente ocorrer a percepção dos sinais e sintomas depressivos e a procura de ajuda qualificada, mais rapidamente poderá ocorrer a remissão do quadro. Desta maneira serão evitados o isolamento social da mulher e os impactos na interação com o bebê, pai e familiares (ZINGA; PHILLIPS; BORN, 2005).

A detecção precoce dos sintomas depressivos da doença é um grande aliado no tratamento da depressão puerperal. DENNIS (2004) aponta evidências de que o estado de humor da mãe imediatamente após o parto pode ser preditivo de DP. FALCONE et al. (2005) acreditam que uma assistência multiprofissional possa prevenir, detectar e tratar transtornos afetivos durante a gravidez tanto em adultos como em adolescentes.

$\mathrm{Na}$ perspectiva da psicologia da saúde, se considera o fato de que os profissionais de saúde/educação que estão atuando em trabalhos com gestantes desempenham um papel importante em reconhecer e diagnosticar famílias e encaminha-las para atendimento psicológico, podendo com este trabalho auxiliar o desenvolvimento infantil saudável (SCHMIDT; PICCOLOTO; MÜLLER, 2005).

Através do rastreamento precoce de transtornos emocionais após o parto ou mesmo durante a gravidez, muito sofrimento pode ser aliviado e muita dor amenizada não apenas para a puérpera mas também para a família que a abriga.

Mesmo com critérios classificatórios cada vez mais precisos, o diagnóstico não se torna fácil nem inequívoco, já que o quadro clínico pode variar na apresentação e intensidade dos sintomas. Muitas vezes os sintomas podem permanecem camuflados tanto pela puérpera como pela sua rede de apoio disponível, atribuindo os sintomas ao "cansaço e desgaste" naturais do puerpério, causados pelo acúmulo de tarefas caseiras e dos cuidados com o bebê (CRUZ; SIMÕES; FAISAL-CURY, 2005). 
A disponibilidade para ouvir a gestante com uma postura de acolhimento é o requisito mais importante para a ação preventiva e pode acontecer em grupos de orientação. A gestante deve ter um local onde, sem receio, possa expor seus sentimentos e medos, trocar experiências, encontrar acolhimento e apoio no aspecto emocional. Os autores sugerem que os grupos formados para orientação devem prever momentos para que a gestante possa expor seus sentimentos e medos sem receio, trocar experiências, encontrar acolhimento e apoio no aspecto emocional. (FALCONE et al.,2005).

Outra forma de abordar o problema da depressão pós-parto é avaliar por rotina todas as mulheres no puerpério, um procedimento fácil e eficaz, mas raramente efetuado. Entre os vários testes de rastreamento, os especialistas têm dado preferência à EPDS (SANTOS et al., 2007).

Ensaios clínicos também utilizaram estratégias psicossociais como tentativa de evitar o desenvolvimento de depressão no pós-parto por meio do alívio ou eliminação dos fatores do risco psicossocial. Tais intervenções adotaram abordagens educativas, melhorias no atendimento pré-natal e/ou no início do puerpério e intervenções com enfoque psicoterapêutico (ZINGA;PHILLIPS; BORN, 2005).

As intervenções educativas pré-natais não demonstraram ser muito eficazes em reduzir a DP. Outro enfoque na luta para prevenir a DP teve como alvo os provedores de saúde das mães. A lógica que alicerça este pensamento é que o aumento no nível da atenção à saúde durante o período pré-natal ou logo após o parto pode, como consequência, reduzir o impacto dos fatores de risco psicossociais no humor pós-parto. No entanto, os ensaios clínicos que constataram melhora na atenção materna até o momento demonstraram um impacto limitado na prevenção de depressão puerperal (ZINGA;PHILLIPS; BORN, 2005).

Localizado na Inglaterra, o Instituto Nacional de Excelência Clínica em Saúde (National Instituite for Health and Clinical Excellence-NICE, 2007) recomenda suporte social informal ou grupal na gravidez e no puerpério a fim de ser evitada a DP. 
Aulas preparatórias para pais podem se configurar como um incremento na percepção masculina acerca da experiência da maternidade após o nascimento que suas parceiras vivenciavam. Breves intervenções psicossociais devem ser implementadas rotineiramente em hospitais ou na comunidade (MATTHEY et al., 2004).

DAVIES; HOWELLS e JENKINS (2003) preconizam visitas de agentes de saúde durante o período de atendimento as puérperas como forma de prevenção. Também são recomendadas visitas mais tardias, destinadas ao rastreamento daquelas mulheres que por algum motivo não foram percebidas como depressivas quando o bebê era mais novo, provavelmente por ainda não manifestarem sintomas depressivos.

Muitas investigações indicam que os sentimentos das mulheres relacionados à experiência do nascimento sofrem alterações no decorrer do tempo, especialmente quando comparados aos sentimentos um ou dois dias após o parto. O "efeito halo" - alívio imediato sentido pelos pais quando o parto acaba com encantamento pelo bebê - dura poucas semanas e protege a mulher temporariamente de impactos negativos. Na medida em que o "halo" protetor dos primeiros momentos vai se esvaindo memórias e sentimentos indesejáveis voltam a aparecer (HODNETT, 2002).

O impacto da intervenção realizada por profissionais de saúde frente aos transtornos afetivos na gestação é estatisticamente significativo. Estudo realizado em São Paulo mostra que de 45 mulheres portadoras de transtorno afetivo na gravidez, 22 melhoraram após a intervenção. 20,4\% das gestantes apresentaram depressão antes da intervenção e apenas $12,6 \%$ após a intervenção multiprofissional (FALCONE et al., 2005).

Outra maneira eficaz na prevenção da DP fica por conta de visitas domiciliares profissionais, tais como visitas intensivas de enfermagem e também cuidados pós-parto flexíveis realizados por parteiras (midwives). DENNIS e CREEDY (2006) concluíram que: aulas antenatais não têm demonstrado efeito preventivo; "debriefing" (conversa semi estruturada com alguém que passou por um evento percebido como traumático) não é recomendado; a eficácia da terapia interpessoal e suporte leigo permanece incerta; visitas domiciliares profissionais tais como visitas intensivas de enfermagem e cuidados pós-parto flexíveis realizados por parteiras (midwives) parecem promissores quanto a prevenção da depressão puerperal. 
Desta maneira é interessante o uso da EPDS como "screening" para individualizar a promoção dos cuidados. Uma recente proposta despertou interesse e esperança quanto à prevenção da depressão materna. ROWE e FISHER (2010) desenvolveram pesquisa reveladora acerca de como prevenir a depressão puerperal comum em primíparas através de uma intervenção psicoeducacional universal. As autoras afirmam que a prevenção de transtornos mentais após o parto é um componente essencial em serviços de saúde, relacionado aos benefícios potenciais para a saúde desta população. Diversas tentativas de ser prevenida a depressão puerperal tem seu sucesso limitado.

O objetivo das autoras foi desenvolver uma intervenção psicoeducacional singular a fim de prevenir transtornos mentais pós-parto em primigestas. Seu uso pode ser universalizado. É um novo conceito vai ao encontro das necessidades não atendidas das mulheres, promovendo confiança e habilidades para lidar com questões relacionadas a um sono adequado e a negociações sem confrontos quanto à carga de trabalho doméstico a ser realizada. A intervenção WWWT ("What Were We Thinking!") (O que estávamos pensando) tem potencial para contribuir na rotina psicossocial informada do cuidado em saúde pós-natal e prevenir transtornos mentais na mulher (ROWE; FISCHER, 2010).

Apesar da importância de intervenções psicossociais para prevenção de depressões menores - com "score" maior que nove, mas menor que doze ou treze segundo a EPDS - ainda não ter sido explorada, não se pode olvida-las. Depressões menores, rastreadas e acompanhadas podem minimizar assim a possibilidade de agravamento do quadro depressivo (DENNIS; CREEDY, 2006).

Considerando-se que a puérpera possa encontrar dificuldades em acessar os serviços de saúde mental, fica evidente a necessidade de um instrumento de rastreamento adequado para as consultas psiquiátricas. A utilização da EPDS e/ou do SRQ-20 O SRQ (Self-Reporting Questionnaire) são instrumentos de rastreamento psiquiátrico que podem ser utilizados por obstetras, enfermeiros e demais profissionais de saúde, no puerpério, possibilitando a identificação de casos de DP e/ou TMC. A versão brasileira do SRQ-20 (versão com as 20 questões para rastreamento de transtornos mentais não psicóticos) foi validada no início da década de 1980. Ao serem identificadas pontuações que sugerem a necessidade de intervenções, o médico da equipe ou o especialista determinará o tratamento adequado, de acordo com a intensidade dos sintomas (DENNIS; CREEDY, 2006; CRUZ, SIMÕES; FAISAL-CURY, 2005). 
A EPDS é um instrumento de fácil aplicação podendo ate mesmo ser autoaplicado e poderia ser mais amplamente utilizado também durante a gravidez de modo a evidenciar estes transtornos mentais frequentemente não identificados (IBIAPINA et al., 2010; DENNIS e CREEDY, 2006; BROCKINGTON, 2004; DAVIES; HOWELLS; JENKINS, 2002; MILLER, 2002; JOSEFSSON et al., 2001; JOHANSON et al., 2000; EVINS et al., 2000).

Segundo SANTOS et al. (2007), para fins de rastreamento o melhor ponto de corte é $\geq 10$ e para detectar casos moderados ou graves, $\geq 11$. A Escala foi desenvolvida na Grã-Bretanha e validada no Brasil, é composta por 10 perguntas, cada questão relacionada a um sintoma depressivo: perda de prazer generalizado, culpa, ansiedade, preocupação, desesperança, medo, tristeza, insônia e ideação suicida. Em cada questão a existem 4 opções de respostas graduadas de 0 a 3 , do normal ao mais severo. O ponto de corte recomendado no Brasil (11/12) para depressão denota sensibilidade $=94 \%$, especificidade $=85 \%$, valor preditivo positivo, $48 \%$, valor preditivo negativo=99\% e acurácia $=86 \%$ na validação brasileira (CANTILINO et al., 2006; SANTOS; MARTINS; PASQUALI, 1999).

As propriedades psicométricas da EPDS a caracterizam como um bom instrumento de triagem da depressão pós-parto e seu uso disseminado no Sistema Único de Saúde poderiam repercutir positivamente com aumento significativo na taxa de reconhecimento, diagnóstico, e tratamento da depressão pós-parto (FIGUEIRA et al., 2009).

FELIX; GOMES e FRANCA (2008) preferem não aplicar a EPDS na primeira semana após o parto, de modo que o cansaço não interfira nos resultados. No entanto, como o desgaste materno relacionado ao cansaço tende a piorar com o passar dos meses, mais de uma abordagem deveria ser realizada. Os autores sugerem que a aplicação do instrumento aconteça consulta de pediatria após uma semana de vida do bebê ou no retorno de puerpério da mãe. Esta abordagem é muito importante, já que esses médicos encontram com as mães de quatro a seis vezes durante o primeiro ano de vida.

Evidências encontradas em ensaios clínicos randomizados não permitem nenhuma espécie de recomendação acerca do papel dos antidepressivos na prevenção da depressão puerperal (HOWARD et al., 2006). A Terapia Interpessoal ou a Terapia Cognitiva Comportamental são recomendações para mulheres com história pregressa da doença (NICE, 2007). 
ENKIN et al. (2005) entendem que as soluções estão principalmente na mudança social: ouvir para descobrir as circunstâncias sociais da mulher e fornecer informações que despertarão expectativas mais realistas acerca da maternidade. FALCONE et al. (2005) concorda, enfatizando que a disponibilidade para ouvir a gestante com uma postura de acolhimento, é o requisito mais importante para a ação preventiva. Por meio da interação interpessoal, o profissional pode detectar variações de humor, de pensamento e comportamento sugestivos de eventual distúrbio psiquiátrico.

A oferta de atendimento preventivo pelas equipes multidisciplinares nesse período pode proporcionar à nova mãe o apoio de que necessita para enfrentar os eventuais episódios de depressão. É bastante oportuno também que tal assistência precoce à mulher aponte para a possibilidade da prevenção do estabelecimento de um padrão negativo de interação com 0 bebê (SCHWENGNER; PICCININI, 2003).

O atendimento pré-natal de gestantes realizado por equipe multiprofissional, conjugando esforços e conhecimentos de diferentes profissionais, revelou-se excelente oportunidade para prevenir, detectar e tratar transtornos afetivos das gestantes e, consequentemente, de seus filhos (FALCONE et al., 2005).

Ainda assim fica o questionamento de ZINGA, PHILLIPS e BORN (2005): "A depressão puerperal pode ser prevenida?" A resposta breve e sem titubeios é: ainda não. A pesquisa aponta para um forte componente biológico subjacente à sua etiologia. A depressão pós-parto pode ocorrer mesmo em mulheres sem histórico psiquiátrico familiar conhecido ou qualquer um dos fatores de risco.

Atualmente ROWE e FISHER (2010) já discordam da declaração de que a depressão puerperal não pode ser prevenida. WWWT (What Were We Tinking) é uma intervenção promissora para a prevenção primária de transtornos mentais em primigestas, baseada em múltiplas fontes de evidencias, sustentada por relevante teoria psicossocial e de promoção da saúde. Integrada aos serviços de saúde existentes, esta intervenção exemplifica a melhor atenção à saúde mental. 
Deve-se acrescentar que o estudo sobre sintomatologia depressiva no pósparto através da EPDS é de extrema importância e magistral pertinência, visto que possibilita triagens rápida e simples, que podem ser aplicadas por quaisquer profissionais da área da saúde. Principalmente em ambientes de atenção primária, onde a maior parte das puérperas é atendida, a validade de uma abordagem desse tipo é justificada sem questionamentos. A literatura científica deve primar pelo uso adequado dos termos técnicos e instrumentos de moto a evitar o risco de difundir informações equivocadas, que contribuam para o já saturado oceano de estatísticas controversas dos nossos dias (SPANENBERG, 2009). Uma vez detectada necessidade de intervenções, quem atenderá esta mulher? Que serviço de saúde integraria profissionais capacitados para prestar uma assistência de qualidade à puérpera seja de prevenção ou de tratamento?

\subsection{RECOMENDAÇÕES DE TRATAMENTO}

Uma vez instalada a depressão puerperal, existem diversas recomendações objetivando uma assistência de qualidade à puérpera. É recomendado o desenvolvimento de uma relação de confiança com a mulher bem como seus familiares, explorando suas idéias, preocupações e expectativas. A sensibilidade quanto ao estigma e vergonha quanto ao transtorno mental deve ser percebida bem como discutido o papel dos familiares e cuidadores no suporte oferecido à puérpera (NICE, 2007). Não se pode ignorar a importância de o tratamento ser preconizado para abreviar o sofrimento materno e minimizar o impacto familiar (ANDRADE et al., 2006).

Contatos rotineiros com profissionais de saúde durante a gravidez e após o parto são momentos de oportunidades quanto à identificação de mulheres que estão ou tem risco de entrar em sofrimento psíquico. A mulher deve ser questionada acerca de sentimentos de desesperança, tristeza ou depressão bem como falta de interesse ou prazer em atividades durante o último mês (NICE, 2007). 
As recomendações quanto ao tratamento de episódios leves ou moderados de DP durante a gravidez ou puerpério são terapia interpessoal ou cognitiva comportamental de curta duração, visitas domiciliares de escuta e aconselhamento e estratégias de autoajuda como. Para mulheres com episódios anteriores da doença são recomendadas terapias de curta duração como a terapia interpessoal ou a terapia cognitiva comportamental (NICE, 2007).

A evidência clínica demonstra que, por um lado existem estreitas relações entre as variações hormonais e alterações do humor, necessitando-se muitas vezes correções ou complementações para a recuperação. Por outro lado, esta variabilidade depende de fatores psíquicos e sociais vivenciados pela mulher durante a gravidez e parto bem como de seus antecedentes depressivos (LUGO; MONGRADON, 2006).

Episódios depressivos leves podem ter boa resposta ao tratamento psicológico. Quando a mulher já fizer uso do tratamento medicamentoso, a psicoterapia também pode ser uma estratégia no momento de descontinuação ou redução das dosagens, diminuindo o risco de recaídas ou os sintomas depressivos na gestação. O uso da terapia cognitiva comportamental (TCC) tem como base avaliar quais são as ideias, os pensamentos e as emoções que a pessoa possui sobre si mesma e que se encontram distorcidos, provocando relações comportamentais disfuncionais. Em pacientes deprimidas, é comum aparecerem relatos de ideias, pensamentos e sentimentos denominados automáticos, que são o cerne da teoria. A mudança desses pensamentos, muitas vezes distorcidos da realidade, faz com que a paciente com depressão passe a reavaliar sua condição e reestruturar seu quotidiano. É comum as mulheres com depressão pós-parto apresentarem pensamentos e sentimentos relacionados aos cuidados com o bebê e á sua situação atual (CARIFETE, 2009).

Uma abordagem individualizada, levando em consideração fatores psicossociais, desejos e expectativas da mulher com esta condição, favorecerá a adesão ao tratamento e facilitará sua recuperação (IBIAPINA et al., 2010).

A despeito de todas as dúvidas e incertezas que rondam o tratamento medicamentoso durante a gravidez e o período de amamentação, muitos estudiosos acreditam no uso da amitriptilina como relativamente seguro. De um modo geral, os antidepressivos tricíclicos são eficazes, mas apresentam importantes efeitos laterais como o ganho de peso, sedação, boca seca e efeitos cardiovasculares (CARIFETE, 2009) 
Estes efeitos são particularmente intoleráveis no período pós-parto. Alem destas desvantagens ainda existe o risco relacionado ao potencial tóxico nas superdosagens, extremamente relevante se associado a ideações suicidas (CARIFETE, 2009).

O autor pondera acerca dos Inibidores Seletivos de Recaptação da Serotonina (ISRS) e sua relativa segurança bem estabelecida ao longo do tempo, embora tenham, obviamente, menos tempo de mercado que os tricíclicos. Essa categoria ainda não foi completamente avaliada. Dentro deste grupo de fármacos, a sertralina e a paroxetina são os mais estudados em relação aos efeitos na amamentação e sobre os lactentes. Por ser comprovado que atingem concentrações reduzidas no leite materno, são por isso os mais usados no tratamento da DP.

A fluoxetina também tem é largamente usada mesmo com o risco relacionado à sua semivida bastante longa. Tem sido associada a cólicas e elevados níveis no sangue da criança. Atualmente, os fármacos de primeira linha são os inibidores seletivos da recaptação da serotonina (ISRS) ou a venlafaxina, por estarem associados a um menor risco de efeitos tóxicos. Os antidepressivos tricíclicos poderão ser considerados em pacientes que obtiveram uma boa resposta aos mesmos em episódios anteriores de depressão (CARIFETE, 2009).

Estudo de ZAMBALDI; CANTILINO e SOLGEY (2008) também verificaram melhora dos sintomas depressivos em mulheres que também apresentavam sintomas obsessivos compulsivos com tratamento através de antidepressivos. $\mathrm{O}$ tempo médio para resposta ao tratamento foi de 4 semanas, exceto em caso de demora entre o início do quadro e a procura para tratamento. Os autores creem que seja possível que os sintomas obsessivo compulsivos na DP tornem o tratamento mais difícil e demorado, sendo necessárias mais pesquisas nessa área.

Os antipsicóticos de gerações mais recentes, em geral, têm sido os preferidos no tratamento quando se verifica a presença de sintomas psicóticos. Destes, a risperidona usufrui mais tempo no mercado, e não the têm sido atribuídos riscos particulares. A quetiapina e olanzapina também são considerados relativamente seguros, pois não se encontrou, ainda, nenhuma associação de teratogenicidade. A quetiapina pode ser uma opção interessante por sua falta de ação sobre a prolactina. A clozapina necessite controle rotineiro relacionado à agranulocitose e tem efeitos hipotensores (CARIFETE, 2010). 
Atualmente não há evidência quanto aos benefícios permanentes ou segurança para o tratamento de longa duração das medicações antidepressivas na terapia da depressão pós-parto (IBIAPINA et al., 2010). As evidências quanto ao uso de antidepressivos no tratamento da depressão puérpera permanecem inconclusivas (HOFFBRAND; HOWARD; CRAWLEY, 2006). Qualquer antidepressivo usado pela mãe que amamenta apresenta risco de desenvolver uma síndrome de abstinência ou intoxicação no bebê (NICE, 2007). Evidências encontradas em ensaios clínicos randomizados não permitem nenhuma espécie de recomendação acerca do papel dos antidepressivos na prevenção (HOWARD et al., 2006).

No entanto, CARIFETE (2009) enfatiza que administração de fármacos antidepressivos não está totalmente contraindicada durante a amamentação. $O$ autor refere que pequenas quantidades dos mesmos atingem a criança através do leite materno, mas os efeitos em longo prazo desta exposição ainda não são totalmente conhecidos. Importa ressaltar que nas pacientes com depressão moderada/grave ou sem resposta à psicoterapia ou ainda as que se afiguram como possíveis suicidas, infanticidas ou psicóticas os benefícios da terapia farmacológica se sobrepõem de longe aos riscos da exposição do lactente aos fármacos. No caso da criança apresentar alguma irritabilidade, deverá ser determinada a concentração plasmática do fármaco e reajustar a dosagem. Poderá ser necessária a inibição da lactação num número significativo de casos.

Até que o impacto do uso de antidepressivos sobre o desenvolvimento de lactentes seja esclarecido, uma possibilidade clínica seria prescrever antidepressivos que não fossem geralmente detectáveis no plasma dos lactentes, como sertralina e paroxetina (MAGALHÃES et al., 2006).

E necessário reforçar que a evidência de prejuízo no desenvolvimento do bebê associado aos antidepressivos não é definitiva, por ser baseada em estudos preliminares. Assim, a prioridade deve ser em tratar mulheres com depressão pós-parto, já que é provável que a depressão tenha maior impacto sobre o desenvolvimento da criança do que exposição a antidepressivos através do leite materno (HENDRICK et al., 2003). 
IBIAPINA et al. (2010) advertem os obstetras afim de que atentem para a possibilidade de quadro depressivo no puerpério, fazendo uma avaliação oportuna e integrada com outros profissionais como psiquiatras, psicólogos, etc. Desta forma, confirmarão a suspeita inicial e estabelecerão tratamento adequado, com melhora da sintomatologia e oferecimento de suporte necessário a esta fase tão importante da maternidade.

Apesar de sua elevada prevalência, frequentemente a depressão pós-parto não é diagnosticada e consequentemente permanece sem tratamento. Mesmo os casos diagnosticados despertam numerosos dilemas para o profissional da atenção primária (LUGO; MOGRADÓN, 2006).

Todos os profissionais que mantêm contato com mulheres durante o ciclo gravídico-puerperal constituem elementos importantes neste processo. Quanto maior for a conscientização e o conhecimento a respeito do assunto, mais precocemente poderão ser detectados os sintomas depressivos e mais mulheres poderão ser beneficiadas. Fica assim o grande desafio de optar-se por um olhar holístico na assistência à saúde da mulher no puerpério, atuando de maneira integral para o restabelecimento de sua saúde tanto física quanto emocional.

\section{ADOLESCÊNCIA}

\subsection{ASPECTOS POLÍTICOS}

A Secretaria de Atenção à Saúde, no ano de 2005, elaborou a publicação de um Manual intitulado "Caminhos para uma política de saúde mental infantojuvenil". Tal publicação passa por uma retrospectiva histórica acerca das ações dirigidas a crianças e adolescentes no Brasil que facilita a compreensão da assistência vigente em nosso país a esta tão distinta faixa etária da população brasileira (BRASIL, 2005a).

Por mais de um século, as ações relacionadas a crianças e adolescentes passaram como um ideário de proteção, que, paradoxalmente, redundou na construção de um modelo de assistência com forte tendência à institucionalização e em uma concepção segmentada, não integradora, da população infanto-juvenil. 
O início do século XX propagou a importância da assistência a crianças e adolescentes, principalmente porque eles representavam um futuro diferenciado para a nação brasileira. No entanto, o excesso medidas calcadas na lógica higieniza e de inspiração normativo jurídica acabou expandindo sobremaneira a oferta de instituições fechadas para o cuidado de crianças e adolescentes, em sua maioria sob a tutela do campo filantrópico. "O discurso hegemônico sobre a importância da criança na organização da sociedade republicana não teve como correspondente a tomada de responsabilidade do Estado que, por outro lado, oficializava o modelo em curso e a concepção da criança a ser assistida: a deficiente social representada pelo "pobre", a deficiente mental e a deficiente moral, chamada de delinquente" (BRASIL, 2005a).

Os resultados desse longo processo que visava a assistir crianças e adolescentes foram a institucionalização do cuidado a criminalização da infância pobre, gerando um quadro que, no limite, é um quadro de desassistência, abandono e exclusão. Historicamente, o vazio no campo da atenção pública para crianças e jovens portadores de transtornos mentais foi preenchido por instituições, na sua maioria de natureza privada e/ou filantrópica. "Para se promover um desenvolvimento saudável para os cidadãos nesse período especial de suas vidas e alcançar o pleno desenvolvimento de suas potencialidades, a sociedade, por meio do Estado, precisa assegurar mecanismos de educação, proteção social, inclusão, promoção e garantia de direitos da criança, do adolescente e da família" (BRASIL, 2005a).

No final da década de 70 , foram ampliadas as condições de possibilidade para que essas questões estruturais pudessem ser alteradas e superadas. A promulgação da Carta Constitucional de 1988 teve o mérito de afirmar sem ressalvas a condição cidadã de crianças e adolescentes, assegurando-Ihes "o direito à vida, à saúde, à alimentação, à educação, ao lazer, à profissionalização, à cultura, à dignidade, ao respeito, à liberdade e à convivência familiar e comunitária, além de colocá-los a salvo de toda forma de negligência, discriminação, exploração, violência, crueldade e opressão" (BRASIL, 2005a).

O processo de afirmação da condição de sujeitos de direitos tributado a crianças e adolescentes resultou na promulgação de Lei n.. 8.069 , de 13/7/1990, conhecida como Estatuto da Criança e do Adolescente (ECA). As linhas gerais de ação que caracterizam as políticas públicas da saúde mental de crianças e adolescentes são baseadas na ética e na lógica do cuidado: 
1. A criança ou o adolescente a cuidar é um sujeito: o sujeito criança ou adolescente é responsável por sua demanda, seu sofrimento, seu sintoma; e um sujeito de direitos, dentre os quais se situa o direito ao cuidado.

2. Acolhimento universal: o serviço não pode fechar suas portas sob qualquer alegação de lotação, inadequação entre demanda e capacidade técnica do serviço; recebida e ouvida a demanda, é preciso que se dê uma resposta.

3. Encaminhamento implicado: aquele que encaminha se inclua no encaminhamento, se responsabilize pelo estabelecimento de um endereço para a demanda, acompanhe o caso até seu novo destino;

4. Construção permanente da rede: articula a ação do cuidado para com o que se situa para fora e para além dos limites da instituição e implica a noção de território; o território é tecido pelos fios que são as instâncias pessoais e institucionais que atravessam a experiência do sujeito, incluindo sua casa, a escola, a igreja, o clube, a lanchonete, o cinema, a praça, a casa dos colegas, o posto de saúde e todas as outras, incluindo-se centralmente o próprio sujeito na construção do território. $O$ território é o lugar psicossocial do sujeito.

5. Intersetorialidade na ação do cuidado: ampliar-se também no serviço, de seus portões para fora, para a rede que inclui outros serviços de natureza clínica (outros Capsis e Caps, ambulatórios, hospitais, PSFs, etc.), mas também outras agências sociais não clínicas que atravessam a vida das crianças e jovens: escola, igreja, órgãos da justiça e da infância e adolescência, conselho tutelar, instituições de esporte, lazer, cultura, dentre outros (BRASIL, 1990).

A Política Pública de Assistência em Saúde Mental aponta para a necessidade de destituir as instituições baseadas na ideologia do reparo, de caráter excludente, isolacionista. O eixo passa a ser definido pelos direitos de cidadania, definindo a esfera pública como um lugar de excelência de ação protetora, de cuidados éticos emancipatórios das pessoas em situação de risco social. Tal direção impõe mudanças que se traduzem na articulação de novos dispositivos de cuidado vinculados ao processo de desinstitucionalização (BRASIL, 2005c). 
Corroborando com a Teoria da Reabilitação Psicossocial que permeia os mais recentes modelos de atenção à saúde mental, a política vigente assegura que esse processo é baseado no princípio de que o portador de sofrimento mental e sua família sejam protagonistas do seu processo de emancipação. Devem assumir seus lugares na vida de sua cidade. Os serviços de saúde mental infantojuvenil precisam assumir uma função social que extrapola o saber técnico do tratar, e que se traduz em ações, tais como acolher, escutar, cuidar, possibilitar ações emancipatórias, melhorar a qualidade de vida da pessoa portadora de sofrimento mental.

O Estatuto da Criança e do Adolescente (ECA), no Art. 6을 define o adolescente como "pessoa em condição peculiar de desenvolvimento". A adolescência é uma etapa da vida que se interpõe entre a infância e a idade adulta, caracterizada por um processo de crescimento e desenvolvimento psicossocial (BRASIL, 2005a). O ECA, em seu Art. $2^{\circ}$, considera adolescente a pessoa entre doze e dezoito anos de idade.

Para a Organização Mundial de Saúde, a juventude é definida entre 15 a 25 anos, sendo a adolescência considerada entre 15 e 19 anos (GONTIJO e MEDEIROS, 2004).

A despeito da adoção do critério cronológico objetivar a identificação de requisitos que orientem a investigação epidemiológica, as estratégias de elaboração de políticas de desenvolvimento coletivo e programações de serviços sociais e de saúde pública, esta acaba por ignorar as características particulares de cada região (BRASIL, 2005a).

LEONE e GALLO (2010) relembram que no Brasil a definição de adolescência não abrange apenas os indivíduos com menos de dezoito anos, mas também os que estão entre os dezoito anos completos e os vinte anos incompletos.

Fica evidente que há um descompasso entre a fixação etária do Estatuto da Criança e do Adolescente e a da Organização Mundial da Saúde, também adotada pelo Ministério da Saúde, entre outras. De acordo com PAPALIA e OLDS (2000), o início ou o fim deste período não pode ser considerado como uma estrutura rígida. A transição entre a infância e a adolescência envolve mudanças grandes e interligadas. Está diretamente relacionada a uma dependência social e econômica total da família. 
O início e o fim da adolescência também variam de sociedade para sociedade e de época para época inclusive numa mesma sociedade. Na medida em que uma sociedade se torna mais longeva, existe uma tendência de ser estendido o período compreendido por adolescência. O ser humano sente necessidade de prolongar a adolescência e a juventude com a perspectiva de uma expectativa de vida aumentada (COSTA, 2009).

Neste período da vida, a mortalidade no Brasil é bastante elevada, principalmente relacionada a causas externas. Também são consideradas morbidades preocupantes a gravidez e as DST (doenças sexualmente transmissíveis) (COSTA, 2009).

O Ministério da Saúde, em sua série Normas e Manuais Técnicos, traz orientações para a organização de Serviços de Saúde em relação ao atendimento de jovens e adolescentes. A realização de visitas domiciliares é vista como vantajosa no sentido de conhecer melhor o contexto de vida dos adolescentes e jovens e a dinâmica de suas famílias. É uma oportunidade para fortalecer vínculos, convidá-los para atividades educativas, identificar situações de dificuldade. Como esses profissionais têm contato com a família como um todo, é vital que seja assegurada a confidencialidade das informações (BRASIL, 2005b).

O Manual acrescenta que independente do motivo principal da consulta, cada visita à unidade é uma oportunidade única de promoção a saúde bem como de detecção e resolução de outras questões importantes. A entrevista é um exercício de comunicação interpessoal, que vai além das palavras e propicia a observação das emoções, dos gestos, do tom de voz e da expressão facial do (a) adolescente. A consulta é uma oportunidade de conhecer seus hábitos, valores e, até mesmo, o vocabulário peculiar. A equipe pode aproveitar o momento para trocar informações e perceber as novas tendências da sua clientela (BRASIL, 2005b).

Adolescentes e jovens frequentemente tem como característica procurar no grupo de companheiros a sua identidade e as respostas para suas ansiedades. Desta forma, o atendimento grupal se constitui numa forma privilegiada de facilitar a expressão de sentimentos, a troca de informações e experiências, bem como a busca de soluções para seus problemas. Vale a pena relembrar que não são todos adolescentes que se beneficiam ou se sentem à vontade em participar do atendimento em grupo, devendo ser considerados a necessidade individual do cliente e o seu desejo em participar (BRASIL, 2005b). 


\subsection{GRAVIDEZ NA ADOLESCÊNCIA}

Durante muito tempo, se casar e ter filhos aos 13 anos ou menos foi considerado um fato corriqueiro e natural do comportamento reprodutivo. $\mathrm{Na}$ década dos anos 80 houve uma alteração quanto à atitude coletiva face à maternidade precoce. Misturam-se metáforas acerca da gravidez na adolescência como doença, porém surgem enunciados admitindo um desejo genuíno das adolescentes pela realização da maternidade (REIS, 1993).

O discurso da Saúde Pública foi paulatinamente situando a questão da adolescente grávida em parâmetros diferentes do quadro de marginalização econômica e social. A questão da adolescência e da gravidez começou a ser percebida como parte de um processo complexo, maior do que se imaginava (REIS, 1993).

A gravidez na adolescência é uma das questões que se mostram relevantes quanto à vulnerabilidade dos adolescentes no plano individual, social ou programático. Estudos realizados em diferentes países e grupos sociais na década passada demonstravam aumento da taxa de fecundidade nas adolescentes, diferente do que acontecia com as taxas na população geral. No Brasil, essa realidade era constatada pelo crescente número de adolescentes nos serviços de pré-natal e maternidade, sua maior incidência nas populações de baixa renda e a associação entre alta fecundidade e baixa escolaridade (BRASIL, 2005a).

Dados atuais do IPEA demonstram uma reversão do quadro. Em 2009 houve redução no número de adolescentes grávidas em todos os grupos de idade, inclusive entre as mulheres de 15 a 19 anos em todas as regiões do País. Entre as adolescentes que tiveram filhos predominaram as cônjuges, de modo que a fecundidade ocorreu predominantemente em uma união, com seu domicílio já constituído (Brasil, 2009).

A gravidez e a maternidade na adolescência têm sido tratadas como problemas de saúde pública, sendo caracterizadas como situações associadas a riscos pessoais e sociais para o desenvolvimento da adolescente e de seu filho (SANTOS; SCHOR, 2003). 
O engravidar na adolescência é uma questão de interesse por parte da população, da classe médica e também dos gestores de saúde em nosso país. Necessita, porém se tornar objeto de maior atenção no que tange à saúde mental dessas jovens que tão precocemente tem seu papel de menina transformado em condição de mães sem estarem preparadas para tal (JATOBA; BASTOS, 2007).

É peremptório cingir-se do olhar de que trabalhar essas questões na atenção à saúde dos adolescentes e jovens é muito diferente de uma assistência clínica individual e da simples informação ou repressão. O modelo assistencial deve permitir discussões sobre as razões da adoção de um comportamento preventivo e o desenvolvimento de habilidades que permitam aos adolescentes o desenvolvimento de resistência às pressões externas, a expressão de sentimentos, opiniões, dúvidas, inseguranças, medos e preconceitos, de forma a dar condições para o enfrentamento e a resolução de problemas e dificuldades do dia-a-dia (BRASIL, 2005a).

O Ministério da Saúde reforça que os direitos sexuais e os direitos reprodutivos do adolescente se constituem de certos direitos humanos fundamentais já reconhecidos nas leis nacionais e internacionais. Tais direitos nascem a partir da definição de saúde reprodutiva, buscando integrar os direitos sociais, principalmente, o direito à saúde, à educação, à informação, com os direitos individuais de não interferência e de não discriminação. Seus comandos centrais são:

- decidir livremente e responsavelmente sobre a própria vida sexual e reprodutiva;

- ter acesso à informação; ter acesso aos meios para o exercício dos direitos individuais livre de discriminação, coerção ou violência.

O Comitê de Direitos da Criança traçou recomendações específicas a partir de 2003 (Recomendação Geral n. 4, de 6 de junho de 2003). A Recomendação garante os direitos dos adolescentes nos serviços de saúde, independente da anuência de seus responsáveis. Tal garantia vem se revelando como elemento indispensável para a melhoria da qualidade da prevenção, assistência e promoção de sua saúde. Também preserva a autonomia, o sigilo e a privacidade do adolescente e o seu acesso aos serviços, independente da anuência ou presença dos pais e responsáveis, para o enfrentamento das suas questões, inclusive sexual e reprodutiva. Não pode ser discriminado por deficiência de qualquer tipo nem sexo ou orientação social (BRASIL, 2005ª). 
Nesse contexto é possível ser desdobrada a questão da gravidez na adolescência em outras possibilidades além dos tradicionais. A despeito de no Brasil ser considerada um problema de Saúde Pública, a adolescente pode optar por engravidar, planejar uma gravidez e mesmo na ocorrência de uma gravidez não planejada ela pode se congratular quando essa possibilidade era conhecida e não descartada em suas expectativas bem como as de seu companheiro. Assim sendo, a gravidez na adolescência não é necessariamente indesejada.

Fatores como viver em união estável e não ter amigos para conversar favorece o desejo de engravidar. Por outro lado, ter entre 12 e 16 anos e ainda estar no primeiro grau diminui este desejo. Tais achados podem ajudar os profissionais de saúde que lidam com essa faixa etária a identificar possíveis situações de risco para a gravidez e assim direcionar sua orientação de forma precisa e adequada (MENESES, 2008).

STUART e LARAIA (2001) acreditam que algumas adolescentes têm baixa autoestima e temores de inadequação. Para o alívio desses temores, elas podem engravidar. Às vezes a gestação é um esforço para escapar de uma situação familiar difícil, ou para forçar os pais a concordarem com um casamento que pode ser inapropriado.

Em si, a adolescência já é um processo de mudança tanto física, como psicológica, quanto mais se neste período uma gravidez for vivenciada. Ter um bebê neste momento de transição é uma decisão bastante difícil e envolve muitas renúncias. Para tanto, o apoio da família da menina e de seu parceiro é de grande importância, tanto pelo lado financeiro como emocional (FRIZZO; KAHL; OLIVEIRA, 2005).

De acordo com o Ministério da Saúde, a gravidez na adolescência é de alto risco de diversas naturezas, tais como clínicas, biológicas, comportamentais, relacionadas à assistência à saúde, sócio-culturais, econômicas e ambientais (PORTO; LUZ, 2002). Cabe acrescentar que os riscos são mais evidentes na adolescência precoce, em meninas de catorze anos ou menos.

O risco social, discurso predominante na saúde pública, traz implícita uma interpretação de que a gravidez resultaria da pobreza, da precariedade e da falta de acesso aos serviços de saúde, e, portanto considerada como um reforço à pobreza e marginalidade. Uma vez indesejada, a gravidez acarretaria prejuízos para as adolescentes como abandono dos estudos e dificuldade em encontrar emprego (PANTOJA, 2003). 
Certas dimensões podem colocar as mães adolescentes em maior risco de vir a apresentar dificuldades em se adaptar à maternidade. Algumas destas dimensões se relacionam aos antecedentes que contribuem para que a gravidez aconteça na adolescência (FIGUEIREDO, 2000).

O avanço do conhecimento científico dos fenômenos físicos em obstetrícia tem proporcionado habilidades fundamentais a médicos e enfermeiros, permitindo uma prática de atendimento que gera, realmente, um estado de confiança maior na mulher. Contudo, condutas baseadas somente nos aspectos físicos não são suficientes. Elas necessitam ser potencializadas, especialmente pela compreensão dos processos psicológicos que permeiam o período grávidopuerperal. Notadamente, no caso de gestantes adolescentes existem especificidades psicossociais da etapa evolutiva que as leva a vivenciar uma sobrecarga emocional trazida pela gravidez (BRASIL, 2005d).

A gravidez é a primeira causa de internações em moças com idade entre 10 e 19 anos na rede SUS. Aproximadamente um quarto do total de partos é em adolescentes de 10 a 19 anos. A segunda causa de internações nessa mesma população corresponde ao grupo de causas externas, entre as quais, a tentativa de suicídio (ANDRADE et al., 2006; FREITAS; BOTEGA, 2002).

Ao ser contemplado o universo de mulheres que engravidam, é nas adolescentes que os prejuízos de uma atenção precária à gestação se mostram mais intensos. Cogita-se a possibilidade de que os efeitos de um pré-natal inadequado nesse grupo sejam mais pronunciados devido a gravidez na adolescência ser um fenômeno muito mais presente nas jovens de grupos sociais excluídos, frequentemente desprovidas do apoio da família, do pai do bebê e da sociedade (GAMA et al., 2004). Segundo os autores, alguns estudos têm mostrado que a grávida adolescente inicia mais tardiamente o acompanhamento pré-natal e termina por fazer um menor número de consultas, quando comparada às mulheres com vinte anos e mais.

A gestação é um momento de mudanças fisiológicas, sociais, familiares e psicológicas, podendo assim ser um período em que se observam aumentos de sintomatologias ou mesmo o desenvolvimento de transtornos psiquiátricos. Um dos transtornos que pode ocorrer durante o período gestacional é a depressão, influenciando negativamente na gestação, já que os sintomas interferem no desempenho das gestantes quanto ao autocuidado e adesão ao tratamento (LAMOUNIER, 2004; SCHWENGBER; PICCININI, 2003). 
Estudo transversal comparativo na zona urbana do município de Marília $\mathrm{SP}$ pesquisou adolescentes entre 13 e 17 anos, primigestas, no ensino fundamental e médio de escolas estaduais. A mediana de idade nos dois grupos de adolescentes foi de 16 anos. Entre as grávidas, 51,3\% encontravam-se fora da escola, das quais $45,8 \%$ já a haviam abandonado há um ano ou mais, ou seja, antes de engravidar. A renda familiar mensal per capita das grávidas foi de $R \$ 120,00$. Comparado às adolescentes não grávidas, o grupo das primigestas apresentou maior prevalência de sintomas de ansiedade e depressão $(24,2 \%$ vs. $15,3 \%$ ) e sintomas de retraimento e depressão (13,0\% VS, 4,5\%), além de maior número de fumantes (21,3\% vs. $11,0 \%$ ) (CAPUTO; BORDIN, 2007).

Observa-se que muitas vezes são cobrados das gestantes, comportamentos que demonstrem felicidade, afeto e cuidados para com a gestação, levando as mulheres que apresentam sintomas depressivos a sentimentos de culpa por não poderem corresponder a estas expectativas. É importante nesse momento que se faça uma avaliação adequada para se discriminar sintomas e sentimentos presentes durante o período gestacional (BANDEIRA et al., 2007).

\subsection{GRAVIDEZ, DEPRESSÃO E SUICÍDIO}

Durante muitos anos acreditou-se que os adolescentes, assim como as crianças, não eram afetados pela depressão, já que, supostamente esse grupo etário não tinha problemas existenciais. Hoje, porém, já é amplamente reconhecido que adolescentes são tão suscetíveis à depressão quanto os adultos e que este é um distúrbio que deve ser encarado seriamente em todas as faixas etárias. Nas últimas décadas ocorreu um aumento no número de casos de depressão na adolescência (CRIVELATTI; DURMAN; HOFSTATTER, 2006).

A partir de 1975 o National Institute of Mental Health of the US (NIMH) reconheceu a existência da depressão em crianças e adolescentes. Ainda assim, em 2002 o reconhecimento oficial da depressão em crianças e adolescentes ainda era tido como recente e os estudos científicos a esse respeito carentes de avanços. (BAHLS, 2002b). 
Atualmente o estudo dos transtornos depressivos na adolescência já definiu que sua presença é comum e grave o suficiente para merecer a atenção de clínicos e pesquisadores. Ainda mais se for considerado o aumento de sua prevalência e seu início cada vez mais precoce. Considera-se que a depressão maior na infância e na adolescência apresente natureza duradoura e persistente, afetando múltiplas funções e causando significativos danos psicossociais (BAHLS, 2002a).

Em si, a adolescência já é um processo de mudança tanto física, como psicológica, quanto mais se neste período uma gravidez for vivenciada. $\mathrm{O}$ apoio da família da menina e de seu parceiro é de grande importância, tanto pelo lado financeiro como emocional (FRIZZO et al., 2005).

A gravidez é considerada como o fator deflagrador mais importante para a depressão na adolescência (AGUINAGA et al., 1999b). Também se associa a um risco suicida elevado, tanto durante a gestação, quanto no pós-parto, paralelamente a uma maior incidência de depressão e a uma percepção negativa da rede de apoio social. Além disso, são frequentes os registros de abusos físicos e sexuais nessa população, o que se associa com a presença de ideação suicida, com tentativas de suicídio e com sintomatologia depressiva crônica no primeiro ano após o parto (ANDRADE et al., 2006).

Os sintomas depressivos já eram três vezes mais frequentes entre jovens que entre adultos há onze anos, com prevalência entre 15 e 50\% (SOARES et al., 1999). Eventos estressores, tais como mudança de vida, perdas ou micro eventos diários vêm sendo considerados como fatores de risco para a ocorrência da depressão na adolescência, com prevalência mais elevada entre adolescentes institucionalizadas entre 12 e 21 anos (DELL'AGLIO et al., 2004).

Verificou-se uma prevalência de depressão entre $16 \%$ e $44 \%$ em adolescentes gestantes, quase duas vezes mais elevada que nas gestantes adultas, o que pode estar relacionado à falta de maturidade afetiva e de relacionamentos dessas pacientes, bem como ao fato de grande parte delas terem que abandonar seus estudos em razão da maternidade (SZIGETHY; RUIZ, 2001). 
A despeito da existência da Lei de n.ำ 6.202/1979 que estabelece que a gestante estudante tenha direito a receber o conteúdo das matérias escolares em casa a partir do oitavo mês de gestação e durante os três meses após o parto, muitas gestantes ainda abandonam os estudos por causa da gravidez. A legislação ainda oferece um prolongamento desse período de acordo com indicação médica. A prestação dos exames escolares é garantida por "regime de exercícios domiciliares" e seu aproveitamento escolar poderá ser aferido por meio de trabalhos feitos em casa (BRASIL, 2005a).

De acordo com o Ministério da Saúde, o alto risco da gravidez na adolescência pode abranger diversas naturezas, tais como clínicas, biológicas, comportamentais, relacionadas à assistência à saúde, socioculturais, econômicas e ambientais (PORTO; LUZ, 2002).

Nesta etapa do ciclo da vida, a depressão maior tem sido considerada comum, debilitante e recorrente, envolvendo um alto grau de mortalidade e morbidade, representando um sério problema de saúde pública (BAHLS, 2002a). Afeta $2 \%$ dos pré-púberes e de cinco a $8 \%$ dos adolescentes (SCIVOLETO; TARELHO, 2002).

Pesquisas epidemiológicas entre crianças e adolescentes confirmam que a diferença de gênero na incidência de depressão maior se manifesta primeiramente entre os 11 e 14 anos, assim se mantendo no decorrer da vida adulta. Tais achados podem sugerir um papel determinante dos hormônios sexuais, especialmente considerando que outras situações de variação hormonal também têm sido associadas a humor depressivo, como o período pré-menstrual, puerpério, menopausa, uso de contraceptivos orais e terapia de reposição hormonal (ANDRADE et al., 2006; DELL'AGLIO; HUTZ, 2004).

Confirmando a prevalência da depressão no sexo feminino, também foi observado o predomínio da raça branca em relação à raça negra. A renda familiar variou entre 1 e 3 salários mínimos, revelando que estes adolescentes pertencem a famílias pobres e comprovando forte influência dos fatores socioeconômicos sobre a saúde mental. (CRIVELATTI; DURMAN; HOFSTATTER, 2006).

Já na década passada, na Costa Rica, estudos encontraram que um em cada dez estudantes entre oito e dezenove anos apresenta sintomas depressivos suficientes para indicar uma avaliação mais detalhada e possivelmente um tratamento específico (SÂNDI et al., 1999). 
Em adolescentes com diagnóstico de depressão na Argentina detectou-se grande frequência de sintomas cognitivos verbais, de sintomas somáticos, e de problemas de conduta. Percebeu-se alta comorbidade especialmente com transtornos de ansiedade e transtornos de conduta (ZAMORA-CABRAL, 1998).

O suicídio muitas vezes é associado a quadros depressivos. $\mathrm{Na}$ adolescência é considerado risco por representar a segunda causa de internações na população de 10 a 19 anos do sexo feminino na rede SUS (FREITAS; BOTEGA, 2002).

DUTRA (2001) identificou menções de tristeza, acabrunhamento, isolamento, tédio, desesperança e retraimentos que podem ser encarados como comuns, quando se discute este tema. Para os autores, os comportamentos suicidas podem ser compreendidos como uma defesa à depressão, enquanto que a depressão pode ser uma defesa contra o suicídio.

Estudo com triagem de sintomas depressivos em crianças e adolescentes em uma cidade do interior do Brasil detectou significativo percentual de positividade, inclusive casos graves, com ideação e intenção suicida (FONSECA; FERREIRA; FONSECA, 2005).

Em pesquisa realizada com estudantes do ensino médio matriculados em escolas públicas do estado da Paraíba, se encontrou um índice de $22,2 \%$ de adolescentes com ideação suicida através da Escala de Ideação Suicida de Beck. $55 \%$ eram do sexo feminino e encontram-se na faixa etária entre 17 e 19 anos; $45 \%$ cursam o 20 ano do ensino médio; $95 \%$ eram solteiros; $85 \%$ moravam com os pais; $70 \%$ afirmaram ser católicos; e $100 \%$ disseram não possuir trabalho remunerado. Os adolescentes que apresentaram ideação se consideram pessoas sozinhas, associando a ideação a sentimentos de desesperança e solidão, ao mesmo tempo em que expressaram um pedido de ajuda diante de seu sofrimento. Os achados enfatizam a importância dos fatores sinalizadores, que podem permitir uma melhor compreensão sobre a problemática do suicídio (ARAUJO; VIEIRA; COUTINHO, 2010).

ARAUJO; VIEIRA e COUTINHO (2010) alertam para o alto índice de adolescentes que apresentaram a ideação suicida em sua pesquisa, representando um dado bastante preocupante, pois esse comportamento representa um fator de risco para o suicídio consumado. As autoras colocam que, uma vez que o suicídio é definitivo e irreversível, devem ser envidados esforços para diminuição dos fatores de riscos individuais e coletivo. 
Pesquisa de JATOBA e BASTOS (2007) detectou a prevalências de sintomas depressivos expressivos e de ansiedade de 59,9\% e 19,9\%, respectivamente. Foram significativas as associações de sintomas depressivos de intensidade grave com o sexo feminino e crenças religiosas diferentes da corrente do cristianismo. A ideação suicida e a tentativa de suicídio foram referidas por $34,3 \%$ dos estudantes. Houve associação significativa de ideação suicida com grau leve ou moderado de sintomas depressivos e moderado de ansiedade, assim como de tentativa de suicídio com sintomas depressivos graves e ansiedade severa. As autoras reforçam a percepção da adolescência como tema frequente nas pesquisas científicas no Brasil e no mundo, mas advertem que ainda existem questões que devem ser melhor exploradas, para que os adolescentes possam viver em plenitude essa fase tão importante de suas vidas.

Em adolescentes sujeitos do estudo de BENICASA e REZENDE (2006), o suicídio foi considerado uma consequência da tristeza. "Briga dos pais", "solidão" e "traição de amigos, namorado(a)" foram apontados como fatores de risco para tristeza entre adolescentes. $O$ fator de proteção apresentado foi "alguém confiável para conversar". Identificou-se a necessidade de criar espaços de escuta e implantar programas de proteção à saúde e à vida, voltados a esta população.

$O$ artigo revela como consequências dos fatores de risco, o suicídio, depressão, prolongamento da tristeza, isolamento e autoagressão. Os adolescentes apontaram como fatores de proteção "família próxima e alguém confiável pra se abrir". Os resultados não mostraram diferenças relevantes entre as classes sociais "A" e " $D$ " quanto ao fenômeno "tristeza". No entanto, adolescentes da classe alta apresentaram mais acentuadamente o fator de risco "sentimento de falta de proteção" como uma peculiaridade. Demonstraram a importância de uma rede de apoio para evitar a tristeza (BENINCASA; REZENDE, 2006).

Muitas vezes a adolescente busca por atendimento especializado quando percebe a seriedade de determinado sintoma, com o objetivo de minimizar as perdas devido à situação de estresse provocada. As perturbações nas relações familiares normais ocasionadas por agressividade, o uso de drogas e 'nervosismo' são pontos importantes para que ocorra a busca de tratamento (ANTUNES; CAMPOS, 2007). 
Segundo os participantes do estudo, os adultos se aproximam com discursos previamente elaborados e não permitem a elaboração espontânea de conceitos a respeito deste e de outros temas. Emerge assim uma necessidade de desenvolvimento de estratégias de intervenção através de programas de promoção ou educação para a saúde, voltados aos adolescentes. "A oferta de um espaço de escuta foi uma das sugestões apontadas pelos sujeitos à coordenação deste projeto. Os participantes relataram que a falta de oportunidade para refletir sobre seus sentimentos, provavelmente, os expõe a mais riscos ou colaboram na intensificação de sentimentos ruins" (BENINCASA; REZENDE, 2006).

Considerando a gravidade de tais eventos, é importante que os devidos cuidados na assistência sejam providenciados, uma vez que tanto a depressão como a ideação suicida podem pode levar a êxito fatal. A ideação suicida é um sintoma importante para o diagnóstico de depressão e é necessária a tentativa de se reconhecer precocemente sinais ou evidências que o adolescente possa estar com tal tipo de ideação. A severidade da doença é percebida também quando a adolescente deixa de realizar atividades que considerava prazerosas (ANTUNES; CAMPOS, 2007).

Muitas vezes o motivo da não procura de ajuda especializada está relacionado ao não convencimento da severidade destes sintomas por parte dos pais ou responsáveis, acreditando em uma remissão espontânea. Outro motivo pode ser a falta de aceitação do fato de que possa existir dentro da família um indivíduo com tal doença, ou seja, a admissão para a sociedade da presença de um "doente mental" na família. Ainda outra situação é a procura de ajuda não profissional, estimulada por influências culturais sendo muitas vezes inerentes às dificuldades financeiras relatadas, impossibilitando a busca de cuidado especializado (JATOBA; BASTOS, 2007).

Os autores advertem que, apesar de nos últimos anos ter acontecido uma clara evolução no tocante ao tratamento medicamentoso da depressão bem como do oferecimento de serviços de psicoterapia, tais tratamentos muitas vezes se tornam inviáveis para indivíduos de classes menos favorecidas. 
ARAUJO; VIEIRA e COUTINHO (2010) alertam para o alto índice de adolescentes que apresentaram a ideação suicida em sua pesquisa, representando um dado bastante preocupante, pois esse comportamento representa um fator de risco para o suicídio consumado. As autoras colocam que, uma vez que o suicídio é definitivo e irreversível, devem ser envidados esforços para diminuição dos fatores de risco, tanto em nível individual quanto coletivo,

As características psicopatológicas dos adolescentes estão a requerer que instituições, como a família e a escola, resgatem sua condição de lugar onde o adolescente possa se desenvolver com saúde, abrigado e protegido. A sala de aula deve ser um lugar no qual as agruras a que estão expostos possam ser minimizadas e o aumento do conhecimento se torne o instrumento de ajuda em seu crescimento. (JATOBA; BASTOS, 2007).

A depressão ou depressões, como uma resposta aos desafios da adolescência, pode ocorrer em função de variados mecanismos tanto como um luto necessário e que deve ser superado, como uma perda irreparável que recai sobre o próprio ego. Segundo as autoras, toda perda sugere uma elaboração e quando esta acontece durante a adolescência, requer mais tempo. $\mathrm{O}$ adolescente necessita elaborar lutos concernentes às perdas da infância, podendo experimentar o afeto depressivo que nem sempre se manifesta com sentimentos de infelicidade. Pode se manifestar como mudanças no comportamento (retardo psicomotor, sono alterado, perda de energia, desmotivação, déficit no desempenho escolar, etc.) e no humor, como irritabilidade, instabilidade, sentimentos de desesperança, baixa autoestima, ideias suicidas etc. (MONTEIRO; LAGE, 2007).

Alguns conflitos importantes podem aparecer durante a construção da identidade do adolescente. A direção que ele dá para sua vida vai receber influências da sociedade, a qual cobra de cada pessoa um papel social o mais definitivo possível. Como a identidade do adolescente ainda não se completou, é mais difícil ainda assumir papel social definitivo. Daí a importância de pais, professores e profissionais de saúde reconhecerem esses sintomas como indicadores de possível depressão, para que os adolescentes possam ser encaminhados para tratamento especializado (FONSECA; FERREIRA; FONSECA, 2005). 
Adolescentes, quando questionados sobre seus sentimentos, se mostram frágeis, solitários, incompreendidos e excluídos. Deixam claro que além das transformações fisiológicas, psicológicas e emocionais, adolescer também é uma atitude cultural, uma postura enquanto ser humano durante uma das fases de seu crescimento, na qual procuram dar retorno às expectativas da sociedade. Como o papel social do adolescente não é explicitamente definido afloram sentimentos de inutilidade, insegurança e confusão (FONSECA; FERREIRA; FONSECA, 2005).

O conhecimento dos adolescentes acerca da depressão se mostra fragmentado e permeado pela menção de sintomas da doença e alterações comportamentais. Uma vez que a desinformação influencia na adesão ao tratamento, predispondo o adolescente ao agravamento do seu quadro clínico e a recaídas, necessidade fica evidente a necessidade e a importância da assistência educacional desenvolvida pela família e pelo meio (CRIVELATTI; DURMAN; HOFSTATTER, 2006).

A despeito de muitos fatores contribuírem para o surgimento da depressão na adolescência, como conflitos familiares, situação socioeconômica, sexualidade, falta de conhecimento, solidão e perdas, a própria família em algum momento consegue identificar a doença seja pelos sintomas ou pela verbalização dos sentimentos do adolescente. A equipe que o atende, não importa em que instituição, deve olhá-lo como um indivíduo que pode apresentar algum distúrbio independente da fase vivenciada. O enfermeiro pode atuar tanto na prevenção como no tratamento, exercendo sua função de educador individualmente ou como membro de uma equipe interdisciplinar, buscando auxiliar no diagnóstico e tratamento precoce (CRIVELATTI; DURMAN; HOFSTATTER, 2006).

Em Porto Alegre, RS, foram sujeitos de estudo 526 adolescentes entre 15 e 19 que frequentavam escolas públicas, no intuito de pesquisar a intensidade de depressão/desesperança, e da ideação suicida. As autoras confirmam o saber dominante nesta temática ao dizerem que o jovem que pensa, ameaça, tenta ou concretiza o suicídio está revelando um colapso em seus mecanismos adaptativos, de modo que tal situação é percebida não somente na adolescência, mas como em qualquer idade, como uma tentativa de alívio de sua dor e seu sofrimento (BORGES; WERLANG, 2006). 
Assim como na maioria dos estudos sobre ideação suicida, as autoras também utilizaram a Escala de Ideação Suicida de Beck, autor também do reconhecido Inventário de Depressão de Beck. Fica a preocupação de BORGES e WERLANG (2006) acerca da ideação suicida como fator de risco relevante para o suicídio consumado, junto com a depressão e a desesperança. Ainda recaracterizam o ideação do suicídio como uma morte antecipada que pode ser evitada por meio de ações preventivas, seja na família, nas escolas, nos meios de comunicação e na comunidade como um todo, procurando, assim, promover o desenvolvimento saudável desses jovens.

$\mathrm{Na}$ amostra estudada foi possível constatar que 36\% adolescentes apresentaram ideação suicida, ou seja, um pouco mais de um terço da amostra. Destes, 67,6\% eram do sexo feminino (BORGES; WERLANG, 2006). É possível visualizar, através destes dados, a grande responsabilidade que cabe aos profissionais de saúde ao prestarem assistência a adolescentes, e em especial àquelas que porventura estiverem vivenciando uma gestação ou um período puerperal nesta fase do ciclo da vida.

SOUZA et al. (2010) pesquisaram a prevalência de ideação suicida e fatores associados em adolescentes entre 11 e 15 anos através do Children's Depreesion Inventory. Foi encontrada uma prevalência de 14,1\% para ideação suicida com fatores associados como gênero feminino, consumo atual de álcool, uso de drogas ilícitas, sintomas de depressão. Os autores sugerem atenção especial para adolescentes do sexo feminino, sexualmente ativas. De acordo com os dados epidemiológicos, os autores recomendam que países da América do Sul despendam tanta atenção para esses aspectos de saúde quanto os países desenvolvidos em relação à ideação suicida já na adolescência precoce.

Uma vez que ter três ou mais parceiros sexuais durante a adolescência precoce está fortemente associado ao uso de drogas ilícitas como a cocaína e a maconha durante a gestação, são sugeridos programas específicos de intervenção e localização destas jovens mulheres. A idade é um fator significativamente associado ao consumo de no mínimo uma espécie de droga. Ter mais de 14 anos diminui a intensidade do consumo de maconha ou cocaína assim como ser mais jovem que 14 anos maximiza a probabilidade do uso dessas drogas (BESSA et al., 2010). 
Revisão bibliográfica de BENNETTI et al. (2007) concluiu que publicações de diversas áreas do saber indicam que a demanda em saúde mental na adolescência é uma questão importante. Essa faixa etária além de se configurar como uma grande parcela da população que procura atendimento é identificada como um grupo etário vulnerável e de risco em diversas categorias: depressão, transtornos de conduta, transtornos alimentares, drogas e violência. Em conseguinte, è necessário tornar visível a grande demanda por atendimento e a diversidade das situações clínicas que afetam os jovens. Definitivamente estes são pontos fundamentais para o desenvolvimento de novas ações em saúde mental.

Segundo o Manual Diagnóstico e Estatístico de Transtornos Mentais (DSMIVTR, 2000), os sintomas básicos de um episódio depressivo maior são os mesmos em adultos, adolescentes e crianças, embora existam dados sugerindo que a predominância de sintomas característicos pode mudar com a idade. São sintomas muito comuns em crianças:queixas somáticas, irritabilidade e retraimento social e sintomas menos comuns retardo psicomotor, hipersonia e delírios. Já a Classificação Internacional das Doenças (OMS, 2009) lida com os transtornos depressivos de forma idêntica em todos os grupos etários, com apenas a seguinte citação específica "apresentações atípicas são particularmente comuns no episódio depressivo na adolescência", mas não fornece maiores esclarecimentos.

Apesar da manifestação da depressão em adolescentes apresentar sintomas semelhantes aos dos adultos também existem importantes características típicas do transtorno depressivo nesta fase da vida. Adolescentes deprimidos não estão sempre tristes; apresentam-se principalmente irritáveis e instáveis, podendo ocorrer crises de explosão e raiva em seu comportamento (BAHLS, 2002a).

São considerados sintomas típicos de depressão em adolescentes: irritabilidade e instabilidade; humor deprimido; perda de energia; desmotivação e desinteresse importante; retardo psicomotor; sentimentos de desesperança e/ou culpa; alterações no sono; isolamento; dificuldade de concentração; prejuízo no desempenho escolar; baixa autoestima; ideia ou tentativa de suicídio; problemas graves no comportamento (BAHLS, 2002a). 
De acordo com o saber prático, a depressão na adolescência acontece como consequência de disfunções afetivas e de relações sociais insatisfatórias e patológicas. Desta forma muitos hábitos prejudiciais são perpetuados, principalmente, no âmbito da escola e da família. O tratamento da depressão tem sido ancorado, majoritariamente, nos afetos, o que fortalece uma posição que priorize o estado psicológico do indivíduo através da atenção, do diálogo e da compreensão (BARROS, 2006).

Em pesquisa de BARROS (2006) com adolescentes no ensino médio, os sujeitos da pesquisa enfatizaram as causas psicoafetivas, sobretudo entre os adolescentes da rede privada. Infere-se que a ênfase nas mudanças no mercado de trabalho, no que diz respeito à exigência de qualificação e de dedicação exclusiva presente na sociedade atual, impede a manutenção das relações afetivas constantes, as colocando em segundo plano. As falas dos entrevistados evidenciam uma associação entre os sintomas da depressão e alguns problemas de ordem social e econômica específicos, como preconceito, desigualdade social, falta de dinheiro, de comida, de amigos, rejeição, e problemas no meio familiar.

$\mathrm{Na}$ atualidade já se conhece de forma relativamente segura, tanto os fatores de risco como os fatores precipitantes do comportamento suicida em crianças e adolescentes, o que permite melhores estratégias de abordagem do problema. Se for considerado ainda que a depressão, devido ao seu resultado terapêutico comumente satisfatório, é a principal causa evitável de suicídio, a doença depressiva na adolescência tem urgência em ser identificada e/ou prevenida, protegendo e impedindo inúmeras possíveis vítimas de comportamento suicida derivado da doença depressiva (BAHLS, 2002a).

Ao ser evidenciado que variáveis sociodemográficas, de estilo de vida e de saúde se revelaram associadas aos distúrbios depressivos, fica inegável a convicção da importância de que profissionais de saúde mental em escolas de ensino médio efetuem rastreio para reconhecer precocemente problemas mentais e fornecer aconselhamento aos estudantes (ZINN-SOUZA et al., 2008). 
FALCONE et al. (2005) trabalharam junto ao Programa de Atenção à Gestante em Paraisópolis, estado de São Paulo, no Centro de Promoção e Atenção à Saúde (CPAS). O objetivo foi desenvolver um sistema de acompanhamento à gestante de baixa renda. Esse acompanhamento foi realizado por uma equipe multiprofissional composta por enfermeiras, nutricionistas, pedagoga, psicólogas, fisioterapeutas, assistentes sociais e agentes comunitárias. Tais profissionais complementam o pré-natal por meio de monitoramento da gravidez, humanização do atendimento e fortalecimento da relação mãe-feto, considerando a saúde mental materna. Os temas abordados para o desenvolvimento e/ou reforço do vínculo mãe/feto foram:

- Relaxamento - exercícios de relaxamento com música afim de propiciar bem estar físico e psíquico, aumentar a disposição e concentração da gestante.

- Automassagem - a gestante foi orientada a utilizar recursos como: bolinha de tênis e/ou óleo, suas próprias mãos, passando pelo corpo, massageando a barriga, estimulando o contato dela com o feto e aliviando tensões.

- Massagem do bebê - fundamentada na técnica de Shantalla, utilizando boneco e enfatizando a importância para o desenvolvimento e saúde do bebê e a aproximação entre mãe e filho.

- Cantigas de ninar - foram cantadas músicas da infância e parlendas populares estimulando as gestantes a reviver experiências infantis. As gestantes ganharam um livro de canções de ninar elaborado pelos profissionais para utilizar durante os encontros do grupo.

- Dinâmicas para trabalhar sentimentos e dúvidas que emergem na gestação - temas discutidos no grupo a fim de diminuir ansiedade e angústia da gestante frente a eles.

- Relação entre mãe e concepto - este tema foi abordado por meio de técnicas específicas favorecendo a percepção e valorização dos movimentos fetais. A partir desse momento, instalam-se na mãe, os sentimentos de personificação do feto, atribuindo a ele características pessoais de acordo com a interpretação desses movimentos.

- Função do pai - discutiu-se a importância da função paterna para o concepto/bebê e para a gestante/mãe. 
Em seguida, eram destinados 60 minutos para discussão de temas relacionados à gestação, parto e pós-natal mediato, com equipe interdisciplinar. Contemplando os resultados obtidos nas avaliações, foi realizado um plano específico de atendimento às gestantes.

O estudo revelou alta prevalência de transtornos afetivos em gestantes adultas $(46,5 \%)$ e em adolescentes $(37,5 \%)$ no primeiro diagnóstico. Após o trabalho multiprofissional realizado com as gestantes, observou-se queda na prevalência de transtornos afetivos: adultas $(25,3 \%)$ e adolescentes (15,6\%), com diferenças estatisticamente significantes antes e após a participação das gestantes. Pode-se inferir que tanto a participação das adolescentes como a das adultas no Programa de Atenção à Gestante, contribui para diminuir os transtornos afetivos, frequentemente presentes no período gravídico (FALCONE et al., 2005).

É fundamental que ocorra um movimento de educação em saúde, como o que já vem ocorrendo com a adoção do modelo de promoção da saúde, com programas como o de Saúde da Família, facilitando assim o acesso à informação, visto que atende a família como um todo, na própria comunidade. Certamente neste programa existe espaço para a inclusão de um trabalho de educação e conscientização em relação à possibilidade de ocorrência de doenças mentais em adolescentes, melhorando o acesso a informações e serviços e facilitando a percepção dos pais e responsáveis pelo adolescente. Tais facilitadores desencadeariam uma descoberta mais precoce da doença e a busca por atendimento para seus filhos (ANTUNES; CAMPOS, 2007).

O treinamento de profissionais em todas as áreas de saúde e principalmente os profissionais de enfermagem que estão mais próximos ao paciente e à família a fim de fornecer informações específicas, também é uma necessidade premente. As autoras sugerem um trabalho educativo realizado em conjunto com os diversos segmentos da sociedade e o mais próximo possível da comunidade com objetivo de criar novas perspectivas e possibilidades de uma maior abrangência de disseminação de conhecimentos básicos à população. Tal trabalho favorece a percepção dos sinais e sintomas da depressão, doença que tem tido importante aumento de incidência no passar dos anos, sobretudo na população adolescente (ANTUNES; CAMPOS, 2007). 


\subsection{DEPRESSÃO PÓS-PARTO NA ADOLESCÊNCIA}

BARBOSA et al. (2006) consideram relevante investigar se as adolescentes estão mais predispostas a apresentar quadros de depressão após o parto a gravidez na adolescência. A gravidez nesta fase do ciclo da vida frequentemente como um problema de caráter social, com um pressuposto de que a gravidez seja mais frequente nas classes menos favorecidas e encarada, na maioria das vezes, como inoportuna ou indesejada, com consequências biológicas, psicológicas e sociais negativas.

A prevalência da DP nas adolescentes tem se mostrado relevante. Em um serviço público de pré-natal adolescente foram obtidos resultados de $23,3 \%$ de ansiedade, 20,8\% de depressão e 16,7\% de ideação suicida, sem diferença quanto aos trimestres gestacionais. A ideação suicida associou-se com depressão, ser solteira sem namorado e contar com pouco apoio social. Estes casos apresentaram alta frequência de sintomas como falta de concentração, ansiedade, depressão, preocupações, obsessões, ideias depressivas, fadiga, preocupações com o funcionamento do corpo e compulsões (FREITAS, 2002).

FREITAS (2002) é bastante oportuno ao advertir que, diante da frequência com que se observam quadros depressivos, ansiosos e de ideação suicida em adolescentes grávidas, é preciso que os profissionais de saúde atentos quanto à detecção precoce de ideias depressivas nestas adolescentes.

A prevalência de TMC entre as gestantes adolescentes na pesquisa de MENESES (2008) foi de 45,3\%. Pesquisa realizada no município de Itapecerica da Serra, São Paulo, observou a ocorrência de grande probabilidade de depressão puerperal em 50\% das adolescentes entre 15 e 19 anos que responderam a Escala de Depressão Pós-parto de Edimburgo. Os sintomas mais evidenciados foram os sentimentos de culpa (14\%), seguidos pelo de ansiedade e angústia (13\%) (BARROS; KÜMPEL, 2007).

Em Quito foi observada prevalência de depressão de 38,9\% em adolescentes primigestas no terceiro trimestre de gestação (AGUINAGA et al., 1999a). Os autores enfatizam que a gravidez na adolescência está associada a significativos riscos médicos e psicossociais tanto para mãe como para o bebê. 
MITSUHIRO et al. (2006), em estudos que determinaram a prevalência de transtornos psiquiátricos em adolescentes grávidas de baixa renda, observou que 12,9\% das gestantes apresentaram depressão, 10\% estresse pós-traumático $35,6 \%$ ansiedade. Pelo menos $27,6 \%$ das entrevistadas apresentou ao menos um transtorno psiquiátrico. Também observou se $6 \%$ das gestantes usando cocaína e maconha no ultimo trimestre da gestação. A pesquisa revela como fatores contribuintes para a manutenção da situação socioeconômica desfavorável a situação familiar desestruturada, evasão escolar, desemprego e a baixa capacitação profissional, criando-se um cenário com elementos importantes também para o uso de drogas no terceiro trimestre da gravidez e transtornos psiquiátricos.

Situações relacionadas a práticas abortivas também acarretam em maior nível de ansiedade em adolescentes com abortos provocados e espontâneos e maior índice de depressão e de sintomas psiquiátricos naquelas que provocaram o aborto (TOLEDO, 1999).

Dados sobre a magnitude do aborto provocado no Brasil devem ser examinados à luz do contexto restritivo da lei. No Brasil, o aborto é considerado crime e as mulheres são penalizadas por sua prática. Os pesquisadores não têm como direito a oferecer sigilo ou proteção às mulheres que participarem das pesquisas, sejam elas realizadas em hospitais ou em suas residências. Foi nesse contexto paradoxal que grande parte dos estudos sobre magnitude do aborto foi conduzida no Brasil nas últimas décadas para subsidiar as políticas de saúde reprodutiva Brasil (BRASIL, 2009).

Os primeiros resultados da Pesquisa Nacional de Aborto (PNA) realizado em 2010, cuja cobertura abrangeu as mulheres com idades entre 18 e 39 anos em todo o Brasil urbano indicam que, ao final da vida reprodutiva, mais de uma em cada cinco mulheres já fez aborto, ocorrendo os abortos em geral nas idades que compõem o centro do período reprodutivo das mulheres, entre 18 e 29 anos. Não se observou diferenciação relevante na prática em função de crença religiosa, mas o aborto se mostrou mais comum entre mulheres de menor escolaridade. Tais resultados levam a concluir que o aborto deve ser prioridade na agenda de saúde pública nacional. Em 2010, no Brasil urbano, 15\% das mulheres entrevistadas relataram ter realizado aborto alguma vez na vida (DINIZ; MEDEIROS, 2010). 
Não se observou diferenciação relevante na prática em função de crença religiosa, mas o aborto se mostrou mais comum entre mulheres de menor escolaridade. Tais resultados levam a concluir que o aborto deve ser prioridade na agenda de saúde pública nacional. Em 2010, no Brasil urbano, 15\% das mulheres entrevistadas relataram ter realizado aborto alguma vez na vida. As evidências do inquérito indicam que o aborto não é feito apenas para retardar o início da vida reprodutiva ou evitar filhos em idades avançadas (DINIZ; MEDEIROS, 2010).

Fica evidenciada a existência de questões que se mostram relevantes quanto à vulnerabilidade dos adolescentes no plano individual, social ou programático. A gravidez na adolescência é uma delas. Estudos realizados em diferentes países e grupos sociais demonstram aumento da taxa de fecundidade nas adolescentes, diferente do que acontece com as taxas na população geral. No Brasil, essa realidade vinha sendo constatada pelo crescente número de adolescentes nos serviços de pré-natal e maternidade, sua maior incidência nas populações de baixa renda e a associação entre alta fecundidade e baixa escolaridade (BRASIL, 2005a).

Em 2009 e houve redução no número de adolescentes grávidas em todos os grupos de idade, inclusive entre as mulheres de 15 a 19 anos em todas as regiões do País. Entre as adolescentes a fecundidade ocorreu predominantemente em uma união, seja como causa ou como consequência desta (BRASIL, 2010)

É peremptória a visão de que trabalhar essas questões na atenção à saúde dos adolescentes e jovens é muito diferente de uma assistência clínica individual e da simples informação ou repressão. O modelo assistencial deve permitir discussões sobre as razões da adoção de um comportamento preventivo e o desenvolvimento de habilidades que permitam aos adolescentes resistência às pressões externas, a expressão de sentimentos, opiniões, dúvidas, inseguranças, medos e preconceitos, de forma a dar condições para o enfrentamento e a resolução de problemas e dificuldades do dia-a-dia (BRASIL, 2005a). 
O Ministério da Saúde reforça que os direitos sexuais e os direitos reprodutivos do(a) adolescente se constituem de certos direitos humanos fundamentais já reconhecidos nas leis nacionais e internacionais, e nascem a partir da definição de saúde reprodutiva, buscando integrar os direitos sociais, principalmente, o direito à saúde, à educação, à informação, com os direitos individuais de não interferência e de não discriminação. Seus comandos centrais são:

- decidir livremente e responsavelmente sobre a própria vida sexual e reprodutiva; - ter acesso à informação; ter acesso aos meios para o exercício dos direitos individuais livre de discriminação, coerção ou violência.

O Comitê de Direitos da Criança traçou recomendações específicas, a partir de 2003 (Recomendação Geral n. 4, de 6 de junho de 2003). A Recomendação garante os direitos dos adolescentes nos serviços de saúde, independente da anuência de seus responsáveis. Tal garantia vem se revelando como elemento indispensável para a melhoria da qualidade da prevenção, assistência e promoção de sua saúde. Também preserva a autonomia, o sigilo e a privacidade do adolescente e ao seu acesso aos serviços, independente da anuência ou presença dos pais e responsáveis, para o enfrentamento das suas questões, inclusive sexual e reprodutiva. E por fim o direito do adolescente não ser discriminado em razão de alguma deficiência física, mental, sorológica (HIV/AIDS) ou por questões de sexo, orientação sexual e estilo de vida (BRASIL, 2005a).

Nesse contexto é possível desdobrar a questão da gravidez na adolescência em outras possibilidades alem dos tradicionais. A despeito de no Brasil ser considerada um problema de saúde pública, a adolescente pode optar por engravidar, planejar uma gravidez e mesmo na ocorrência de uma gravidez não planejada ela pode se congratular quando essa possibilidade era conhecida e não descartada em suas expectativas bem como as de seu companheiro.

Uma vez que a adolescência é a fase final do crescimento físico e emocional, algumas ações podem ser desenvolvidas no atendimento aos adolescentes. COSTA (2009) cita informações sobre crescimento e desenvolvimento, detecção precoce de dificuldades físicas, psíquicas e sociais, estimular o exercício da sexualidade responsável evitando DST e gravidez não planejada, acompanhamento pré-natal se gestante. É preciso "mostrar-se solidário e não se colocar no papel de crítico ou juiz". 
Certamente o rastreamento da depressão entre puérperas adolescentes é de grande importância e pode ser realizado tanto na instituição de saúde quanto nas visitas domiciliares ou em qualquer outro espaço onde se manifeste a necessidade de maneira que a adolescente possa ser assistida adequadamente (De ROSA; LOGSDON, 2006).

As dificuldades diagnósticas são evidentes relacionadas aos mais variados profissionais de saúde que assistem estas adolescentes. Muitos comportamentos se confundem com sintomas depressivos (DUTRA, 2001). O diagnóstico também pode ser dificultado pela presença de comorbidades psiquiátricas (SCIVOLETO; TARELHO, 2002).

Daí a importância e a necessidade de identificar de maneira acurada cada caso de maneira a evitar alterações afetivas pós-parto mediante um tratamento que responda a um diagnóstico acertado (LUGO; MONGRADON, 2006).

\section{OBJETIVOS}

1. Determinar a prevalência do transtorno depressivo em puérperas adolescentes que são atendidas na Estratégia de Saúde da Família do Município de Embu Guaçu.

2. Caracterizar puérperas adolescentes cadastradas na Estratégia de Saúde da Família do Município de Embu Guaçu e que apresentem grande probabilidade de desenvolverem transtorno depressivo através da aplicação da EPDS, com pontuação igual ou maior que 12 segundo a EPDS. 


\section{FINALIDADES}

A depressão na adolescência vem sendo considerada um grave problema de saúde pública, evidenciado pela crescente prevalência tanto no Brasil como ao redor do mundo. Envolve alto grau de morbimortalidade especialmente quando levado em consideração que ideação suicida é muito relacionada ao transtorno.

Tanto a depressão pré-natal como a pós-natal vêm sendo frequentemente ignoradas durante as consultas de rotina, uma vez que muitos comportamentos característicos da adolescência se confundem com sintomas depressivos.

A detecção precoce da depressão nestas puérperas possibilitaria uma intervenção adequada minimizando seus efeitos deletérios tanto para a jovem mãe quanto para o recém-nascido.

O impacto da intervenção de enfermagem sobre a qualidade de vida da adolescente neste período do ciclo da vida pode ser determinante no sentido de prevenir o agravamento de sintomas depressivos. Estas intervenções podem desencadear mudanças tanto na vida pás usuárias como nas atitudes dos enfermeiros frente as suas responsabilidades relacionadas ao portador de transtorno mental assistido na rede básica de atenção á saúde. 


\section{MÉTODO}

\subsection{DESCRIÇÃO DO LOCAL DE PESQUISA}

A pesquisa em tela teve lugar no município de Embu Guaçu. Município paulista, situado na região sudoeste, a 45 quilômetros do marco zero de São Paulo. Com cerca de 63.000 habitantes, tem sua área totalmente sob a vigilância da lei de proteção dos mananciais, apresentando assim características urbanísticas precárias. É um município tipicamente rural com áreas de maior e menor densidade demográfica. O bairro Cipó é o mais distante de centro (10 km) e possui uma área geográfica de $25 \mathrm{~km}^{2}$ com população aproximada de 20.000 habitantes. Antes da implantação do então Programa de Saúde da Família (PSF), a rede de saúde contava com cinco Unidades Básicas de Saúde (UBS) e uma Unidade Mista de Saúde. A partir de 2003 se iniciou a implantação do projeto para a implantação do então PSF no município, a principio em duas UBS já existentes.

Dados do SIAB (Sistema de informação da Atenção Básica, 2009) apontam para um total de 1349 meninas cadastradas nas 3 Unidades da ESF existentes no município. Apenas $3,4 \%$ das adolescentes estavam no puerpério durante o período da pesquisa.

As três Unidades ESF estão localizadas na beira de estradas que margeiam o município, cada qual em posição geográfica de fronteira com municípios adjacentes. A cobertura das três Unidades contempla apenas $22 \%$ da população do município. O Município tem revelado interesse e investimentos na saúde dos adolescentes. Em 2007 foi implantado o projeto Saúde do Adolescente no Bairro do Cipó na UBS Paulo Maneta, atendendo adolescentes entre 12 e 19 anos através de grupos, oficinas e atendimento individual enfocando a família. (PREFEITURA MUNICIPAL DE EMBU GUAÇU, 2009). 


\subsection{SUJEITOS DO ESTUDO}

O estudo em tela teve caráter observacional descritivo transversal. A população estudada abrigou todas as adolescentes cadastradas nas três unidades da ESF do município. Foram estabelecidos critérios de inclusão na amostra: tempo de pós-parto até um ano; nascimento do recém-nascido entre 34 e 42 semanas de gestação; idade materna entre 12 e 20 anos; desejo de participar da pesquisa e consentimento do responsável em caso de menor de 18 anos.

Os critérios de exclusão foram: o desejo explícito da puérpera em não participar da pesquisa; a recusa do responsável em aceitar a participação da puérpera menor de idade; idade maior que 20 anos ou menor que 12 anos; puérpera com transtorno mental atual ou uso atual de psicotrópicos; depressão anterior; tratamento psiquiátrico prévio ou durante a gestação atual; natimorto ou neomorto na gestação atual; abuso de substâncias psicoativas.

A população foi de 1349 meninas entre 10 e 19 anos segundo dados do SIAB. Quarenta e seis puérperas adolescentes compuseram a amostra. Foi prevista a possibilidade de desistência por parte de quaisquer participantes e em qualquer momento da pesquisa, direito este que Ihes é assegurado no Termo de Consentimento Livre e Esclarecido (anexo III). No entanto não houve recusas nem desistências, tanto por parte das adolescentes quanto de seus responsáveis em menores de 18 anos.

A despeito de a OMS (2010) considerar a adolescência até os 19 anos, na literatura são encontrados várias divergências quanto à idade que compreende 0 período da adolescência. De acordo com PAPALIA et al. (2000) o início ou o fim deste período não pode ser considerado como uma estrutura rígida.

Uma vez que no Brasil a definição de adolescência não abrange apenas os indivíduos com menos de dezoito anos, mas também os que estão entre os dezoito anos completos e os vinte anos incompletos (LEONE; GALLO, 2010), a pesquisadora optou por incluir sujeitos de estudo com até 20 anos de idade. 


\subsection{PROCEDIMENTOS PARA A COLETA DE DADOS}

A coleta se dados foi realizada pela própria pesquisadora e teve lugar majoritariamente nos domicílios das puérperas. As Unidades de Saúde demonstraram total apoio à pesquisa, disponibilizando agentes comunitários de saúde e/ou enfermeiros para acompanharem a pesquisadoras, facilitando assim a adesão das puérperas. Em regiões mais remotas, a própria Secretaria de Saúde disponibilizou o veículo oficial com o motorista de maneira a facilitar a localização dos domicílios na zona rural.

Momentos não previstos ocorreram onde a puérpera se encontrava na Unidade de Saúde no mesmo momento que a pesquisadora, de modo que a coleta de dados foi realizada no local.

Aos participantes e aos responsáveis foram explanados os objetivos e procedimentos da investigação, bem como o a importância do seu papel em todo o processo. A colaboração foi solicitada em regime voluntário e garantida a confidencialidade de todas as informações prestadas. Após o aceite e assinatura do Termo de Consentimento Livre e Esclarecido (Anexo III), iniciaram-se os momentos da coleta de dados propriamente ditos.

Apesar de a coleta de dados prever local privativo no domicilio das puérperas, na prática, ocorreram circunstâncias inusitadas. Muitas mães, avós, companheiros, irmãs e amigas queriam conhecer o questionário e esclarecer dúvidas quanto aos cuidados com o bebê. Algumas puérperas anuíram com a presença de outras pessoas. Por conta do clima e configurações das residências, a coleta de dados ocorreu em quintais, cozinhas, caminhando na estrada para o bebê dormir, na beira do lago, entre outros.

Os instrumentos para a coleta de dados foram a EPDS (Anexo I) e o Questionário socioeconômico e obstétrico elaborado pela pesquisadora (Anexo II), com informações socioeconômicas, comportamentais e obstétricas e neonatais relacionadas à puérpera. 
Para a EPDS (anexo I), utilizou-se o ponto de corte 12. Por ter melhores índices de predição, a pontuação 11/12 torna-se mais útil em se tratando de encaminhamento para avaliação por profissional de saúde mental. O estudo indica que 0 instrumento discrimina casos de depressão no pós-parto e que o corte em 11/12 é mais adequação ao contexto do Brasil. A pesquisadora optou pelo ponto de corte em 12 em consonância a realidade brasileira, já que o encaminhamento de falsos positivos poderia constituir uma sobrecarga em um sistema de saúde com reduzido número de profissionais especializados em saúde mental, comprometendo em longo prazo a utilização do instrumento (SANTOS; MARTINS; PASQUALI, 1999).

Algumas adolescentes se sentiram mais a vontade com a própria pesquisadora preenchendo a escala e tal procedimento foi adotado sem restrições. A partir do rastreamento obtido através da EPDS, foi calculada a prevalência do transtorno depressivo após o parto nesta população.

As puérperas participantes forma respeitadas em suas necessidades individuais de horários e locais respeitadas, com opções que foram mais convenientes para as mesmas. Não foram observadas possibilidades de risco para os participantes.

\subsection{ASPECTOS ÉTICOS E LEGAIS}

Os sujeitos receberam o documento "Consentimento Livre e Esclarecido" (anexo III) que foi assinado também pelo responsável caso a participante fosse menor de 18 anos de idade. Foi realizado todo o esclarecimento necessário, tornando voluntária a participação como sujeitos do estudo. Tratando-se de relatos relativos a mudanças ocorridas após o nascimento do bebê, bem como questões sócio demográficas, não foram observadas possibilidades de risco para os participantes. $O$ anonimato e possibilidade de identificação dos envolvidos foram resguardados, sendo as entrevistas numeradas no momento dos relatórios. 
Acredita-se que a pesquisa possa beneficiar os sujeitos envolvidos na medida em que muitas dúvidas foram esclarecidas no momento da coleta de dados e novas possibilidades de ajuda para o período do puerpério foram desvendadas. Foi assegurado às Unidades de ESF que as abrigam o envio dos resultados tão logo quanto a pesquisa seja encerrada de modo a colaborar com um planejamento para futuras intervenções em relação às adolescentes.

\subsection{ANÁLISE DOS DADOS}

Contemplando os objetivos propostos, a análise dos dados foi processada entre as puérperas que obtiveram pontuação maior ou igual a 12 na EPDS. Os aspectos relacionados à maternidade destas puérperas (Tabela 5) foram comparados com os resultados das puérperas que pontuaram menos que 12 .

As variáveis quantitativas (anexo 4) foram descritas por meio de medidas de tendências centrais, de variabilidades e intervalo de confiança. As qualitativas foram apresentadas por frequências e proporções. Os dados foram exibidos em forma de tabelas e discutidas em sequencia.

As variáveis relativas às idades estão apresentadas como variáveis contínuas e proporções. Utilizados na análise o Teste de Shapiro-Wilk, Quiquadrado de Pearson e Teste exato de Fisher. 


\section{RESULTADOS E DISCUSSÃO}

Tabela 1. Distribuição em frequências e porcentagens da EPDS das adolescentes puérperas atendidas na Estratégia de Saúde da Família do Município de Embu Guaçu com pontuação maior ou igual a 12. 2008/2009.

\begin{tabular}{|c|c|c|c|c|c|c|c|c|c|c|c|c|c|}
\hline \multirow{3}{*}{ Questões } & \multicolumn{13}{|c|}{ Escores } \\
\hline & \multicolumn{2}{|l|}{ 0 } & \multicolumn{2}{|l|}{1} & \multicolumn{2}{|l|}{2} & \multicolumn{7}{|l|}{3} \\
\hline & $\mathrm{N}$ & $\%$ & $\mathrm{n}$ & $\%$ & $\mathrm{n}$ & $\%$ & $\mathrm{n}$ & $\%$ & Média & $\overline{D P}$ & Mediana & $\begin{array}{l}1^{\circ} \\
\text { quartil }\end{array}$ & $\begin{array}{l}3^{\circ} \\
\text { quartil }\end{array}$ \\
\hline 1- rir & 23 & 50,00 & 8 & 17,39 & 9 & 19,57 & 6 & 13,04 & 0,96 & 1,1 & 0,5 & 0 & 2 \\
\hline $\begin{array}{l}\text { 2-prazer no } \\
\text { dia a dia }\end{array}$ & 22 & 47,83 & 13 & 28,26 & 9 & 19,57 & 2 & 4,35 & 0,80 & 0,91 & 1 & 0 & 1 \\
\hline 3 - culpa & 10 & 21,74 & 5 & 10,87 & 16 & 34,78 & 15 & 32,61 & 1,8 & 1,1 & 2 & 1 & 3 \\
\hline 4- ansiedade & 13 & 28,26 & 3 & 6,52 & 12 & 26,09 & 18 & 39,13 & 1,8 & 1,3 & 2 & 0 & 3 \\
\hline 5- assustada & 25 & 54,35 & 1 & 2,17 & 11 & 23,91 & 9 & 19,57 & 1,1 & 1,3 & 0 & 0 & 2 \\
\hline 6- tarefas & 20 & 43,48 & 3 & 6,52 & 10 & 21,74 & 13 & 28,26 & 1,3 & 1,3 & 1,5 & 0 & 3 \\
\hline 7-sono & 28 & 60,87 & 3 & 6,52 & 8 & 17,39 & 7 & 15,22 & 0,87 & 1,2 & 0 & 0 & 2 \\
\hline 8-tristeza & 21 & 45,65 & 10 & 21,74 & 6 & 13,04 & 9 & 19,57 & 1,1 & 1,2 & 1 & 0 & 2 \\
\hline 9-choro & 21 & 45,65 & 12 & 26,09 & 4 & 8,70 & 9 & 19,57 & 1,0 & 1,2 & 1 & 0 & 2 \\
\hline $\begin{array}{l}10- \\
\text { autoagressão }\end{array}$ & 34 & 73,91 & 3 & 6,52 & 5 & 10,87 & 4 & 8,70 & 0,54 & 1,0 & 0 & 0 & 1 \\
\hline
\end{tabular}

Houve um equilíbrio nas respostas dos 46 adolescentes nas questões: 3 , 4, 6, 8 e 9. Os itens "culpa", "ansiedade", "sobrecarga de tarefas", "tristeza" e "choro" parecem ter uma distribuição simétrica (valor da média de cada questão é parecido ao da mediana), embora com uma leve assimetria, à esquerda para as três primeiras (Tabela 1).

Sentimentos de culpa (32,61\%), ansiedade (39,13\%) e sobrecaga de trabalho $(28,26 \%)$ foram assinalados na EPDS como pontuação "3" por grande número de puérperas. Se forem adicionados os valores assinalados na pontuação em "2", todos os resultados ultrapassam os $50 \%$. Evidencia-se assim um sofrimento psíquico bastante presente no cotidiano de grande número das adolescentes puérperas. Tristeza e choro foram outras reações relatadas por mais de $40 \%$ das puérperas adolescentes. Uma das puérperas que pontuou 21 na EPDS relatou também que a ideia de fazer mal a si mesma já havia passado pela sua cabeça depois da gravidez. 
Desenvolvida na Grã-Bretanha e validada no Brasil, trata-se de uma escala de auto registro composta por dez questões fechadas e graduadas que podem pontuar de zero a três, de acordo com a presença ou intensidade do sintoma depressivo (SANTOS, 1999).

Dentre as tentativas de se desenvolverem instrumentos de triagem para facilitação da identificação e tratamento dos quadros de DP, um dos instrumentos mais utilizados é a EPDS. Foi traduzida, adaptada e validada em diversos países, incluindo o Brasil. A Escala mede a presença e intensidade de sintomas depressivos através de respostas do ocorrido nos últimos sete dias. Existem diferenças relacionadas ao ponto de corte mais indicado para identificação da DP em estudos realizados no Brasil. Tais diferenças podem ser explicadas por variações metodológicas e inter-regionais, sugerindo a necessidade de estudos em outras regiões.

No geral, os estudos que validaram a EPDS mostram uma alta sensibilidade e especificidade, assim como um alto valor preditivo. $O$ estudo conduzido em Brasília (DF) incluiu 69 mulheres que apresentavam um tempo médio de puerpério de 10,2 semanas. De acordo com os autores, o melhor ponto de corte para a escala foi 11 , com $84 \%$ de sensibilidade, e $82 \%$ de especificidade (SANTOS; MARTINS; PASQUALI, 1999).

A despeito de a EPDS ter sido originalmente como um instrumento rastreador, seu autor e outros pesquisadores propõe que, ao usá-la com ponto de corte $\geq 13$ a escala tem valor preditivo para diagnóstico da depressão pós-parto (SANTOS et al. 2007). Os achados revelados na coleta de dados apontam para a urgência de intervenções pelos serviços de saúde bem como para a identificação precoce destas manifestações.

O estudo de SANTOS et al. (2007), feito em Pelotas, incluiu 378 mulheres no terceiro mês após o parto, sugerindo 10 como o melhor ponto de corte para a triagem da DP, com $82,6 \%$ de sensibilidade e $65,4 \%$ de especificidade. Além de mostrar boa capacidade de discriminar gestantes com o diagnóstico de DP, o instrumento apresentou boa consistência interna.

No estudo de FIGUEIRA et al.(2009), a sensibilidade da EPDS foi semelhante às encontradas anteriormente e a especificidade para os diferentes pontos de corte foi mais elevada. O melhor ponto de corte foi dez, como no estudo de Pelotas (RS), com $86,4 \%$ de sensibilidade e $91,1 \%$ de especificidade. 
Pesquisa de COUTINHO e SARAIVA (2008b) que compara resultados da EPDS em puérperas com sintomatologia e sem sintomatologia depressiva observou que, para o item 2 da Escala, relacionado à de perda de prazer, 59\% das mães com sintomatologia obtiveram pontuações válidas, comparado aos $12,3 \%$ das mães sem sintomatologia. Quanto às respostas ao item 3, que aborda o sentimento de culpa, 29,2\% das mães deprimidas fizeram pontuações válidas enquanto as mães do outro grupo apenas 10,7\%. Para as respostas ao item 7, acerca de distúrbios no sono, foram registradas as pontuações válidas em $42,3 \%$ das mães deprimidas contrastando com os 3,1\% das mães sem sintomatologia depressiva. Entre as mães com sintomatologia, foi observado que 46,2\% destas fizeram pontuações válidas quanto aos sintomas de humor deprimido, sendo que o índice das mães sem sintomatologia ficou em 3,1\%. No item 9, que trata de humor deprimido, combinado com a manifestação de choro, 47,7\% das mães deprimidas obtiveram pontuação positiva, enquanto, no caso das mães sem sintomatologia, esse percentual ficou em 18,5\%.

Em relação ao item 10, que trata de ideias de morte e de suicídio, nenhuma mãe do grupo sem sintomatologia da depressão pós-parto apresentou pontuação positiva nesse item. Enquanto isso há o registro de $37,5 \%$ de mães com sintomatologia da depressão puerperal que fizeram entre 1 e 3 pontos para esse item (COUTINHO; SARAIVA, 2008b).

É necessário destacar que o transtorno depressivo se apresenta de forma heterogênea já desde a infância, requerendo cuidadosa avaliação diagnóstica dos profissionais envolvidos com crianças e adolescentes. A existência de patologias psiquiátricas comórbidas traz dificuldades diagnósticas gerando múltiplas hipóteses no estudo das depressões infanto-juvenis. Especialmente nestes períodos é necessário considerar a importância da utilização de várias fontes de informações (pais, professores e amigos) ao se estabelecer uma investigação clínica (BAHLS, 2002a). 
Gestantes assistidas pelo sistema público de saúde no Brasil tem alta prevalência de depressão. As evidências de danos e consequências negativas de uma depressão anterior ao nascimento encontradas na literatura sugerem a aplicação de breves instrumentos de rastreamento para sintomas severos. É apontado que o uso de escalas como a EPDS, o Inventário de Depressão de Beck e a Escala de Hamilton durante a assistência pré-natal seria extremamente benéfico.

Tabela 2. Prevalência do transtorno depressivo em adolescentes puérperas atendidas na Estratégia de Saúde da Família do Município de Embu Guaçu com pontuação maior ou igual a 12 segundo a EPDS. 2008/2009.

\begin{tabular}{lll}
\hline Total de amostra & Transtorno depressivo & \\
$\mathrm{N}$ & Prevalência & Intervalo de confiança \\
\hline 46 & 0,39 & $(0,25 ; 0,54)$ \\
\hline
\end{tabular}

A prevalência do transtorno depressivo em adolescentes puérperas que são atendidas na Estratégia de Saúde da Família do Município de Embu Guaçu foi de 39\% com IC95\% (25; 54). Este intervalo de confiança indica que a prevalência varia neste intervalo, com nível de confiança de 95\% (Tabela 2). Das puérperas que apresentaram pontuação maior ou igual a 12 de acordo com a EPDS, 94,44\% estavam entre 14 e 19 anos e apenas uma adolescente tinha 20 anos de idade $(5,56 \%)$.

$\mathrm{Na}$ busca de produção científica acerca da depressão puerperal em adolescentes, percebeu-se que a produção brasileira tem aumentado em relação aos últimos anos. A maioria dos artigos publicados versa em torno da descrição do problema, porém em pouco revela acerca de inovações quanto à prevenção e recomendações de intervenções. 
Em revisão bibliográfica realizada por BENETTI et al. (2007), ficou evidente que as questões relacionadas aos aspectos de intervenção, incluindo estratégias psicoterápicas individuais ou grupais, serviços institucionais ou outro tipo de atendimento permearam apenas $23 \%$ dos trabalhos. As áreas da Medicina e Psicologia foram as que mais publicaram trabalhos sobre intervenções em saúde mental. Os trabalhos sobre prevenção tiveram menor frequência (6\%) e foram publicados predominantemente pela área de Saúde Coletiva (50\%) e se restringindo apenas aos quadros de violência e delinquência.

BENETTI et al. (2007) ressaltam que de 1995 até 1998 a publicação científica acerca da depressão aumentou em torno de $3 \%$ em relação a anos anteriores. A partir daí, cresceu $10 \%$ ao ano, indicando interesse científico sobre a temática. A depressão na adolescência foi discutida como quadro clínico em 11 artigos e nos demais em comorbidade com outros quadros, como suicídio, ansiedade, quadros neurológicos, transtorno bipolar, gestação, maus-tratos infantis e delinquência e estratégias terapêuticas.

Embora esteja havendo crescimento quanto à produção cientifica acerca da maternidade, um fator comum a todos os países que têm investigado os resultados da saúde após o parto, seja em um país desenvolvido ou em desenvolvimento, é a aparente invisibilidade do período pós-natal e a falta de um reconhecimento sistemático que o cuidado após o parto é uma continuidade essencial do cuidado na gravidez e parto (BICK; BASTOS; DINIZ, 2008).

Torna-se imperativo concordar com BENETTI et al. (2007) quanto ao fato de o levantamento da produção nacional de artigos indexados em periódicos nacionais sobre saúde mental na adolescência ter apontado para um crescimento constante da produção nacional nos últimos anos. Tal incremento nas publicações acadêmicas revela um maior reconhecimento da comunidade científica acerca da necessidade e a importância de investimentos de pesquisas nesta área.

Pesquisa de revisão conclui através das publicações das diversas áreas que a demanda em saúde mental na adolescência é uma questão importante. Essa faixa etária além de se constituir como uma grande parcela da população que procura atendimento é identificada como um grupo etário vulnerável e de risco em todas as categorias - depressão, transtornos de conduta, transtornos alimentares, drogas e violência. Portanto, a grande demanda por atendimento e a diversidade das situações clínicas afetando os jovens são pontos fundamentais para o desenvolvimento de ações em saúde mental. 
A prevalência da DP no estudo de FIGUEIRA et al. (2009) foi de $26,9 \%$ e esteve dentro da margem frequentemente encontrada na literatura que, segundo VESGA-LÓPEZ et al. (2008), tem variado entre 15\% e 29\%. Quando comparada a outros estudos brasileiros, a prevalência de DP encontrada por FIGUEIRA et al. (2009) foi maior. MORAES et al. (2006) encontraram 9,1\% em Pelotas, RS; Da SILVA et al. (1995) obtiveram 12\% no Recife e SANTOS et al. (1999) registraram 13,2\% em Brasília, DF.

O estudo de RUSCHI et al. (2007) foi o que mais se aproximou dos resultados obtidos pela pesquisadora em Embu Guaçu (39\%), com 39,4\% em Vitória, ES. Observa-se que estudos mais recentes revelam maiores prevalências, provavelmente devido ao crescimento tanto no conhecimento bem como no investimento do Sistema Único de Saúde na saúde mental de seus usuários e mais especificamente na prevenção e detecção precoce da DP. As diferenças entre os estudos também podem demonstrar diferenças quanto a características sócio demográficas, regionais, e no caso da pesquisa em tela, o fato de as puérperas serem adolescentes e oriundas da zona rural.

Em estudo de revisão de literatura, HALBREICH e KARKUN (2006) levantaram 43 pesquisas onde conheceram a prevalência da DP em 40 países. Assim como nos estudos brasileiros, os autores encontraram um intervalo bastante significativo, com uma variação de quase 0\% a 60\%. Em alguns países como Cingapura, Malta, Malásia, Áustria e Dinamarca há pouquíssimos relatos acerca da DP ou de sintomas depressivos no puerpério. Em outros países como Brasil, Guiana, Costa Rica, Itália, Chile, África do Sul, Taiwan e Coréia os sintomas depressivos relatados são muito prevalentes.

FIGUEIRA et al. (2009) acreditam que estudos futuros utilizando procedimentos uniformes de avaliação em diferentes regiões brasileiras poderão contribuir para esclarecer prevalências divergentes. Sugerem que a EPDS é um instrumento adequado de triagem da depressão pós-parto, podendo ser implementada na rede pública de saúde devido a sua facilidade, rapidez de aplicação, baixo custo e possibilidade de aplicação por qualquer profissional de saúde. Com muita propriedade os autores recomendam o amplo uso da escala com o intuito de incrementar os índices de diagnóstico e tratamento da doença, minimizando assim seus possíveis efeitos deletérios sobre mãe e filho. 
Alem das respostas objetivas da EPDS, a pesquisadora também fez uso de uma abordagem qualitativa no que tange ao autocuidado das adolescentes após o parto. Quando computados os relatos de $100 \%$ das adolescentes entrevistadas, foram relacionados depoimentos, desabafos, confissões, sempre com poucas, mas significativas expressões verbais.

Foram relatos literais: "não passeio nem tenho tempo pra me cuidar"; "auto cuidado diminuído, durmo mal"; "lazer diminuído, pois sinto fraqueza"; "alimentação, sono, lazer e auto cuidado, tudo diminuído"; "às vezes não durmo, não dá tempo para se cuidar"; "sem tempo para se cuidar, sem fome, durmo quando dá"; "o lazer tá diminuído, acordo junto com o nenê, falta vontade de se arrumar, sem fome"; "sem tempo pra se cuidar, pra comer, sinto sono durante o dia, ainda não saí para passear"; "não tenho tempo de me arrumar"; "diminuiu o apetite e o lazer"; "não durmo de preocupação, sinto menos fome, mas visito a sogra e vou à quermesse"; "sem tempo de me cuidar".

Interessante perceber que apesar de terem sido identificadas 18 puérperas adolescentes com escores maior ou igual a 12 segundo a EPDS, apenas quatro delas $(22,2 \%)$ relataram dificuldades com o autocuidado como: "dificuldade de dormir do começo até o meio da noite"; "dificuldade de dormir pelo neném"; "a alimentação, sono, autocuidado e lazer estão deficientes"; "o autocuidado está diminuído, durmo mal, mas como bem"; falta de vontade, diminuição da fome.

Atentando para as puérperas com pontuação menor que 12, apenas quatro (14\%) relacionaram mudanças negativas quanto ao autocuidado, sono, lazer e apetite após o nascimento do bebê. Uma delas verbalizou que a ideia de fazer mal a si mesma só havia passado pela sua cabeça enquanto estava grávida, sendo que sua pontuação na EPDS foi 11 . Se for levada em consideração a gravidade de pensamentos suicidas em uma adolescente antes ou após o nascimento de seu bebê e o desfecho que tais sentimentos ou ideações podem favorecer, fica entendido que uma puérpera (5,5\%), entre as 18 que apresentaram pontuação maior ou igual a 12, assume uma dimensão que exige intervenções imediatas e acertadas. 
A identificação de $15,21 \%$ (7) de puérperas adolescentes com escores maior ou igual a 9 e menor que 12 também se revelou um dado significativo. Embora não tenham pontuado o suficiente para a grande possibilidade de transtorno depressivo no pós-parto, o escore identificado demanda ações preventivas urgentes de modo a minimizar ou extinguir a possibilidade de uma evolução para um transtorno mental instalado.

Mesmo que pontuação obtida não indique o transtorno, a puérpera deve ser informada da possibilidade da DP e de seus sintomas. É importante o envolvimento do cônjuge, família ou de outra pessoa em quem a paciente confie nesse processo. Os profissionais de saúde devem estimular a presença dessas pessoas nas consultas, de modo a fortalecer os laços familiares e de apoio social, dos quais depende o sucesso tanto da prevenção, quanto do tratamento dos transtornos mentais (FELIX; GOMES; FRANCA, 2008)

Recentemente a temática que cerca a depressão puerperal tem sido reavaliada. Seu conceito tem sido muito debatido em decorrência da comorbidade que a acompanha. São percebidos sintomas ansiosos, TEPT por vezes com prevalência mais alta que a da DP. Tais dificuldades na identificação de uma entidade mórbida geram questionamentos quanto às fronteiras nosológicas dos transtornos. 
Tabela 3. Características sociodemográficas das adolescentes puérperas atendidas na Estratégia de Saúde da Família do Município de Embu Guaçu, com pontuação maior ou igual a 12 segundo a EPDS. 2008/2009.

\begin{tabular}{|c|c|c|}
\hline Variáveis & $\mathbf{N}$ & $\%$ \\
\hline \multicolumn{3}{|l|}{ Idade da puérpera* (anos) } \\
\hline $14-19$ & 17 & 94,44 \\
\hline 20 & 1 & 5,56 \\
\hline \multicolumn{3}{|l|}{ Idade do pai do bebêe (anos)*** } \\
\hline $17-19$ & 3 & 16,67 \\
\hline $20-25$ & 11 & 61,11 \\
\hline $26-31$ & 4 & 22,22 \\
\hline \multicolumn{3}{|l|}{ Idade do filho (meses) ** } \\
\hline $1-5$ & 10 & 55,56 \\
\hline $6 e+$ & 8 & 44,44 \\
\hline \multicolumn{3}{|l|}{ Estado civil } \\
\hline Mora junto & 14 & 77,78 \\
\hline Solteira & 3 & 16,67 \\
\hline Casada & 1 & 5,56 \\
\hline \multicolumn{3}{|l|}{ Cor da pele } \\
\hline Branca & 8 & 44,44 \\
\hline Negra & 2 & 11,11 \\
\hline Amarela & 4 & 22,22 \\
\hline Parda & 4 & 22,22 \\
\hline \multicolumn{3}{|l|}{ Escolaridade } \\
\hline Médio incompleto & 8 & 44,44 \\
\hline Médio completo & 3 & 16,67 \\
\hline Fundamental incompleto & 4 & 22,22 \\
\hline Fundamental completo & 2 & 11,11 \\
\hline Superior incompleto & 1 & 5,56 \\
\hline \multicolumn{3}{|l|}{ Renda familiar (reais) } \\
\hline Até 1 salário mínimo & 6 & 33,33 \\
\hline Entre 1 e 2 salários mínimos & 3 & 16,67 \\
\hline Ignorados & 6 & 33,33 \\
\hline Entre 3 e 4 salários mínimos & 3 & 16,67 \\
\hline \multicolumn{3}{|l|}{ Mora com o pai do bebê } \\
\hline $\operatorname{Sim}$ & 15 & 83,33 \\
\hline Não & 3 & 16,67 \\
\hline \multicolumn{3}{|c|}{ Uso de algum medicamento diário } \\
\hline $\operatorname{Sim}$ & 13 & 72,22 \\
\hline Não & 5 & 27,78 \\
\hline \multicolumn{3}{|l|}{ Uso de algum tipo de droga } \\
\hline $\operatorname{Sim}$ & 3 & 16,67 \\
\hline Não & 15 & 83,33 \\
\hline
\end{tabular}

Pelo Teste de Shapiro- Wilk. * Não há evidências de que os dados sejam normalmente distribuídos $(\mathrm{p}=0,011)$; ** Não se rejeita a hipótese da normalidade (Idade do pai do bebê - $\mathrm{p}=0,302$; Idade do filho - $\mathrm{p}=0.453$ ). As variáveis relativas as idades estão apresentadas como variáveis contínuas e proporções. 
Tabela 4. Características de aspetos relacionados à moradia das adolescentes puérperas atendidas na Estratégia de Saúde da Família do Município de Embu Guaçu, com pontuação maior ou igual a 12 segundo a EPDS. 2008/2009.

\begin{tabular}{|c|c|c|}
\hline Variáveis & $\mathbf{N}$ & $\%$ \\
\hline \multicolumn{3}{|l|}{ Material usado na construção } \\
\hline Alvenaria & 17 & 94,44 \\
\hline Madeira & 1 & 5,56 \\
\hline \multicolumn{3}{|c|}{ Número de cômodos na moradia ** } \\
\hline$<5$ & 13 & 72,22 \\
\hline $5 e+$ & 5 & 27,78 \\
\hline Média & 3,5 & \\
\hline DP & 1,4 & \\
\hline IC & $(2,8 ; 4,2)$ & \\
\hline \multicolumn{3}{|l|}{ Dono da moradia } \\
\hline Alugada & 1 & 5,56 \\
\hline Cedida & 11 & 61,11 \\
\hline Própria & 6 & 33,33 \\
\hline Moradia possui água encanada & $\mathbf{N}$ & $\%$ \\
\hline Sim & 14 & 77,78 \\
\hline Não & 4 & 22,22 \\
\hline \multicolumn{3}{|l|}{ Moradia possui esgoto } \\
\hline Sim & 2 & 11,11 \\
\hline Não & 15 & 83,33 \\
\hline Ignorado & 1 & 5,56 \\
\hline \multicolumn{3}{|l|}{ Lixo é coletado diariamente } \\
\hline 1vez por semana & 9 & 50,00 \\
\hline 2 vezes por semana & 5 & 27,78 \\
\hline Variáveis & $\mathbf{N}$ & $\%$ \\
\hline Não & 4 & 22,22 \\
\hline \multicolumn{3}{|l|}{ Moradia tem fogão } \\
\hline Sim & 15 & 83,33 \\
\hline Não & 3 & 16,67 \\
\hline \multicolumn{3}{|l|}{ Moradia tem geladeira } \\
\hline Sim & 17 & 94,44 \\
\hline Não & 1 & 5,56 \\
\hline \multicolumn{3}{|l|}{ Moradia tem televisão } \\
\hline Sim & 17 & 94,44 \\
\hline Não & 1 & 5,56 \\
\hline \multicolumn{3}{|l|}{$\begin{array}{l}\text { Moradia tem máquina de lavar } \\
\text { roupa }\end{array}$} \\
\hline Sim & 3 & 16,67 \\
\hline Não & 15 & 83,33 \\
\hline \multicolumn{3}{|l|}{ Moradia tem computador } \\
\hline $\operatorname{Sim}$ & 2 & 11,11 \\
\hline Não & 16 & 88,89 \\
\hline \multicolumn{3}{|l|}{ Moradia tem telefone } \\
\hline Sim & 3 & 16,67 \\
\hline \multirow{2}{*}{\multicolumn{3}{|c|}{ Moradia tem filtro }} \\
\hline & & \\
\hline Sim & 6 & 33,33 \\
\hline Não & 12 & 66,67 \\
\hline
\end{tabular}


De um modo geral, as adolescentes com pontuação igual ou superior a 12 parecem ser mais novas do que os seus parceiros, têm filhos com cerca de 5 meses, moram juntos com parceiros, são brancas, com ensino médio incompleto. Pouco mais da metade delas tem renda de até dois salários mínimos, a maioria usa anticoncepcionais e não utiliza drogas ou substâncias ilícitas. (Tabela 3).

As adolescentes que apresentaram pontuação maior ou igual a 12 segundo a EPDS estavam predominantemente na faixa etária dos 14 aos 19, com mediana em 18 anos. Apenas uma das puérperas já havia completado 20 anos e expressou desejo importante em participar da pesquisa. Os companheiros das adolescentes se revelaram significativamente mais velhos. A faixa etária que predominou foi a dos 20 aos 31 anos, perfazendo $83,33 \%$ dos companheiros investigados, com idade média de 22,5 anos.

Contrário aos dados encontrados pela pesquisadora quanto à idade paterna, estudo de SABROZA et al. (2004) revelou que quase a metade dos pais dos bebês das puérperas mais jovens também eram adolescentes, enquanto entre mais velhas o percentual foi de $19,9 \%$. Poucas adolescentes relataram usar algum tipo de método contraceptivo, e entre as mais jovens a ausência dessa prática era ainda mais acentuada $(81,8 \%)$ quando comparadas às de mais idade $(74,4 \%)$.

Os resultados desta pesquisa revelaram que dentre as 18 adolescentes que foram rastreadas com pontuação indicativa de transtorno depressivo apenas uma relatou ser casada. $77,78 \%$ mora junto com o companheiro sem serem casadas (união consensual) e 16,67\% permanecem solteiras.

Pesquisa de MENESES (2008) encontrou resultados diferentes, onde a união estável (ou casamento) foi referida por $65,5 \%$ das adolescentes, incluídas entre as $93,1 \%$ que têm contato com o pai do bebê. Das puérperas referidas, $72,4 \%$ encontravam-se da primeira gravidez. A predominância quanto à cor de pele referida foi "branca", seguida por valores iguais em "amarela" e "parda", e $11,11 \%$ de "negra".

Ao ser analisada a escolaridade da amostra se constatou que $61,11 \%$ das adolescentes relataram ensino médio completo ou incompleto. As demais $(33,33 \%)$ relataram ensino fundamental completo ou incompleto. Uma das adolescentes cursava Ensino Superior. 
Se contemplado todo o universo da população de puérperas independente da pontuação na EPDS, 47,8\% (22) não pararam de estudar por causa da gravidez e 50\% (23) desistiram de ir à escola alegando "preguiça", "safadeza", "a barriga incomodava", "pra cuidar da casa", "nunca gostou de estudar", "só pela gravidez", "pelo parto", "para amamentação", "pelos enjoos", "por dor", "vergonha", "porque mudou de cidade", "porque quis". Uma puérpera se absteve de responder.

As puérperas adolescentes que apresentaram pontuação maior ou igual a 12 de acordo com a EPDS tiveram distribuição semelhantes às da população total da pesquisa, com $44,4 \%$ (8) meninas que pararam de estudar durante a gravidez ou após o parto e $50 \%$ (9) que já haviam parado antes de engravidarem. Das que já se encontravam fora da escola antes da gestação, as justificativas foram quase unânimes quanto a referências de haverem parado de estudar por vontade própria. Uma delas relatou haver parado de estudar por ter entrado em licença. As declarações das meninas que abandonaram o estudo por causa da gravidez tiveram temas associados a enjoos, preguiça, à própria gravidez e a haver mudado de cidade. Uma puérpera se eximiu de responder, sendo respeitada sua vontade.

MENESES (2008) descobriu em sua coleta de dados que, com relação à raça e/ou cor, a maior prevalência de desejo de engravidar (65\%) ocorreu entre as adolescentes que se autodeclararam amarelas ou indígenas, seguidas das que se declararam pretas ou pardas $(47,6 \%)$ e brancas $(37,7 \%)$. As gestantes casadas ou em união estável desejaram muito mais a gravidez que as solteiras ou separadas, respectivamente, 54, 0\% e 31, 2\%. Adolescentes entre 12 e 16 anos que cursavam o primeiro grau apresentavam uma redução em torno de $43 \%$ na prevalência de desejo de engravidar. Aquelas que se encontravam na faixa etária dos 17 aos 20 apresentavam mais desejo de engravidar quando possuíam menor escolaridade. 
Assim emerge a questão do desejo de engravidar na adolescência relacionada à escolaridade e a união estável. Cabe à sociedade e a rede social que as abriga compreender e aceitar as expectativas que cada adolescente tem para seu futuro. Por muito tempo a maioria das mulheres tiveram como projeto de vida cuidar da casa e dos filhos, muitas por imposições culturais, mas muitas outras por se sentirem satisfeitas e realizadas no desempenho deste papel. A decisão de deixar os estudos antes, durante ou após a gravidez deve ser respeitada a despeito das evidências sobre a importância dos estudos nas oportunidades de trabalho para qualquer indivíduo.

Os achados da presente pesquisa vão ao encontro dos resultados obtidos por MENESES (2008) que constataram a maioria das puérperas adolescentes fora da escola ao engravidar. Na pesquisa da autora, 48,8\% das gestantes adolescentes relataram ensino fundamental completo ou ensino médio incompleto, sendo que $32,8 \%$ abandonaram a escola ao engravidar. SANTOS et al. (2007) também descobriram poucos anos de estudo nas adolescentes puérperas que foram sujeitos do estudo dos autores.

Um dos possíveis motivos que levariam a adolescente grávida a abandonar a escola seria o receio de ser discriminada, especialmente pelo fato de expor sua vida sexual ativa nessa faixa etária e pela baixa aceitação pela sociedade relacionada a engravidar na adolescência (SABROZA et al., 2004).

FRIZZO; KAHL e OLIVEIRA (2005) constataram que nenhuma menina que havia participado do estudo tinha primeiro grau completo, todas já haviam repetido um ano ou mais na escola, já revelavam defasagem no processo educacional. Quatro delas já haviam parado de estudar quando engravidaram, duas relataram que não pretendiam parar de estudar e três disseram que pararam ou vão parar por causa do bebê. Isto significa que apenas um terço das gestantes admite que irá parar de estudar em função da gravidez.

A despeito da existência da Lei n.ㅇ 6.202/1979 que garante direitos à gestante estudante, muitas delas já haviam interrompido seus estudos mesmo antes de engravidarem e algumas interromperam os estudos durante a gestação. Elas poderiam ter exercido seu direito a receber o conteúdo das matérias escolares em casa a partir do oitavo mês de gestação e durante os três meses após o parto. Provavelmente as adolescentes não tiveram conhecimento dessa possibilidade e quiçá a própria unidade de saúde não atentou para este benefício. (BRASIL, 1990). 
Uma vez que grande parte das adolescentes da pesquisa em tela já havia abandonado o estudo antes de engravidar, a existência ou não da lei que as favorece no período gestacional não traz consequências à maioria delas. $O$ fato de a faixa etária ser bastante diferente entre os casais, sendo a maioria das puérperas vários anos mais nova que seus parceiros talvez as leve as uma crença equivocada acerca da segurança que os parceiros poderiam Ihes oferecer, não sentindo assim a necessidade de continuar os estudos.

As mulheres menos instruídas, de um modo geral vivem na periferia e áreas rurais. Poucas vezes procuram um ginecologista ou um obstetra para consulta de planejamento familiar. A distância, a fraca informação e mesmo os hábitos culturais tradicionais, podem estar na base de muitas gravidezes não planejadas. Nesse meio, algumas mulheres recorrem ao método tradicional e fisiológico de planejamento, amamentando por um período mais longo (CARIFETE, 2009).

Nesta pesquisa, três puérperas mencionaram usar maconha e cigarro. $\mathrm{O}$ uso diário de medicamento se mostrou parte da rotina das "meninas-mães" com escore maior ou igual a 12 na EPDS. O uso de anticoncepcionais foi referido por $72,22 \%$ (13) delas. Algumas (27,78\%) relataram não usar nenhum tipo de medicamento.

Diferente da presente pesquisa, SABROZA et al. (2004) detectou que poucas adolescentes relataram usar algum tipo de método contraceptivo, e entre as mais jovens a ausência dessa prática era ainda mais acentuada, $81,8 \%$, quando comparadas às de mais idade, $74,4 \%$.

A renda familiar mensal referida ficou em torno de um e um e meio salário mínimo em aproximadamente $50 \%$ das respostas. $16,67 \%$ das entrevistadas relataram ganhos familiares em torno de quatro salários mínimos. O restante das adolescentes não soube estimar quanto o companheiro recebia mensalmente.

MENESES (2008) observou em sua pesquisa que a faixa de renda familiar de maior prevalência foi de 1 a 3 salários mínimos $(46,1 \%)$, renda esta maior que os achados da pesquisa em tela realizada em Embu Guaçu. Os ganhos acima de 5 salários mínimos mensais foram relatados por apenas $6,9 \%$ das puérperas na pesquisa de MENESES (2008) contrastando com os $16,67 \%$ da pesquisa em tela. 
Adolescentes mais jovens, na maioria das vezes, não exercem atividade remunerada e passam a ser mais dependentes financeiramente, seja da família, seja do companheiro. Paralelamente, a tendência para estabelecer uniões com homens ainda adolescentes também concorre para 0 desemprego do companheiro (SABROZA et al., 2004). Pesquisa com mulheres atendidas por duas unidades da Estratégia de Saúde da Família da cidade de São Paulo revelou nível socioeconômico muito baixo, renda familiar média de 2,3 salários mínimos (CRUZ; SIMÕES; FAISAL-CURY, 2005).

Cuidar de um bebê em si já é uma no mínimo desgastante, sem muitos retornos emocionais em curto prazo, quanto mais quando a mãe é muito jovem. Apesar das condições financeiras muitas vezes se apresentarem desfavoráveis para a nova família, na grande maioria dos casos a mãe assume seu papel apenas no lar nos primeiros meses de vida da criança. Muitas ainda, especialmente na zona rural onde foi desenvolvida esta pesquisa, relatam como projeto de vida cuidar da casa e dos filhos.

Tais situações talvez justifiquem a afirmação de MENESES (2008) quando descobre que a despeito da condição financeira predominante ser preocupante, $86,6 \%$ das adolescentes puérperas pesquisadas referiu não trabalhar.

SABROZA et al. (2004) também se preocuparam com os relatos de ausência de trabalho remunerado tanto pelos companheiros como pelas puérperas adolescentes. $O$ estudo foi realizado entre gestantes adolescentes, sendo $26 \%$ com idade entre 12 e 16 anos e $74,0 \%$ entre 17 e 19 . A média de idade das puérperas adolescentes foi de 17,3 anos, semelhante aos achados da pesquisa em tela (18 anos). Foi percebida uma situação mais desfavorável entre as mães mais jovens, o predomínio de puérperas de cor parda ou negra na amostra e a dificuldade de empregos remunerados para o casal. Entre as mais jovens, foi maior a proporção de adolescentes cuja primeira gravidez ocorreu antes dos 15 anos. Os resultados encontrados demonstram que menos da metade delas considera o estudo como uma possibilidade de ascensão social, e no grupo de 17 a 19 anos esse achado é mais evidente, correspondendo a $38,3 \%$. Por outro lado, a maioria demonstrou interesse em vir a trabalhar no futuro, sobretudo as mais velhas. 
É possível que a falta de recursos econômicos leve muitas mulheres jovens a arranjar um companheiro muito cedo na vida, procurando algum suporte. Quando falham no relacionamento, voltam a viver com os progenitores ou outros familiares (CARIFETE, 2009). Adolescentes e seus companheiros, muitas vezes ambos desempregados após o nascimento do bebê, se percebem numa situação socioeconômica mais precária, o que pode deixar as novas mães mais expostas a outras situações de risco social (SABROZA et al., 2004).

Quanto à moradia, os resultados desta pesquisa revelam que grande parte das adolescentes pesquisadas mora em casas de alvenaria, com menos do que 5 cômodos, com água encanada, fogão a gás, geladeira, máquina de lavar roupa, telefone e TV (Tabela 4). Outros eletroeletrônicos foram mencionados espontaneamente, como micro-ondas, tanquinho, DVD, rádio, celular, vídeo, som, ferro de passar roupa, forninho, chuveiro e videogame. Contudo, as residências não possuem esgoto, computador e telefone.

Gerou preocupação o relato das puérperas acerca da água que oferecem a seus bebês. Foi referido por uma delas o uso de água da torneira, por 3 delas a água fervida e por uma água da garrafa, uma vez que $66,67 \%$ não possui filtro. Em 22,22\% das moradias não existe a coleta de lixo, sendo mencionados como destino do mesmo "queimá-lo" e "jogar no terreno". Associado a problemas sanitários surge a marcante ausência de rede água em 22,22\% das moradias e quanto à rede de esgoto $83,33 \%$ das residências não tem acesso.

A associação entre variáveis sociodemográficas e a ocorrência de transtornos mentais no pós-parto tem sido alvo de diversas pesquisas. Os achados trazem correlações percebidas, mas ainda acreditam que não possam ser universalizadas (ZINN-SOUZA et al., 2008).

Interessante conhecer a lógica de CARIFETE (2009) quanto à influência dos fatores socioeconômicos e estudo sobre o desfecho de vida das adolescentes. $\mathrm{O}$ autor acredita que uma mulher instruída tem conhecimentos que a ajudam compreender e a planejar quando é que deverá engravidar. Além disso, uma mulher instruída terá mais facilidade em encontrar um emprego e mesmo um companheiro que lhe poderá proporcionar um bom suporte social. 
SECCO et al. (2007) estudaram fatores associados à maior vulnerabilidade das gestantes adolescentes à depressão e concluíram que a situação socioeconômica estava intensamente associada aos sintomas depressivos no pós-parto. Existem estudos, tanto na literatura mundial como na brasileira, que relacionam a renda familiar baixa a uma maior prevalência de gravidez na adolescência.

CHALEM et al. (2007) ponderam que, no Brasil, as trajetórias das jovens de diferentes classes sociais têm características bastante divergentes. Nos estratos sociais mais elevados ocorre permanência na casa da família por um período mais prolongado, o que permite maior escolarização. Já nas classes mais pobres, a juventude tende a ser mais breve, com a interrupção precoce dos estudos e inclusão prematura no mercado de trabalho. Alem da possível perpetuação na situação de pobreza, a jovem gestante que pertença a classes sociais menos favorecidas estará mais propensa a desenvolver transtornos mentais, que em nada a auxiliarão na melhora de suas condições de vida e bemestar.

As características sociodemográficas dos sujeitos do presente estudo com grande probabilidade de desenvolverem DP nesta pesquisa demonstram semelhanças com a publicação de SANTOS et al. (2007). Foi predominante a renda mensal pequena, a raça branca, o morar com o pai do bebê e os poucos anos de estudo.

Para BAHLS (2002a), a melhor fonte de informação quanto ao seu sofrimento depressivo é o próprio adolescente. Seus colegas e amigos são os que mais facilmente percebem as modificações ocasionadas pela patologia. Vários autores destacaram que os pais e professores muitas vezes não estão cientes da depressão em seus filhos e alunos adolescentes. O primeiro episódio depressivo costuma durar entre cinco a nove meses. Acredita-se que crianças e adolescentes com depressão tenham risco de recorrência elevado, persistindo até a idade adulta. Em média, a depressão maior na adolescência se manifesta entre os 13 aos 19 anos.

Durante a coleta de dados em pesquisa de BARROS (2006), foi percebida no discurso dos adolescentes, comumente seguido de choros, uma aparente perda do sentido da vida como sinal de uma profunda tristeza. Para os sujeitos do estudo a depressão é o mesmo que uma tristeza causada por dores existenciais profundas. 
A presença de uma doença na vida de uma pessoa traz alterações significativas não apenas em sua psique, mas também no seu organismo, no seu modo de vida e nas relações sociais estabelecidas. A sintomatologia da depressão pode implicar severas dificuldades, uma vez que a imprecisão diagnóstica pode resultar em fortes sequelas, privações sociais e, inclusive, em morte (BARROS, 2006).

PEREIRA e LOVISI (2008) advertem que em países de baixa renda como o Brasil, o alto índice de gestações, principalmente em adolescentes, e as repercussões negativas da depressão materna na saúde do recém-nascido, tornam a questão da depressão gestacional central no desenvolvimento de políticas públicas de saúde materno-infantil.

Divergindo em alguns aspectos com dados acima relatados, de acordo com o PNDS, a taxa de fecundidade manteve sua tendência de queda, atingindo, em 2006, o valor de 1.8 filhos por mulher A maior redução ocorreu nas áreas rurais. A escolaridade das mulheres continua sendo um diferencial importante: para aquelas sem instrução a taxa foi igual a 4, enquanto que ficou abaixo de 1.6 para mulheres com escolaridade mínima de 9 anos. Entre as jovens de 15 a 19 anos, 23\% estavam grávidas no momento da pesquisa e $12 \%$ já estiveram grávidas, mas não tiveram filhos nascidos vivos (BRASIL, 2006a).

O risco social, discurso predominante na saúde pública, traz implícita uma interpretação de que a gravidez resultaria da pobreza, da precariedade e da falta de acesso aos serviços de saúde, e, portanto é considerada como um reforço à pobreza e marginalidade. Uma vez indesejada, a gravidez acarretaria prejuízos para as adolescentes como abandono dos estudos e dificuldade em encontrar emprego (PANTOJA, 2003).

Alguns pesquisadores consideram que a classe baixa da população tem maior risco para transtornos psiquiátricos porque enfrentam maiores problemas diários que a classe alta, tem menor poder de resolutividade destes problemas e com isso passam por prolongados períodos de estresse (STUART e LARAIA, 2001).

São considerados fatores contribuintes para a manutenção da situação socioeconômica desfavorável a situação familiar desestruturada, evasão escolar, desemprego e a baixa capacitação profissional, criando-se um cenário com elementos importantes também para o uso de drogas e transtornos psiquiátricos no terceiro trimestre da gravidez (MITSUHIRO et al., 2006). 
Mulheres com menor escolaridade, maior número de gestações, maior paridade, maior número de filhos vivos e menor tempo de relacionamento apresentaram mais depressão. Uma vez que uma alta ocorrência de depressão pós-parto está relacionada a fatores sociais, é necessário visibilizar a importância dos profissionais da atenção básica na detecção precoce da depressão, tendo como auxílio instrumentos como a EPDS, pela sua eficácia e praticidade (RUSCHI et al., 2007).

A realização de visitas domiciliares é vista como vantajosa no sentido de conhecer melhor o contexto de vida dos adolescentes e jovens e a dinâmica de suas famílias. É uma oportunidade para fortalecer vínculos, convidá-los para atividades educativas, identificar situações de estresse. Como esses profissionais têm contato com a família como um todo, é vital que se assegure ao adolescente a confidencialidade das informações (BRASIL, 2005b).

As mães solteiras e muito jovens, sem apoio familiar, com antecedentes familiares de depressão e condições socioeconômicas precárias, devem ser objetos de atenção especial durante a gravidez e após o parto, uma vez que apresentam possível risco. A provisão de apoio intensivo no pós-parto e a atenção adequada por parte de profissionais da atenção primária capacitados para a identificação de sintomas e tratamentos da depressão puerperal em muito as aliviará. Desta feita podem prevenir episódios mais graves e duradouros, diminuir o sofrimento psíquico da mãe e do filho e também colaborar na diminuição dos índices de suicídio e infanticídio (LUGO; MONGRADON, 2006).

A investigação no âmbito da maternidade na adolescência tem vindo a estudar o contexto de cuidados à criança que podem contribuir para um desenvolvimento menos adequado. Tal contexto muitas vezes associado à maternidade na adolescência é desfavorável sob diversos pontos de vista, sendo particularmente em circunstâncias adversas como: baixo nível socioeconômico, baixo nível educativo e mono parentalidade. Estas condições de desvantagem podem contribuir para os efeitos adversos que se observam nas crianças em consequência da maternidade na adolescência. A estas circunstâncias se associam outras condições que têm a ver com o contexto mais imediato dos cuidados e da interação da mãe com a criança e que podem de igual modo ser desfavoráveis (FIGUEIREDO, 2000). 
Tabela 5. Características dos aspectos relacionados à maternidade das adolescentes puérperas atendidas na Estratégia de Saúde da Família do Município de Embu Guaçu, com pontuação maior ou igual a 12 e com pontuação menor que 12 segundo a EPDS. 2008/2009.

\begin{tabular}{|c|c|c|c|c|c|}
\hline Pontuação na EPDS & & $\begin{array}{c}\text { EPDS } \\
\text { maior/ } \\
\text { igual a } 12\end{array}$ & & $\begin{array}{l}\text { EPDS } \\
\text { menor } \\
\text { que } 12\end{array}$ & \\
\hline Variáveis & $\mathrm{n}$ & $\%$ & & $\%$ & \\
\hline Sua reação quando descobriu que estava grávida & & Grupo A & & Grupo B & \\
\hline Boa & 9 & 50,00 & 13 & 46,43 & \\
\hline Ruim & 8 & 44,44 & 15 & 53,57 & \\
\hline Indiferente & 1 & 5,56 & 0 & 0,00 & \\
\hline $\mathrm{P}$ & & & & & 0,081 \\
\hline \multicolumn{6}{|c|}{ Reação da sua família quando descobriu que estava grávida } \\
\hline Boa & 9 & 50,00 & 20 & 71,43 & \\
\hline Ruim & 6 & 33,33 & 8 & 28,57 & \\
\hline Indiferente & 3 & 16,67 & 0 & 0,00 & \\
\hline $\mathrm{P}$ & & & & & 0,081 \\
\hline \multicolumn{6}{|c|}{ Reação do seu companheiro quando descobriu que estava grávida } \\
\hline Boa & 10 & 55,56 & 22 & 78,57 & \\
\hline Ruim & 5 & 27,78 & 6 & 21,43 & \\
\hline Indiferente & 3 & 16,67 & 0 & 0,00 & \\
\hline $\mathrm{P}$ & & & & & 0,065 \\
\hline \multicolumn{6}{|l|}{ Parou de estudar durante a gravidez ou após o parto } \\
\hline Sim & 11 & 61,11 & 11 & 39,29 & \\
\hline Não & 7 & 38,89 & 15 & 53,57 & \\
\hline Não respondeu & 0 & 0,00 & 2 & 7,14 & \\
\hline $\mathrm{P}$ & & & & & 0,383 \\
\hline \multicolumn{6}{|l|}{ Quantos filhos tem* } \\
\hline 1 & 16 & 88,89 & 26 & 92,85 & \\
\hline 2 & 2 & 11,11 & 2 & 7,14 & \\
\hline Mediana & 1 & & 1 & & \\
\hline Mínimo & 1 & & 1 & & \\
\hline Máximo & 2 & & 2 & & \\
\hline Média & & & & 1,0714 & \\
\hline Desvio Padrão & & & & 0,0495 & \\
\hline $\mathrm{P}$ & & & & & 0,6499 \\
\hline \multicolumn{6}{|l|}{ Tipo de parto } \\
\hline Normal & 14 & 77,78 & 25 & 89,29 & \\
\hline Cesárea & 4 & 22,22 & 3 & 10,71 & \\
\hline $\mathrm{P}$ & & & & & 0,407 \\
\hline \multicolumn{6}{|l|}{ Tipo de parto que você preferia ter tido } \\
\hline Normal & 16 & 88,89 & 26 & 92,86 & \\
\hline Cesárea & 2 & 11,11 & 1 & 3,57 & \\
\hline $\mathrm{P}$ & & & & & 0,729 \\
\hline
\end{tabular}




\begin{tabular}{|c|c|c|c|c|c|}
\hline $\begin{array}{l}\text { Continuação da tabela } \\
\text { Pontuação na EPDS }\end{array}$ & & $\begin{array}{c}\text { EPDS } \\
\text { maior/ } \\
\text { igual a } 12\end{array}$ & & $\begin{array}{l}\text { EPDS } \\
\text { menor } \\
\text { que } 12\end{array}$ & \\
\hline Variáveis & $\mathrm{n}$ & $\%$ & & $\%$ & \\
\hline Comparecimento à consu & & & & & \\
\hline $3-5$ & 1 & 5,56 & 1 & 3,57 & \\
\hline $6-10$ & 4 & 22,22 & 10 & 35,71 & \\
\hline $11-15$ & & & 17 & 60,7 & \\
\hline 15 & 12 & 66,67 & & & \\
\hline Ignorado & 1 & 5,56 & 3 & 10,71 & \\
\hline $\mathrm{P}$ & & & & & 0,388 \\
\hline Quem ajudou ou ainda ajud & & & & & \\
\hline Mãe ou pai & 4 & 22,22 & 10 & 35,71 & \\
\hline Dois ou mais familiares & 7 & 38,89 & 8 & 28,57 & \\
\hline Sogra ou amiga & 2 & 11,11 & 3 & 10,71 & \\
\hline Marido & 0 & 0,0 & 3 & 10,71 & \\
\hline Ninguém & 5 & 27,78 & 4 & 14,29 & \\
\hline $\mathrm{P}$ & & & & & 0,482 \\
\hline
\end{tabular}

Observa-se na Tabela 5, que aproximadamente a metade dos familiares e mais da metade dos parceiros das adolescentes com o risco de transtorno depressivo teve uma boa reação quando descobriu a gravidez delas. A maioria das adolescentes não parou de estudar por conta da gravidez; teve 1 filho, foi submetida a parto normal, fez 15 consultas pré-natal, não faltou às consultas prénatal e teve ajuda da mãe ou pai ou de dois ou mais familiares nos primeiros meses de vida do bebê.

A comparação com os indicadores das puérperas com pontuação maior ou igual a doze (grupo A) com as puérperas que pontuaram menos que 12 (grupo B) segundo a EPDS revelou dados importantes.

Quanto à reação da família, a maioria dos familiares do grupo $B$ teve boa aceitação, e no grupo $A$ apenas $50 \%$. Três adolescentes do grupo $A$ se colocaram como "indiferentes". Ser indiferente frente a uma constatação de gravidez pode revelar certa apatia como forma de alienação aos eventos que a cercam. Nesta concepção o resultado do grupo A "indiferente" poderia ser incorporado ao resultado da categoria "ruim", perfazendo um total de $50 \%$ contra apenas $28,57 \%$ no grupo B. A reação desfavorável da família em relação à gravidez da adolescente pode se revelar como um fator destrutivo em relação à saúde mental. 
Os resultados demonstram que $61,11 \%$ do grupo $A$ parou de estudar durante a gravidez, em comparação com $32,29 \%$ do grupo B. Quanto ao número de filhos não houve diferença.

Os resultados da pesquisa confirmaram que as adolescentes puérperas, qualquer que seja seu escore na EPDS sentem necessidade da ajuda da família após o nascimento do bebê. Foram categorizadas em ajuda doméstica, ajuda emocional e ajuda que já está sendo prestada. Os membros da família que mais prestavam ajuda foram mencionados como cunhada, sogra, tio, ACS que era tia, mãe, marido, avó, amiga, pai do bebê e toda família. $O$ grupo $A$ revelou que $27,78 \%$ das adolescentes não recebeu ajuda de ninguém. Já no grupo $B$ este valor ficou em $14,29 \%$.

Quanto à ajuda doméstica foram relacionadas as seguintes necessidades reproduzindo a fala das puérperas: ajudar nos cuidados com o nenê e comigo; ajudasse-me mais; que a mãe ajude e ensine a cuidar; olhar a nenê para eu arrumar a casa; ajudar com a bebê para procurar trabalho, olhar o filho menor e ajudar em casa quando estou doente; cuidar da nenê; parassem de falar o que eu devo fazer e de pegar e acordar o nenê; ajudassem-me mais no dia a dia; cuidar da casa; cuidar do nenê para procurar serviço; ajuda da mãe; arrumar a casa, dar banho; ajudar a terminar de estudar; ajudar; olhar meu filho; que me ajudassem com os afazeres da casa; tudo, cuidar da nenê, o marido ajudar, fica chateada com a sogra; ficar perto, ajudando; cuidar da nenê; trocar fralda, cuidados com o bebê; ajudar nas coisas da casa, olhar a menina.

Em relação à ajuda emocional as adolescentes expressaram de maneira bastante clara e coerente suas necessidades e desejos: eu queria conversar mais; conversar; elogiar o nenê, trazer lembrancinhas para ela e visitar; família visitar mais e a sogra ser mais cuidadosa com o bebê; deixar eu desabafar; visitar e telefonar; mostrar compreensão, atenção e carinho; atenção; dar atenção; dar atenção, fazer companhia, conversar; que meu marido me respeitasse; dar conselhos; ter minha mãe por perto; ser carinhoso com o nenê e dar atenção para a mãe do bebê; dar mais carinho, atenção. $O$ desejo de conversar foi bastante central e repetido por várias adolescentes, bem como a necessidade de atenção em relação a si mesma e a seu bebê. 
Pesquisa de BENINCASA e REZENDE (2006) também identificou a necessidade de espaços para expressão dos sentimentos e trocas de ideias. A oferta de um espaço de escuta foi uma sugestão bastante repetida pelos sujeitos. Os participantes relataram que a falta de oportunidade para refletir sobre seus sentimentos, provavelmente, os expõe a mais riscos ou colaboram na intensificação de sentimentos ruins.

Uma parte das puérperas da pesquisa em tela já se sentia bastante grata pela ajuda que a mãe dava tanto nos cuidados com o bebê e com a casa, dando depoimentos quanto a seus desejos de ajuda como: nada, já ajudam; minha mãe já me agrada fazendo tudo, mas meu tio me condena; todos tem feito o que eu queria, me ajudaram e mostraram que apesar de ter um filho a vida é a mesma, mais feliz que antes; tendo ele já está bom; não sei, está tudo bem; nada, todos estão super bem comigo; nada; nada especial; elas já fazem tudo, ajudando; só meu marido que me ajuda bastante.

Quando questionadas acerca do tipo que ajuda ou assistência que esperavam por parte da ESF após o nascimento do bebê, os anseios manifestados demonstraram uma simbiose com a ajuda que esperavam da família. Termos como cuidar; dar algumas dicas para melhor cuidar da minha filha; colocar um grupo ensinando e ajudando cuidar do bebê nos primeiros dias, eu tenho minha mãe, mas tem gente que não!; ensinar cuidar do bebê; dar conselho de como cuidar do bebê; cuidados com o bebê; orientar como cuidar do bebê; berçário 1 vez por semana; cuidar melhor, conversar, escutar; conselhos, mais médicos e conversar; atender bem em todas as consultas; atender bem; ajudar a receber a bolsa; reuniões e conversas; orientação, conversa; grupo de conversa e conversa individual; grupo de meninas para se encontrar; conversar, explicar, grupo de apoio; ter psicólogo, psiquiatra; passeio em grupo com os bebês; grupos de troca de ideias; conversar; ajuntar todas as meninas; que arrumasse creche; grupos para conselhos e dúvidas; exercícios para as mães com os bebês; grupo de mãe adolescente; ter psicóloga. As declarações com conteúdo idêntico não foram repetidas, em especial o termo conversar, que vem imbuído do sentido de romper o silêncio. 
Foram detectadas sugestões de ajuda por parte da ESF que emergiam como reclamações: o pediatra não explica nada, é muito seco, a sala de espera é cheia e demora; ser mais pontual nas consultas médicas e dar mais informação; atender bem; passar só com o médico; tratar bem, conversar; ter pediatra de $2^{\mathrm{a}} \mathrm{a}$ $6^{\mathrm{a}}$ feira. Apesar das queixas terem se apresentado em menor número, não é possível ignorar que atender bem, tratar bem, explicar bem e conversar sejam condições sine qua non para qualquer atendimento em qualquer segmento do mercado, quanto mais em se tratando da área da saúde e da população adolescente que se demonstra muito mais vulnerável a transtornos físicos e psíquicos.

Algumas declarações também demonstram o trabalho digno e dedicado de muitos profissionais a estas meninas que, alem de serem adolescentes, estão vivenciando o papel de gerar, parir, cuidar e criar um bebê. Foram relatadas expressões de apreciação como: tudo o que já tem feito me orientando; já me ajudam bastante; quando tenho dúvida eu sempre pergunto; já fazem tudo; o que eu preciso eles já fazem; nada.

Da população total entrevistada (46), 24 adolescentes compareceram a quinze ou mais consultas durante o pré-natal. A assiduidade às consultas de prénatal no grupo $A$ foi de $66,57 \%$ com 15 consultas e $22,22 \%$ de 6 a 10 consultas. No grupo B 60,7\% das adolescentes participaram de 11 a 15 consultas e $35,72 \%$ de 6 a 10. 10,71\% não soube precisar. As que não compareceram em todas as consultas propostas justificaram com expressões como: "só descobriu a gravidez após 18 semanas"; "fui em 7 consultas porque só fui após 1 mês"; "fui após 5 meses, esperei o marido marcar"; "fui em 4 por causa do filho menor"; "fui em 6 consultas, comecei mais tarde"; "fiz mais de 8 consultas"; "tive dificuldade com condução e dinheiro"; "faltei porque chovia forte e tem outro menino"; "não sabia da gravidez"; "viajava para são Paulo"; "não ia quando estava muita chuva".

Ainda contemplando o universo de toda a população de adolescentes, foram observadas diversas expressões revelando o que sentiram no momento em que souberam que estavam grávidas. Relacionando os sentimentos ou manifestações emocionais favoráveis à gestação, foram encontradas as seguintes declarações: "não acreditei"; "fiquei surpresa"; "feliz"; "contente"; "alegria"; "queria ter"; "gostou"; "felicidade"; "já tinha 2 anos de casada"; "surpresa"; "alegre"; "normal”; "já esperava"; "uma grande felicidade"; "tontura e feliz"; "riso". 
Também houve depoimentos desfavoráveis ou negativos relacionados à constatação da gravidez. Foram identificadas expressões verbais como: "choro"; "desespero e susto ao mesmo tempo"; "nervosa"; "ansiosa"; "medo do pai"; "quase caiu de costas"; "não sabia o que fazer"; "medo"; "medo da mãe": "podia ter esperado mais"; "medo de falar para minha mãe"; "não queria"; "em choque"; "traumatizada"; chorou desesperada"; "triste": "chorei"; "preocupada com o marido sem emprego"; "assustada"; "tremendo"; "medo da mãe, só contou depois dos 6 meses"; "não planejado"; "nervosa"; "ansiosa"; "com medo do pai"; "medo do parto"; "como vai ser a vida, cuidar dele"; "envergonhada"; "com o coração na boca"; "desespero"; "me senti mal e depois acostumei"; "preocupada como ia cuidar"; "não queria"; "assustada"; "triste"; "paralisada"; "não queria agora"; "difícil de aceitar"; "abalada".

Os resultados obtidos quanto à reação do companheiro e dos pais quando receberam a notícia da gravidez da adolescente mostraram que aproximadamente a metade dos familiares e mais da metade dos parceiros das adolescentes com o risco de transtorno depressivo teve uma boa reação quando descobriu a gravidez delas. Quando questionadas acerca da reação do pai do bebê, muitas puérperas e também alguns pais do bebê que estavam presentes no momento da coleta de dados, revelaram sentimentos e expressões como: "normal"; "disse que vai ter que trabalhar"; "não se surpreendeu"; "ficou besta"; "só soube depois que o nenê nasceu"; "gostou"; "contente"; "feliz"; "muito feliz"; "uma alegria sem tamanho"; "mais que contente"; "queria muito"; "muito feliz"; "ficou bobo"; "deu pulos"; "bom".

Ao associar-se o item "indiferente" ou "ruim" tem-se $44,45 \%$ dos companheiros apresentando uma reação ruim ao receber a notícia da gravidez no grupo A e apenas $21,43 \%$ no grupo B. As reações e sentimentos negativos ao serem informados da gestação da companheira foram: "não queria"; "ficou enciumado"; "desesperado"; "disse "como vai ser'?"; "queria tirar o nenê"; "preocupado por não estar trabalhando"; "desesperado no começo"; "nervoso com ele mesmo"; "não gostou muito, pois evitava com remédio"; "ele não sabe".

Os familiares também vivenciam emoções e sentimentos diversos ao serem informados acerca da gravidez da adolescente com seu companheiro. Levando em consideração o conhecimento da família sobre o namoro ou a união de seus filhos e filhas, as reações assumem conotações de aprovação ou reprovação. 
As entrevistadas relataram reações da família como: "metade ficaram bravos"; "mãe e tio gostaram"; "mãe gostou"; "gostou"; "feliz"; "contente"; "fazer o que"; "boa"; "aceitaram"; "mãe em depressão e pai sem reação"; "triste"; "mãe ficou louca e triste"; "surpresa"; "nervosos só no primeiro mês"; "mãe chorou muito"; "não ligaram"; "preocupados pelo risco"; "mãe nervosa, pai parou de falar comigo"; "pai ficou nervoso"; "apoiaram, todos gostaram"; "não aceitaram no começo só"; "a família dele não gostou"; "terrível"; "bravos"; "xingou"; "me mandou embora"; "difícil".

Comparando a reação dos familiares quanto à reação da família, a maioria dos familiares do grupo B teve boa aceitação, e no grupo A apenas $50 \%$. Três adolescentes do grupo A se colocaram como "indiferentes". Ser indiferente frente a uma constatação de gravidez pode revelar certa apatia como forma de alienação aos eventos que a cercam. Nesta concepção o resultado do grupo $A$ "indiferente" poderia ser incorporado ao resultado da categoria "ruim", perfazendo um total de $50 \%$ contra apenas $28,57 \%$ no grupo B. A reação desfavorável da família em relação à gravidez da adolescente pode se revelar como um fator destrutivo em relação à saúde mental.

MENESES (2008) obteve resultados semelhantes aos achados em Embu Guaçu, com $94,0 \%$ das adolescentes referindo ter apoio da família na gravidez e $78,5 \%$ revelando ter amigas para conversar. $\mathrm{O}$ apoio familiar e de amigos foi fator importante na associação com presença de TMC. As jovens gestantes que referiram não contar com o apoio da família apresentaram prevalência duas vezes maior de transtornos mentais comuns e aquelas que referiram não ter amigas ou amigos para conversar apresentaram uma prevalência $48 \%$ mais elevada de TMC.

$\mathrm{Na}$ pesquisa em tela, as adolescentes puérperas moravam em sua totalidade na zona rural, e as distâncias entre suas residências e as unidades de Estratégia da Saúde da Família eram longas. A maioria precisava usar o transporte público e algumas caminhavam até o local, muitas vezes empurrando o carrinho do bebê. Todavia, nem a distância nem a necessidade de tomar uma condução paga as impedia de frequentarem as reuniões e consultas oferecidas. Ao serem verificados os cartões de pré-natal foi constatado que a maioria das adolescentes frequentaram todas as 15 consultas oferecidas pelo serviço de saúde. 
As adolescentes que se tornam mães nem sempre o fazem sem assim o desejarem e, portanto, a equipe de saúde que lida com essa faixa etária deve estar pronta para entender e apoiar essas jovens, orientando-as da melhor forma possível para que vivam em plenitude etapa tão importante de suas vidas (MENESES, 2008).

DA SILVA et al. (2010) encontraram fortes associações entre ter planejado a gravidez e depressão. Acredita-se que este fato possa ser consequência das expectativas quanto à maternidade e aos medos intrínsecos durante a gestação.

HEAVEY et al. (2008) examinaram outras variáveis associadas ao desejo de engravidar entre adolescentes americanas de baixa renda e observaram que meninas de origem hispânica desejaram muito mais a gravidez do que as afroamericanas e, da mesma forma, aquelas que se encontravam fora da escola também mostraram maior desejo pela gravidez.

As meninas que engravidam adolescentes necessitam sobremaneira de apoio por parte da família e de amigos, para que consigam vencer essa etapa conturbada de suas vidas sem maiores prejuízos emocionais (JATOBA; BASTOS, 2007).

Pesquisa de FRIZZO; KAHL e OLIVEIRA (2005) também ressalta a reação positiva dos familiares para quase todas as adolescentes que anunciaram sua gravidez. Apenas duas mães disseram para suas filhas que elas deviam ter se cuidado, que elas ainda eram muito jovens para serem mães.

Tais achados conduzem a percepções de mudanças de paradigmas quanto a engravidar na adolescência, não apenas por parte das próprias adolescentes, mas com ramificações para suas famílias, seus companheiros e a família de seus companheiros.

A cultura vigente em nosso país revela ainda de maneira sutil, porém perceptível, que tais mudanças se manifestarão inclusive e indubitavelmente nas condutas escolhidas para a assistência à saúde desta nova clientela.

$O$ aspecto fundamental da assistência pré-natal eficiente deve incluir o cuidar da mulher grávida considerando as suas necessidades biopsicossociais e culturais. Durante esse período, os serviços de saúde têm oportunidade de trabalhar adequadamente tais fatores, procurando contribuir para promoção de uma gestação mais saudável (FALCONE et al., 2005). 
DE CARVALHO et al. (2008a) acreditam que o objetivo do pré-natal seja assegurar o nascimento de uma criança saudável e minimizar os riscos maternos. Para os autores, toda assistência deve ser pautada na prevenção, identificação de riscos e tratamento adequado quando necessário.

No esforço para tornar efetiva a declaração de DE CARVALHO (2008a), é preciso compreender que a saúde é um setor privilegiado para promoção e garantia dos direitos humanos dos adolescentes. A partir deste espaço é possível intervir de forma satisfatória na implementação de uma série de direitos, aperfeiçoando as políticas de atenção a essa população por meio de ações e atividades articuladas e conjuntas entre os setores de Saúde, Educação, Justiça, Segurança e a própria população jovem (BRASIL 2005a).

Em pesquisa de FRIZZO; KAHL e OLIVEIRA (2005), a reação dos familiares também foi positiva em quase todos os casos. Apenas duas mães disseram para suas filhas que elas deviam ter se cuidado, que elas ainda eram muito jovens para serem mães. Quatro meninas relataram preocupações por serem muito nova para ser mãe. Algumas meninas também referiram receio de não serem boas mães. O principal motivo atribuído tanto à questão da gravidez na adolescência em geral quanto à própria gravidez das participantes foi a falta de cuidado, que significava usar camisinha ou pílula. $O$ apoio dado para essas meninas por parte das mães pode ser entendido porque muitas delas também foram mães cedo e também porque neste contexto social é bastante comum a maternidade precoce. Um dado interessante do presente estudo é que todas as adolescentes disseram que o companheiro gostou de saber que ia ser pai e que a está apoiando neste período.

O aconchego e aceitação da gravidez por parte de familiares e companheiro da adolescente também é demonstrada através da presença de um acompanhante no momento do parto. Diversas puérperas relataram espontaneamente a segurança que sentiram por ter alguém da família na sala de parto. Também há de se considerar o fato de que muitas gestantes sentem medo do momento do parto, medo da dor, medo de morrer, medo de o bebê morrer, enfim, cada gestante atribui significados diferentes a este evento. Se for acrescentado o fato de a gestante ser adolescente esses significados podem ter representações bastante angustiantes. 
O processo de parir tem, ao longo do tempo, sofrido influência direta e, por vezes, perversa da cultura hospitalocêntrica. No Brasil, atualmente, a medicalização do parto alcança vários recordes, que contribuem para elevar os índices oficiais do Ministério da Saúde, particularmente no que se refere ao número crescente de cesarianas. Além dos dados, tal conduta pode causar desconfortos, especialmente numa época em que políticas de humanização têm ganhado espaço no sistema de saúde governamental (BASSO; MONTICELLI, 2010).

Na prática assistencial junto a mulheres e seus acompanhantes durante os momentos do parto, é percebido que a parturiente e seu acompanhante pouco atuam neste processo. As decisões ficam exclusivamente nas mãos dos profissionais, que resolvem e decidem qual a melhor conduta ou procedimento a ser implementado no decorrer da internação na maternidade. Existe uma aparente entrega ou aceitação acerca daquilo que é seu de direito e de fato (BASSO; MONTICELLI, 2010).

A grande maioria dessas pessoas revela que preferem processos sociais e fisiológicos de parir e nascer, diferente da realidade atual, com eventos hospitalares e patológicos em sua absoluta maioria. As mulheres explicitam suas expectativas concretas de participação, valorizam o "trabalho do corpo", a sociabilidade promovida pelos encontros com os profissionais de saúde e o próprio processo do parto como algo que pode ser vivenciado de modo prazeroso tanto pela mulher como pela criança, pelo acompanhante e pelas demais pessoas que Ihes são significativas. Querem se preparar para ter condições de negociar cuidados e modalidades de parto sem se sentirem intimidadas pelo conhecimento e autoritarismo profissional (BASSO; MONTICELLI, 2010).

Apesar de as experiências emocionais da mulher durante o trabalho de parto e parto serem um aspecto essencial do cuidado obstétrico, a grande maioria das pesquisas acerca de aspectos emocionais relativos ao nascimento são realizadas apenas após o parto (ALEHAGEN; WIJMA; WIJMA, 2001). 
O foco apenas no parto normal pode inadvertidamente fazer com que os responsáveis por serviços de maternidade deixem de promover o que deveria ser um cuidado eficaz e contínuo durante a gravidez, no parto e no período do pósparto, de modo que cada fase da gravidez de uma mulher, assim como a jornada do parto não seja gerenciada ou financiada como uma entidade separada, e nenhuma fase da jornada tenha prioridade sobre a outra (BICK; BASTOS; DINIZ, 2008).

Muito pertinente a observação das autoras acerca de que muito do nosso conhecimento sobre o impacto do parto na saúde física e psicológica das mulheres tem sido baseada em suposições. "A história da obstetrícia é manchada com as consequências negativas das intervenções introduzidas, pois foi suposto que as mesmas seriam benéficas, e mais tarde foi demonstrado que eram prejudiciais ou não traziam nenhum benefício específico."

Entre tais suposições são mencionadas a realização rotineira de episiotomia; monitoramento fetal eletrônico de rotina; e a rotina de fazer tricotomia na região do períneo no momento de admissão hospitalar quando em trabalho de parto. Durante o pós-parto se supunha que as mulheres se recuperariam completamente do parto dentro de 6 a 8 semanas. Por quase um século após a introdução da tocologia pós-natal universal no Reino Unido, essa suposição foi aceita quando, na realidade, ninguém havia perguntado nada às mulheres (BICK; BASTOS; DINIZ, 2008).

É de indubitável importância que existam políticas e provedores de serviço que promovam e protejam o cuidado pós-natal como um componente essencial da saúde pública, garantindo que as habilidades dos provedores de serviços sejam otimizadas para atenderem as necessidades em saúde de acordo com as diretrizes nacionais (BICK; BASTOS; DINIZ, 2008).

A equipe que atende a parturiente deveria considerar a questão do medo durante o trabalho de parto e redobrar a atenção quanto à primíparas. Estas apresentam níveis mais altos de medo durante os estágios iniciais do franco trabalho de parto, comparado ao medo das multíparas. O grande desafio conseguir minimizar tais sentimentos (ALEHAGEN; WIJMA; WIJMA, 2001). 
Segundo MOTTA e CREPALDI (2001), o acompanhante é fundamental para oferecer qualidade na assistência, proporcionando conforto, segurança e confiança à parturiente. Em um estudo com 40 pais, foi constado que a maioria desconhece o seu direito legal de comparecer ao nascimento do filho e atribui à equipe médica essa oportunidade (TOMELERI et al., 2007).

Estudos científicos apontam evidências de que os partos realizados com a presença de um acompanhante trazem muitos benefícios e minimizam problemas quanto à saúde da gestante. As mulheres atendidas pelo Sistema Único de Saúde (SUS) têm o direito de escolher alguém de sua confiança para estar presente na sala de parto e também durante o pós-parto. A presença do acompanhante no parto e pós-parto nas maternidades do Sistema Único de Saúde (SUS) é garantida pela Lei 11.108, de abril de 2005 (BRASIL, 2005d).

DINIZ et al. (2007) destacam que esta lei proverá bases para cuidados na maternidade que incluirão segurança, eficácia, direitos de escolha informada, de informações imparciais e de integridade corporal, frequentemente ignorados nos serviços de maternidade do Brasil. É necessário que o país debata e dissemine questões sobre os direitos da maternidade e monitore sua implementação.

Acredita-se que o pai seja o acompanhante ideal para participar do processo de nascimento, pois promove formação de vínculo e reforça os laços familiares. O acompanhamento do pai no trabalho de parto e parto é a melhor forma de prestar uma assistência humanizada (STORTI, 2004).

De acordo com 14 estudos científicos brasileiros e internacionais realizados em mais de cinco mil mulheres, as gestantes que contam com um acompanhante no parto e no pós-parto ficam mais tranquilas e seguras durante o processo. A presença do acompanhante também contribui para redução do tempo do trabalho de parto e para diminuir o número de cesáreas (BRASIL, 2005d). "Durante o trabalho de parto, é normal a mulher sentir medo e insegurança. Esse medo muitas vezes aumenta a dor das contrações e a experiência do parto torna-se traumática", explica a técnica da Coordenação de Saúde da Mulher do Ministério da Saúde, Daphne Rattner. "A presença do acompanhante diminui esses obstáculos e transforma o acontecimento em uma experiência positiva e inesquecível" (BRASIL, 2005d). 
Para a mulher em trabalho de parto, a presença do marido ou companheiro proporciona apoio afetivo e suporte, ajudando-a a enfrentar medo e insegurança, gerados principalmente pelo ambiente desconhecido e a falta de um acompanhante de sua confiança (SILVEIRA et al., 2004).

A permanência de outra pessoa junto à parturiente contribui ainda para reduzir a possibilidade de a paciente sofrer de depressão pós-parto. Além de oferecer tranquilidade e segurança para a mulher, o acompanhante pode ajudar em tarefas básicas com o bebê no pós-parto, quando a mãe se encontra em fase de adaptação e reabilitação (BRASIL, 2005d).

Segundo o Ministério da Saúde, existe uma série de vantagens evidenciadas em relação à presença de um acompanhante no momento do trabalho de parto e parto:

- Vínculo afetivo - a participação dos companheiros na assistência ao parto pode melhorar o vínculo afetivo entre o casal. No momento no pós-parto em que é estabelecido um vínculo emocional entre mãe e filho, a participação do pai fortalece os laços entre os membros da família. "Em partos cirúrgicos, nos quais raramente é permitida a participação do companheiro, a chance de viver essa experiência é perdida".

- Tecnologia - Os avanços tecnológicos na medicina nem sempre são positivos no que diz respeito aos atendimentos aos partos. Alguns medicamentos que nem sempre são essenciais para o bemestar da mãe ou de seu bebê acabam ministrados frequentemente (BRASIL, 2005d).

O momento do nascimento do filho é considerado por alguns pais como o auge do afloramento de muitos sentimentos positivos, predominando o sentimento de alegria seguido de sensação de alívio devido ao sucesso do parto e as boas condições de saúde do filho (MAZZIERI, 2005).

Para muitas mulheres o parto normal e a experiência do nascimento são vivenciados como uma ameaça à sua integridade emocional e física (D'OLIVEIRA; DINIZ; SCHRAIBER, 2002). TOMELERI et al. (2007) constataram em sua pesquisa que dentre as motivações para os pais assistirem ao parto, a que mais se destacou foi a de oferecer proteção à sua mulher. 
A equipe de enfermagem e médicos exercem um papel fundamental no processo de parturição Deverão orientar e incentivar o acompanhante da parturiente de acordo com suas limitações. Quanto melhor a integração entre o acompanhante e a equipe maior a participação deste. Ao oferecer orientação para o casal ocorre a promoção de um apoio emocional efetivo e consequentemente um envolvimento maior com o momento único do parto (MOTTA; CREPALDI, 2005).

Pesquisa realizada por STORTI (2004) revela que na percepção dos casais a escolha do pai para acompanhante se relaciona a formação de um vínculo familiar, gerando confiança e segurança para a parturiente. No entanto, é preciso atenção para que essa escolha seja voluntária e nunca imposta pela mulher ou pela instituição como se fosse o único caminho para fortalecer o vínculo e a construção da família.

Diversos sujeitos do presente estudo explicitaram a presença de acompanhante durante o pré-parto e parto, sendo mencionados: o pai do bebê, a mãe das adolescentes e também a sogra. Os acompanhantes das puérperas que assistiram ao parto normal demonstraram, através da fala, expressões ouvidas pelas suas companheiras adolescentes como: "o pai que sentiu ansiedade e agonia", "pai também sentiu a dor", "subiu a pressão da minha mãe e ela brigou comigo", "a sogra entrou e chorou", "meu namorado atual assistiu e passou mal", "o pai do nenê assistiu, gostou".

A despeito de as impressões dos acompanhantes terem se revelado majoritariamente negativas em relação ao evento do parto, as parturientes expressaram emoções variadas durante o nascimento de seus bebês. Houve discursos positivos e protetores como: "foi bom, mas preferia cesárea"; "normal"; "não tive trabalho"; "rápido, senti agonia"; "achei engraçado, foi rápido"; "não deu tempo do marido chegar, minha mãe ficou"; "normal, a mãe ficou junto"; minha mãe foi comigo, foi legal, ótimo"; "foi doloroso, rápido, bom, o marido entrou"; "foi bom, não senti muita dor, a mãe acompanhou".

Em contrapartida, os relatos de processos potencialmente traumáticos em relação ao trabalho de parto e parto não deixam de evidenciar como a assistência humanizada ao parto ainda está aprendendo seus primeiros passos. 
Foram ouvidos relatos como: "péssimo, horrível, acho que o médico nunca fez parto, uma correria"; "medo de ser cesárea, subiu a pressão, medo de morrer e de o nenê morrer, nervosa, o pai não quis assistir"; "muita dor"; "inesquecível pela dor, preferia ter cesárea pra não ter normal"; "dói demais"; "difícil pela dor, mas rápido, o pai não teve tempo de chegar"; "assustada e apavorada, com muita dor"; "terrível"; "difícil, muita dor, horrível foi induzido por 2 dias"; "não deixaram o pai assistir, foi horrível, muita dor, sofri 10 horas, pensei que fosse morrer"; "ninguém assistiu"; "o pai não assistiu".

Tais declarações, muitas diametralmente diferentes entre si, confirmam a forte influência que o significado que se atribui evento do parto é único e particular para cada mulher que o vivencia. Cada queixa, solicitação, inquietação deve ser avaliada de modo a revelar um plano terapêutico individual, onde a empatia do profissional que atende a parturiente sempre se torna visível como uma ferramenta terapêutica.

Apesar de avanços quanto à presença do pai no Centro Obstétrico durante todo o processo de parturição ainda existem dificuldades. É preciso compreensão e colaboração das instituições quanto a não discriminar a presença do acompanhante apenas para o trabalho de parto que tem como desfecho o parto normal, mas especialmente quando a conduta aponta para uma intervenção cirúrgica. As necessidades emocionais das parturientes não são magicamente esvaziadas ao saberem da necessidade de uma intervenção cirúrgica. Pelo contrário, muitas vezes o parto operatório traz apreensões, preocupações e medo do desconhecido.

Os resultados obtidos no presente estudo quanto ao tipo de parto das adolescentes com escore da EPDS maior ou igual a 12 revelaram que, apesar dos $77,78 \%$ de partos terem sido normais, $22,22 \%$ foi parto cesárea. Apenas $11,11 \%$ relatou que preferia ter feito cesárea $(A)$ e $3,57 \%$ no grupo $B$.

As parturientes que foram submetidas ao parto operatório relataram que a dor sumiu logo, que foi bom e que o nenê sai logo. Outras reclamaram, referindo que a cirurgia demorou muito, que preferia normal, que não deixaram ninguém assistir, que tinha que pagar para alguém assistir e que queria ter tido normal. Apenas uma adolescente declarou que realmente queria ter tido cesárea. 
Segundo DINIZ e CHACHAM (2006), a cesárea é praticada em mais de dois terços dos nascimentos do setor privado de saúde no Brasil. A prevenção de cesáreas e episeotomias desnecessárias e a promoção do parto normal vaginal com um períneo intacto exigem transformações profundas na assistência obstétrica. Será preciso uma mudança nos estereótipos de gênero e uma compreensão mais profunda do corpo feminino antes que essas práticas possam ser transformadas.

Isto está relacionado ao direito da mulher de ter acesso à informação baseada em evidência, privacidade, liberdade de escolher a posição para o trabalho de parto e o parto, direito de ter um acompanhante no parto e apoio social durante o trabalho de parto, direito a um adequado controle da dor e prevenção de dor iatrogênica, bem como direito ao aprendizado de exercícios pélvicos para obter uma vagina "poderosa" (DINIZ; CHACHAM, 2006).

O Brasil é um país em desenvolvimento, com índice de fertilidade de 1,8 filhos por mulher. O Sistema Único de Saúde (SUS) segue o princípio da universalidade, atendendo a todos sem discriminação de raça, cor, idade ou gênero, entre outros. Suas organizações sociais têm influenciado, através de seus ativistas, o desenvolvimento e a implantação progressiva de políticas nacionais relacionadas às mulheres. O típico parto normal no Brasil inclui um excesso de rotinas no trabalho de parto como, posição litotômica para o parto e episeotomia. $O$ direito de a mulher ter um acompanhante não é rotineiramente oferecido (DINIZ; CHACAM, 2006).

O parto normal é estimulado em cursos para enfermeiras obstetras. Cerca de 1.700 profissionais já receberam qualificação. O ministério também tem investido na qualificação de doulas. São mulheres voluntárias com vasta experiência em ajudar e tranquilizar as gestantes durante o trabalho de parto. $\mathrm{O}$ Ministério da Saúde já treinou 350 doulas em 13 cursos. O Ministério da Saúde também desenvolve o programa "Trabalhando com Parteiras Tradicionais" a fim de melhorar a atenção ao parto domiciliar e busca sensibilizar os gestores do SUS e profissionais de saúde para que reconheçam as parteiras como parceiras, apoiando e qualificando o trabalho destas profissionais (BRASIL, 2005d). 
Tabela 6. Características dos aspectos relacionados à Estratégia da Saúde da Família do Município de Embu Guaçu percebidas pelas adolescentes puérperas com pontuação maior ou igual a 12 segundo a EPDS. 2008/2009.

\begin{tabular}{|c|c|c|}
\hline Variáveis & $\mathbf{N}$ & $\%$ \\
\hline \multicolumn{3}{|c|}{$\begin{array}{l}\text { Unidade de Saúde é longe da sua } \\
\text { casa }\end{array}$} \\
\hline Sim & 12 & 66,67 \\
\hline Não & 6 & 33,33 \\
\hline \multicolumn{3}{|c|}{ Dificuldade para marcar consulta } \\
\hline Sim & 8 & 44,44 \\
\hline Não & 10 & 55,56 \\
\hline \multicolumn{3}{|c|}{$\begin{array}{l}\text { Consultas de pré-natal } \\
\text { esclareceram as suas dúvidas }\end{array}$} \\
\hline Sim & 16 & 88,89 \\
\hline Não & 2 & 11,11 \\
\hline \multicolumn{3}{|c|}{$\begin{array}{l}\text { Teve algum problema em receber } \\
\text { os remédios na Unidade de Saúde }\end{array}$} \\
\hline Sim & 10 & 55,56 \\
\hline Não & 8 & 44,44 \\
\hline \multicolumn{3}{|c|}{$\begin{array}{l}\text { Teve mais contato na ESF } \\
\text { durante o pré-natal }\end{array}$} \\
\hline Enfermeiro & 8 & 44,44 \\
\hline Médico & 4 & 22,22 \\
\hline 2 ou mais profissionais & 5 & 27,78 \\
\hline Agentes comunitários & 1 & 5,56 \\
\hline \multicolumn{3}{|c|}{$\begin{array}{l}\text { Contato continuou igual após o } \\
\text { parto }\end{array}$} \\
\hline Sim & 9 & 50,00 \\
\hline Não & 7 & 38,89 \\
\hline Ignorado & 2 & 11,11 \\
\hline \multicolumn{3}{|l|}{ Tipo de UBS } \\
\hline Penteado & 2 & 11,11 \\
\hline Progresso & 14 & 77,78 \\
\hline Sapateiro & 2 & 11,11 \\
\hline
\end{tabular}


A maioria das adolescentes é atendida na UBS de Progresso $(77,78)$. A maior parte destas adolescentes tinha mais contato com as enfermeiras, durante o pré-natal e após o parto, morava longe das Unidades de Saúde, tinha algum problema para receber os remédios destas unidades de saúde. Porém, elas não tinham dificuldade para marcar as consultas e as consultas de pré-natal esclareciam as suas dúvidas (Tabela 6).

A atual Estratégia Saúde da Família (ESF) surgiu em 1994 e chegou ao final de 2005 como mais de 24.000 equipes completas. A decisão política que decidiu reorganizar toda a rede de assistência à saúde se concretizou através das políticas que universalizam o acesso da população à atenção básica, através do SUS (ANDRADE et al., 2009). Os autores continuam afirmando que o impacto gerado pelo comprometimento de recursos federais para a expansão da rede assistencial local e autonomia dos municípios na orientação de estratégias foi extremamente positivo.

Para ser entendido o modelo de atenção à saúde proposto pela ESF no Brasil, é preciso a percepção de que a ESF de uma comunidade específica é distinta das demais. Possui prioridades próprias, potencialidades e limitações. Resulta de um processo de adaptação baseado em capacitação dos profissionais, tempo de implementação, compromisso dos gestores, estabilidade de financiamento e nível de empoderamento comunitário (ANDRADE et al., 2009).

Fazer saúde mental é uma tarefa que compete a todos os profissionais de saúde, sejam médicos, enfermeiros, auxiliares de enfermagem, dentistas, ACS, assistentes sociais, terapeutas ocupacionais, fonoaudiólogos, psicopedagogos e psicólogos (LANCETTI; AMARANTE, 2009).

Especialmente os profissionais que atuam da atenção primária são convocados para intervir nos processos de reabilitação de pessoas que referem ouvir vozes, abusar de substâncias ilícitas, sofrer de angústias e opressões graves. $O$ tratamento destas pessoas deve acontecer muito mais nos bairros, nas famílias, nas comunidades e nas unidades de saúde que em hospitais psiquiátricos (LANCETTI; AMARANTE, 2009).

Ao observarmos os relatos de toda a população de adolescentes da presente pesquisa foi percebida uma cumplicidade e um vínculo muito estreito entre as puérperas e o ACS. Enquanto o agente comunitário de saúde demonstrava conhecer as necessidades e história de vida da família, a adolescente depunha confiança e satisfação com a visita realizada. 
No entanto, ao serem questionadas se o contato com a ESF continuou após 0 parto as adolescentes mencionaram quase que unanimemente a continuidade de contato com o médico e a enfermeira. Poucas relataram contato mantido igual com a ACS.

A pesquisa em tela também revela as dificuldades que as adolescentes enfrentam quanto a manter o contato com a ESF após o nascimento do bebê. A distância tem se mostrado o maior empecilho, com expressões como "precisa ir a pé", "pego lotação até a estrada", "ando $2 \mathrm{Km}$ a pé", "uso perua para chegar a UBS".

Considerando-se a importância de uma intervenção adequada na Estratégia Saúde da Família (ESF), os profissionais médico e enfermeiro se situam em uma posição favorável para detectar precocemente e intervir, evitando o agravamento do processo da depressão puerperal (SANTOS JÚNIOR; SILVEIRA; GUALDA, 2009).

CAMPOS e ROMAGNOLI (2007) acreditam que as visitas domiciliares podem ser coadjuvantes no processo de desinstitucionalização do transtorno mental e desencadearem novas formas de acolhimento e de convivência com o portador de transtorno mental. No entanto os autores perceberam que ainda persiste o desejo de manter os portadores de transtorno mentais estigmatizados como agressivos e incapazes. "A incapacidade e a agressividade (periculosidade) são pontos percebidos por nossa equipe como circulantes entre os agentes, os portadores de transtorno mental, os familiares deles e os CAPS, bem como vislumbrados na fala de um dos médicos das unidades ESF visitadas".

A saúde mental é considerada por alguns como o eixo da ESF. É neste espaço que os pacientes conhecem pelo nome os profissionais que os assistem. E o mesmo acontece com a equipe, que também conhecem seus usuários individualmente. Os usuários deixam de ser um número de prontuário para serem tratados na trama organiza suas vidas. A continuidade de atendimento sempre pela mesma equipe exige que os profissionais lidem com o sofrimento humano. Esse campo relacional pode corroborar objetivos terapêuticos ou tornar-se uma carga emocional insuportável. Daí a importância de uma capacitação e do apoio dos profissionais de saúde mental (LANCETTI; AMARANTE, 2009). 
É deveras interessante a analogia que LANCETTI e AMARANTE (2009) estabelecem entre a ESF e um Programa de Saúde Mental. Em ambos acontece um tratamento continuado, e nesta base os pacientes podem dar novos significados a seus sintomas e sofrimentos; há também o acolhimento, praticado em uma forma de escuta, considerada um dispositivo fundamental nas práticas de saúde mental. Alem disso, as ações coletivas promovidas pela ESF, como caminhadas, grupos terapêuticos, atividades educativas, incentivo à participação comunitária, entre outras, favorecem o envolvimento e a corresponsabilização dos pacientes e seus grupos familiares. Os autores explicitam os princípios fundamentais na atenção:

- Ética - a relação profissional de saúde com os adolescentes e jovens deve ser pautada pelos princípios de respeito, autonomia e liberdade, prescritos pelo Estatuto da Criança e do Adolescente e pelos códigos de ética das diferentes categorias.

- Privacidade - adolescentes e jovens podem ser atendidos sozinhos, caso desejem.

- Confidencialidade e sigilo - adolescentes e jovens devem ter a garantia de que as informações obtidas no atendimento não serão repassadas aos seus pais e/ou responsáveis, bem como aos seus pares, sem a sua concordância explícita. No entanto, eles devem ser informados sobre as situações que requerem quebra de sigilo, ou seja, sempre que houver risco de vida ou outros riscos relevantes tanto para o cliente quanto para terceiros, a exemplo de situações como abuso sexual, ideia de suicídio, informação de homicídios e outros.

Esses princípios reconhecem adolescentes e jovens como sujeitos capazes de tomarem decisões de forma responsável. $O$ atendimento, portanto, deve fortalecer sua autonomia, oferecendo apoio sem emitir juízo de valor. A viabilização desses princípios contribui para uma melhor relação clienteprofissional, favorecendo a descrição das condições de vida, dos problemas e das dúvidas. Esses mesmos princípios também ampliam a capacidade do profissional no encaminhamento das ações necessárias e favorecem o vínculo dessa clientela aos serviços. (BRASIL, 2005b). 
A recepção na Unidade de Saúde configura-se como uma oportunidade de formação de vínculo com o serviço. Para que se estabeleça um clima de confiança e de compromisso, torna-se fundamental a adoção de atitudes acolhedoras, cordiais e compreensivas, visando a proporcionar segurança e tranquilidade, bem como autonomia nos cuidados com a saúde. Quanto mais os serviços se tornam eficazes e acolhedores, mais os adolescentes e jovens irão procurá-los. É importante atentar para alguns fatores que prejudicam a aceitabilidade dos serviços, tais como:

- atitudes autoritárias e preconceituosas de alguns profissionais;

- longas filas de espera;

- dificuldade para agendar consultas;

- falta de privacidade e/ou de confidencialidade;

- falta de material e insumos (preservativos, medicamentos, etc.);

- falta de flexibilidade para atender fora dos horários agendados;

- não cumprimento das consultas agendadas. (BRASIL, 2005b)

A prevalência bastante significativa de transtornos mentais comuns entre as gestantes adolescentes desperta reflexões acerca da maneira que estas estão sendo recebidas e orientadas nos diversos centros de saúde a que recorrem. Também é importante analisar e tentar interferir positivamente nas redes sociais de apoio que têm essas jovens (JATOBA; BASTOS, 2007).

Os profissionais das diversas áreas devem interagir por meio de um enfoque transdisciplinar. $O$ atendimento por equipe concentra-se no cliente, evitando-se visões fragmentadas. As decisões devem ser compartilhadas em discussões conjuntas, resultando em uma intervenção mais eficaz. Sempre que necessário, recomenda-se a interconsulta ou a referência para outros profissionais/serviços (BRASIL, 2005b).

É necessário não perder o foco nas ações educativas no pré-natal. Muitas vezes provavelmente pela sobrecarga de trabalho as consultas deste período se restringem a solicitação de exames, encaminhamentos, aferição da pressão arterial, mensurações de altura uterina, vacinações, entre outras. Neste modelo de atendimento é perdido o vínculo gestante-profissional de saúde tão importante para um desfecho favorável e feliz para a mãe e seu bebê. 
O objetivo da assistência durante o pré-natal é assegurar que a criança nasça saudável e que a mãe tenha o mínimo de risco possível. A assistência deve embasar-se na prevenção, identificação precoce e tratamento de gestantes de alto risco (DE CARVALHO, 2008).

Tais objetivos certamente podem ser extrapolados para outras instâncias além do sucesso biológico da mãe o bebê. O pré-natal é um período privilegiado tanto para as gestantes como para a equipe de saúde que a assiste. $O$ longo período que se passa desde a concepção até o nascimento do bebê permite conhecimento e investigação profunda das necessidades, anseios, dúvidas e desejos da mulher, tanto de caráter físico biológico como em aspectos psíquicos e emocionais.

A partir do estudo de BORGES e WERLANG (2006), 36\% dos adolescentes pesquisados apresentaram ideação suicida, se tornando necessário pensar na intensidade e abrangência da problemática que se está enfocando. Tais jovens podem expressar algo que vai além das características próprias da adolescência, como um importante sofrimento decorrente de um conflito interno, vislumbrando a possibilidade de morte como alternativa.

As autoras acreditam que para uma perspectiva preventiva, torna-se essencial identificar adolescentes com ideação suicida, já que este pode ser o primeiro passo para o suicídio, principalmente, quando associada a aspectos de depressão e desesperança. Desta forma, destaca-se a importância de programas de prevenção que evitem que as pessoas desenvolvam comportamentos suicidas ou adotem condutas autodestrutivas (BORGES e WERLANG, 2006).

É necessário que os distúrbios psicológicos da maternidade sejam referenciados pelos profissionais da saúde mental. A atuação preventiva das equipes multidisciplinares, nesse período, pode proporcionar à nova mãe o apoio de que necessita para enfrentar os eventuais episódios de depressão. 0 atendimento precoce à mãe deprimida representa a possibilidade da prevenção do estabelecimento de um padrão negativo de interação com o bebê, o qual pode trazer importantes repercussões para o seu desenvolvimento posterior (COUTINHO; SARAIVA, 2008a). 


\section{CONCLUSÃO}

O presente estudo revelou dados importantes no que tange à saúde da "mulher menina adolescente e puérpera" concomitantemente. A exemplo de qualquer atenção a saúde de caráter holístico, sério, competente e atualizado, se procurou a compreensão dos aspectos depressivos no puerpério da adolescente sem ignorar sua condição de mulher, de adolescente, de estudante, de filha-mãeesposa, enfim, de cidadã brasileira. Foram investigadas as relações da depressão puerperal nesta população com aspectos socioeconômicos, obstétricos, geográficos, e epidemiológicos.

Respondendo ao objetivo inicial do estudo de determinar a prevalência do transtorno depressivo em puérperas adolescentes que são atendidas nas Unidades da Estratégia de Saúde da Família do Município de Embu Guaçu, foi revelado que a prevalência da depressão puerperal foi de 39\% ( $n=18)$ com IC95\% (25\%; 54\%). Este intervalo de confiança indica que a prevalência varia neste intervalo, com nível de confiança de $95 \%$.

Das 18 puérperas adolescentes com escores maior ou igual a 12 segundo a EPDS, apenas quatro delas $(22,2 \%)$ relataram dificuldades com o autocuidado relacionadas a sono, alimentação, autocuidado e lazer.

Atentando para as puérperas com pontuação menor que 12, apenas quatro (14\%) relacionaram mudanças negativas quanto ao autocuidado, sono, lazer e apetite após o nascimento do bebê. Uma delas verbalizou que a ideia de fazer mal a si mesma só havia passado pela sua cabeça enquanto estava grávida, sendo que sua pontuação na EPDS foi 11 . Foram rastreadas $15,21 \%$ (7) das puérperas adolescentes com escores maior ou igual a 9 e menor que 12 que apesar de não terem pontuação diagnóstica necessitam um minucioso olhar por parte dos profissionais de saúde para minimizar a possibilidade de evolução para um transtorno depressivo.

No que diz respeito às características sociodemográficas das adolescentes puérperas da amostra, os achados deste estudo revelaram que as adolescentes com o risco de transtorno depressivo parecem ser mais novas do que os seus parceiros, têm filhos com cerca de 5 meses, moram juntos com parceiros, são brancas, com curso médio incompleto. São brancas, com curso médio incompleto. 
Pouco mais da metade tem renda de até oitocentos reais, a maioria usa algum tipo de medicamento e não utiliza drogas ou substâncias ilícitas. As adolescentes estavam predominantemente na faixa etária dos 14 aos 19 , com mediana em 18 anos. Nos companheiros predominou a faixa 20 aos 31 anos, com idade média de 22,5 anos. 92,85\% das puérperas com escore maior ou igual a 12 eram primigestas e daquelas que pontuaram menos que 12, 92,85\% também só tinham 1 filho.

Em $61,11 \%$ das adolescentes foi constatado ensino médio completo ou incompleto. As demais $(33,33 \%)$ relataram ensino fundamental completo ou incompleto. Uma das adolescentes cursava Ensino Superior.

A renda familiar mensal referida ficou em torno de um e um e meio salário mínimo em aproximadamente $50 \%$ das respostas. $16,67 \%$ das entrevistadas relataram ganhos familiares em torno de quatro salários mínimos. O restante das adolescentes não sabia estimar quanto o companheiro recebia mensalmente.

Ao serem analisadas questões relacionadas à habitação ou moradia foi evidenciado que grande parte das adolescentes pesquisadas mora em casas de alvenaria, com menos do que 5 cômodos, com água encanada, fogão à gás, geladeira, máquina de lavar roupa, telefone e TV. Contudo, mora em casa sem esgoto, computador e telefone.

Sobressaiu e preocupou a descoberta que $66,67 \%$ das adolescentes não tem filtro, em $22 \%$ das moradias não existe a coleta de lixo, sendo mencionados como destino do mesmo "queimá-lo" e "jogar no terreno" e em $22,22 \%$ das moradias e quanto à rede de esgoto $83,33 \%$ das residências não tem acesso.

Aspectos que dizem respeito à maternidade em si foram considerados e registrados segundo a impressão e declaração de cada puérpera adolescente. Os resultados atestam que aproximadamente a metade dos familiares e mais da metade dos parceiros das adolescentes com o risco de transtorno depressivo teve uma boa reação quando descobriu a gravidez delas. Existe evidência consistente de que a qualidade do relacionamento entre o casal se associa fortemente à saúde mental pós-natal das mulheres. A qualidade de tal relação se configurará como fator protetor ou destrutivo (HOROWITZ; DAMATO; SOLON, 2005).

A maioria das adolescentes não parou de estudar por conta da gravidez, estava na primeira gravidez, vivenciou o parto normal, fez 15 consultas pré-natais, não faltou às consultas pré-natais e teve ajuda da mãe ou pai ou de dois ou mais familiares nos primeiros meses de vida do bebê. 
Os resultados deste estudo mostraram que as adolescentes puérperas sentem necessidade da ajuda da família após o nascimento do bebê, categorizando-a em ajuda doméstica, ajuda emocional e ajuda já prestada. Os membros da família que mais prestavam ajuda foram mencionados como cunhada, sogra, tio, ACS que era tia, mãe, marido, avó, amiga, pai do bebê e toda família.

Foram sugeridas como de ajuda por parte da ESF: o pediatra não explica nada, é muito seco, a sala de espera é cheia e demora; ser mais pontual nas consultas médicas e dar mais informação; atender bem; passar só com o médico; tratar bem, conversar; ter pediatra de $2^{\mathrm{a}}$ a $6^{\mathrm{a}}$ feira. Atitudes de gratidão também foram verbalizadas pelas adolescentes em relaça ao atendimento pela ESF: tudo o que já tem feito me orientando; já me ajudam bastante; quando tenho dúvida eu sempre pergunto; já fazem tudo; tudo que eu preciso eles já fazem; nada.

A maioria das adolescentes é atendida na UESF do Jardim Progresso (77,78\%), seguida da UESF Penteado e por último a UESF Sapateiro. A maior parte destas adolescentes tinha mais contato com as enfermeiras, durante o prénatal e após o parto, morava longe das unidades da saúde, tinha algum problema para receber os remédios destas unidades de saúde. Porém, elas não tinham dificuldade para marcar as consultas e as consultas de pré-natal esclareciam as suas dúvidas.

Acredita-se que estes resultados em muito contribuirão para planejamentos futuros que gerem discussões e inovações quanto atendimento das puérperas adolescentes nas Unidades de Estratégia da Saúde da Família (UESF). O desvelar da prevalência da depressão puerperal nos locais da coleta de dados bem como o conhecimento dos aspectos sócio demográficos associados a realidade das adolescentes possibilitará as ESF redirecionarem seu atendimento de forma efetiva e pautada na realidade objetiva que vivenciam. A cultura vigente em nosso país tem esperado das mães uma atitude sempre terna, acolhedora e disponível, sem nunca demonstrar sentimentos de tristeza, afinal, tudo isso está ligado ao "milagre da vida" que pressupõe um instinto materno é uma predisposição inata para o sacrifício. Para algumas mulheres, se opor a essa visão romanceada da maternidade significa opor-se à feminilidade. Desta maneira, a mãe moderna vive sentimentos de culpa, e frustração e conflitos de identidade, sem permissão para sentimentos ambivalentes quanto à maternidade. O natural passa a ser o sacrifício e o amor irrestrito (AZEVEDO; ARRAIS, 2006). 
Segundo o pensamento das autoras modelo de "naturalidade" traduz para a mulher que não vivencia tal sacrifício e amor que seus sentimentos estão essencialmente errados, trazendo uma sobrecarga emocional ainda maior.

$\mathrm{Na}$ família moderna, ainda que o pai esteja mais presente em casa, a mãe continua sendo o maior parâmetro para os filhos pequenos. É ela quem continua com a maior parte das responsabilidades junto a casa e aos filhos, quem controla e cria os filhos e quem thes dá uma imagem do mundo. Há uma nova mulher, mas que vive sendo idealizada por velhas representações, pois continuamos cobrando delas o velho modelo de mãe idealizada. Muitas mulheres de hoje, já não são preparadas, não sabem e nem querem cuidar dos seus filhos como suas mães faziam. Elas têm outros interesses, desejos, informações, expectativas e, sobretudo alternativas para se realizarem como mulher, que não estão mais restritas à maternidade. Acontece assim um conflito na vivência do papel moderno de mãe, que acarreta mais dúvidas, angústias e se manifesta como culpa pela ambivalência materna (AZEVEDO; ARRAIS, 2006).

Diante da impossibilidade de muitas mães corresponderem a todas estas expectativas de felicidade incondicional, sacrifício, disponibilidade emocional entre outras, muitas vezes adoecem física e emocionalmente, sendo necessária uma atenção rápida, coerente e eficiente para minimizar as desabilidades emocionais e fortalecer qualidades e virtudes.

O amor materno nem sempre brota espontaneamente nas mulheres imediatamente após o parto. É um processo que se constrói dia a dia na vivência diária da mãe com seu bebê, sujeito a imperfeições, oscilações e modificações, o que trouxe para as mães, de forma geral, grande alívio (AZEVEDO; ARRAIS, 2006).

Avaliações tanto biológicas como psicossociais inerentes à maternidade $\mathrm{e}$ ao bebê deveriam começar já no início da gestação a fim de possibilitar a elaboração de identificação eficiente de fatores de risco e das mulheres em risco. Esta simples ação facilitaria o desenvolvimento de intervenções preventivas bem como tratamentos. Também proveria ferramentas para influenciar decisões políticas e desenvolvimento de sistemas de saúde do parto para as mulheres (HALBREICH; KARUN, 2006). 
A EPDS é um excelente instrumento para a detecção da dimensão da depressão no puerpério. No entanto é necessário o desenvolvimento de ferramentas culturalmente sensíveis para uma gama de desordens no puerpério. Há culturas onde formulários autoaplicados têm a tendência de receberem sempre alternativas negativas. Nestes casos se torna necessário à aplicação de entrevistas culturalmente sensíveis que tenham seu foco nas necessidades, queixas e sintomas pertinentes ao local e a cultura, mesmo que sejam muito diferentes dos modelos ocidentais (HALBREICH; KARUN, 2006).

Apesar de a adolescência ter se tornado tema muito presente nas pesquisas científicas no Brasil e no mundo, ainda existem questões que devem ser melhor exploradas, para que os adolescentes possam viver em plenitude essa fase tão importante de suas vidas. A gravidez na adolescência é questão de interesse não apenas por parte da classe médica e dos gestores de saúde em nosso país, mas também por parte da população. Há que se dedicar maior atenção à saúde mental dessas jovens que tão precocemente e às vezes sem assim o desejarem, são alçadas à condição de mães sem estarem preparadas para tal (MENESES, 2008).

No estudo de MENESES (2008) foi observada uma prevalência bastante relevante de transtornos mentais comuns entre as gestantes adolescentes analisadas. Tal achado suscita reflexões acerca de como essas meninas estão sendo recebidas e orientadas nos diversos serviços de saúde a que recorrem. É importante analisar e tentar interferir positivamente nas redes sociais de apoio que têm essas jovens, uma vez que elas necessitam sobremaneira de apoio por parte da família e de amigos, para que consigam vencer essa etapa conturbada de suas vidas sem maiores prejuízos emocionais (MENESES, 2008).

Segundo achados de CARIFETE (2009), um número expressivo de gestações ocorre em jovens, despertando a necessidade de implementação de serviços de educação sexual e de planejamento familiar para jovens, principalmente em países com condições econômicas e sociais deficitárias para o acolhimento de mães excessivamente jovens e de seus filhos.

CARIFETE (2009) concluiu em sua tese que as mulheres de zonas rurais estarão particularmente desprotegidas em relação a cuidados obstétricos enquanto puérperas provenientes de meio urbano apresentam níveis superiores de instrução e níveis socioeconômicos mais altos. 
A maioria das mulheres da zona rural revelou ter baixa escolaridade, com taxa de analfabetismo em $6 \%$. Metade delas exercia trabalhos indiferenciados ou estava desempregada. As mulheres com emprego eram na sua esmagadora maioria casadas ou com companheiro. Desse modo a larga maioria das mulheres pertencia a classes sociais mais desfavorecidas (CARIFETE, 2009).

As condições em que o estudo foi realizado permitiram identificar $15 \%$ de depressão puerperal nesta amostra. $\mathrm{O}$ grupo de mulheres identificadas como deprimidas tem uma maior percentagem de antecedentes pessoais, maior número de episódios depressivos e uma maior presença de fatores de risco (CARIFETE, 2009).

A construção das representações sociais da experiência materna se encontra ancorada na mediação das suas vivências e das suas lembranças, envolvidas nas adversidades psicossociais que histórica e socialmente as acompanharam durante 0 desenvolvimento das fases que antecederam 0 nascimento de seus bebês. Dentre as manifestações psico cognitivas da depressão pós-parto, emergem situações preocupantes, relacionadas a pensamentos mórbidos, fazem prever a possibilidade da concretização de condutas destrutivas a serem exercidas por essas mães, com foco em si e em seus bebês (SARAIVA; COUTINHO, 2008b).

Faz-se sentir assim uma necessidade de programas diferenciados de políticas públicas de saúde coletiva, voltados para a comunidade feminina durante sua fase reprodutiva. Não é mais admissível que a comunidade acadêmica, particularmente no que se refere aos especialistas das diversas áreas do saber, continue ignorando verdades simples e triviais como as referentes às mães puérperas, comprovando o quanto o pensamento dito ingênuo veicula significado e merece atenção (SARAIVA; COUTINHO, 2008b).

Revisão de PAULA; MIRANDA e BORDIN (2010) aponta para um crescente número de pesquisadores brasileiros interessados em estudar o campo da saúde mental de crianças e adolescentes, com dados nacionais mais consistentes. Os problemas de saúde mental se revelaram frequentes em crianças e adolescentes brasileiros com prevalência variando entre 12 e $24,6 \%$ ao serem usados instrumentos rastreadores e entre 7 e $12 \%$ com o uso de entrevistas diagnósticas. 
São considerados fatores de risco: crianças adolescentes vivendo em condições socioeconômicas desfavoráveis, vítimas de punições físicas ou expostas a discórdias familiares e filhos de mulheres com transtornos mentais (PAULA; MIRANDA; BORDIN, 2010).

O conjunto articulado de saberes e práticas focadas na saúde mental infanto-juvenil é uma construção recente, sendo sua história relativamente distinta da psicopatologia em adultos. Estudos e cuidados relacionados à psiquiatria infantil se originaram a partir de manifestações percebidas em escolas. As atividades de médicos interessados na psiquiatria infanto-juvenil acabavam por retratar uma derivação quase mecânica da psicopatologia adulta para crianças e adolescente (REIS et al., 2010). Termos relacionados a incapacidades intelectuais, centrada nos déficits foram os primeiros a serem formulados genuinamente na psicopatologia infanto-juvenil. As percepções foram sendo refinadas e se percebeu que a questão de saúde ou doença mental não se limitava aos bancos escolares, mas refletiam dificuldades de ordem social (REIS et al., 2010).

A partir daí, diversas iniciativas em prol da criança e dos adolescentes surgiram em vários países ao redor do mundo, sendo importantíssimas na formação do campo da saúde mental infanto-juvenil. Só no início do século $X X$ foi reconhecido o uso de ferramentas como testes psicométricos, teorias sobre a sexualidade infantil, neurose em crianças, entre outros. Até 1930 os psiquiatras adultos não conheciam a criança e os pediatras não entendiam de psiquiatria.

Para a consolidação da política de saúde mental atual, os Centros de Atenção Psicossocial Infanto-juvenil (CAPSi) se configuraram como o principal equipamento público na atenção à saúde mental de crianças e adolescentes, se articulando à rede de equipamentos existentes na comunidade (BRASIL, 2007).

O pensar, elaborar, atuar ou efetivar políticas, projetos, atividades e ações voltadas para a saúde requerem especificidade de acordo com a população a ser contemplada. Só assim poderá ser apresentada uma proposta efetiva e viável. Em se tratando de uma população de crianças e adolescentes, é necessária a percepção de que as necessidades dos mesmos estão em constante transformação (LEONE e GALLO, 2010). 
O professor Pedro de Alcantara é muito oportunamente lembrado por LEONE e GALLO (2010) quando define que a atenção à criança deve ser sempre global. Este conceito implica que qualquer atendimento prestado à criança (e certamente também ao adolescente) não deve ser focada apenas na queixa atual, mas na fase de desenvolvimento, com suas possibilidades e riscos a fim de prevenir futuros agravos e promover a saúde desta população.

Recentemente consolidou-se um modelo universal realmente efetivo de prevenção da depressão puerperal. WWWT é um modelo de operacionalização da saúde mental da mulher, que atua em nível individual procurando modificar fatores de seu ambiente social mais do que aspectos internos da mulher: relacionamento com o pai do bebê e com o bebê; saúde mental pós-parto como responsabilidade da família toda; promoção do funcionamento familiar e maternidade/paternidade confiante (ROWE; FISHER, 2010).

Fica assim a expectativa de que tal modelo preventivo realmente seja universalizado de modo a prevenir as dores psíquicas de tantas mulheres com eficiência e cientificidade. Intervenções com tal enfoque melhorarão não apenas a qualidade de vida da mãe, mas também privilegiará o relacionamento entre mãe, bebê, pai, irmãos e familiares que compõe a realidade da família.

A imersão na realidade das puérperas adolescentes, tanto em seus aspectos sociais como em suas emoções e sentimentos, revelou um universo muitas vezes não compreendido pelos adultos tanto da família quanto da atenção primária à saúde. O exercício da empatia facilita percepções e descobertas que não se efetivariam de outra maneira a não ser o contato próximo e frequente com essas meninas. A percepção do estado emocional do outro facilita uma conexão emocional, se tornando uma das características mais importantes em uma relação terapêutica, auxiliando o cliente a identificar sentimentos que vem sendo negados ou suprimidos.

A despeito de situações adversas aos olhos da pesquisadora fazerem parte do cotidiano das adolescentes desta pesquisa, aparentemente a grande maioria elabora satisfatoriamente essa vivência, se adaptando e descobrindo maneiras de interpretar as dificuldades de maneira divertida, por vezes exaltada e irritadiça, e também pessimista, características da adolescência que as abriga. 
Espera-se que a releitura do transtorno depressivo pós-parto na adolescência e a descoberta de aspectos sociodemográficos e emocionais provavelmente ainda não identificados não apenas contribua para uma reinvenção nas estratégias de atenção à adolescente no Município de Embu Guaçu, mas que possa ser generalizada para outros municípios com características semelhantes ao local da pesquisa. 


\section{REFERÊNCIAS BIBLIOGRÁFICAS}

AGUINAGA, C. S. et al. Prevalencia de depresión en la adolescente embarazada y su repercusión en el peso del recién nacido. 1999. Dissertação (Especializaçao) - Universidad Central del Ecuador, Facultad de Ciencias Médicas, Quito. A

AGUINAGA C. S. et al. Estudio de depresión en la adolescente embarazada. Rev. CIEZT, v. 4, n.5, p.134-139, 1999 b.

ALEHAGEN, S.; WIJMA, K..; WIJMA, B. Fear during labor. Acta Obstet Gynecol Scand, Denmark, v.80, n.2, p. 315-320, 2001.

APA - American Psychiatric Association: Diagnostic and Statistical Manual of Mental Disorders, Fourth Edition, Text Revision. Washington, DC: American Psychiatric Association, 2000, p. 323-329.

ANDRADE, L.O.M. et al. Atenção primária e estratégia saúde da família. In: CAMPOS et al. (Org.). Tratado de saúde coletiva. 2.ed. São Paulo: Ucitec; Rio de Janeiro: Fiocruz, 2009. p. 802-807.

ANDRADE, L.H.S.G. et al. Epidemiologia dos transtornos psiquiátricos na mulher. Rev. Psiq. clín., São Paulo, v. 33, n. 2, p. 43-54, 2006.

ANTUNES, H.M.; CAMPOS, C.J.G. Pais e responsáveis do adolescente deprimido: buscando conhecer experiências que levaram à procura de atendimento especializado.

Rev Esc Enferm USP, v.41, n.2, p.205-212, 2007.

ARAUJO, L.C.; VIEIRA, K.F.L; COUTINHO, M.P.L. Ideação suicida na adolescência: um enfoque psicossociológico no contexto do ensino médio. PsicoUSF, Itatiba, v.15, n.1, p.47-57, jan./abr. 2010.

AYERS, S. Thoughts and emotions during traumatic birth: a qualitative study. Birth, v.34, n.3, p. 253-63. 2007. 
AZEVEDO, K.R.; ARRAIS, A.R. O Mito da Mãe Exclusiva e seu Impacto na Depressão Pós-Parto. Psicol. reflex. crit, v.19, n.2, p.269-276. 2006.

BAHLS, SC. Aspectos clínicos da depressão em crianças e adolescentes. J.Pediatr., Rio de Janeiro, v.78, n.5, p.359-366. 2002a.

BAHLS, SC. Epidemiologia de sintomas depressivos em adolescentes de uma escola pública em Curitiba, Brasil. Rev. Bras. Psiquiatr., São Paulo, v.24 n.2, p.63-67, jun. 2002b.

BANDEIRA, M. et al. Avaliação da ocorrência de transtornos mentais comuns em usuários do Programa de Saúde da Família. J. bras. Psiquiatr, Rio de Janeiro, v.56, n.1, p.41-47. 2007.

BAPTISTA, M.N.; BAPTISTA, A.S.D.; TORRES, E.C.R. Asociación entre soporte social, depresión y ansiedad en embarazadas. Psic, São Paulo, v.7, n.1, p.39-48, jun. 2006.

BARBOSA, E.M.S. et al. Depressão pós-parto na adolescência: um problema relevante? Rev Saúde Pública, v.40, n.5, p. 935-937. 2006. Carta ao editor.

BARROS et al. 2007. As representações sociais da depressão em adolescentes no contexto do ensino médio. Estud. Psicol, Campinas, v.23 n.1 jan.-mar. 2006.

BARROS, M.E.R.; KÜMPEL, M. Manifestações, fatores predisponentes e sintomas da depressão puerperal em adolescentes de uma unidade básica de saúde do município de Itapecerica da Serra. 2007. 43p. Monografia de conclusão de curso (Graduação em Enfermagem) - Centro Universitário Adventista de São Paulo, São Paulo.

BASSO, J.F.; MONTICELLI, M. Expectativas de participação de gestantes e acompanhantes para o parto humanizado Rev. Latino-Am. Enfermagem, v.18, n.3, p.97-108, mai.-jun. 2010. 
BENINCASA, M.; REZENDE, M.M. Tristeza e suicídio entre adolescentes. Bol. Psicol, São Paulo, v.55, n.124, p.93-110, jun. 2006.

BENNETTI, H. A. et al. - Prevalence of depression during pregnancy: systematic review. Obstet Gynecol, v.103, n.4, p.698-709. 2004.

BESSA, M.A. et al. Correlatos do uso de substâncias durante a gravidez na adolescência em São Paulo. Rev. Bras. Psiquiatr., Brasil, v.32, n.1, p.66-67, mar. 2010.

BICK, D.; BASTOS, M.H.; DINIZ, S.G. Revelando o potencial do cuidado eficaz para a saúde maternal e infantil por toda vida: a necessidade de abordar o serviço 'invisível' no período pós-natal. Rev Esc Enferm USP, São Paulo, v. 42, n. 3, sep. 2008. Editorial.

BLOCH, M.; DALY, R. C.; RUBINOW, D.R. - Endocrine factors in the etiology of postpartum depression. Compr Psychiatry, v.44, n.3, p.234-246, 2003.

BORGES, V.R.; WERLANG, B.S.G. Estudo de ideação suicida em adolescentes de 15 a 19 anos. Estud. psicol, Natal, v.11, n.3, p.345-351, set.-dez. 2006.

BOYCE, P. M. et al. Functioning and well-being at 24 weeks postpartum of women with postnatal depression. Archives of Women's Mental Health, Hamilton, Canadá, v. 3, n.3, p. 91-97, 2000.

BRASIL Estatuto da Criança e do Adolescente (ECA). Lei o 8.069 de 13 de julho de 1990. Dispõe sobre o Estatuto da Criança e do Adolescente e dá outras providências. Brasília, DF, 1990.

BRASIL. Ministério da Saúde. Portal da Saúde. Acompanhante no parto traz mais segurança para a mãe. Disponível em http://portal.saude.gov.br/portal/saude/visualizar texto.cfm?idtxt=24112; acessado em 12/09/2010, 2005d. 
BRASIL.Ministério da Saúde. Secretaria de Atenção à Saúde. Departamento de Ações Programáticas Estratégicas. Área Técnica de Saúde da Mulher. Pré-natal e puerpério: atenção e qualificada e humanizada. Manual Técnico. Brasilia,DF, 2006.

BRASIL. Ministério da Saúde. Secretaria de Atenção à Saúde. Área de Saúde do Adolescente e do Jovem. Marco legal: saúde, um direito de adolescentes / Ministério da Saúde, Secretaria de Atenção à Saúde, Área de Saúde do Adolescente e do Jovem. - Brasília : Ministério da Saúde, 60 p.: il. - (Série A. Normas e Manuais Técnicos) 2005a.

BRASIL. Ministério da Saúde. PNDS (Programa Nacional de Demografia e Saúde da Criança e da Mulher. 2006a. Acessado em 29/11/2010, disponível no formato eletrônico em http://bvsms.saude.gov.br/bvs/pnds/morbidade feminina.php.

BRASIL. Secretaria de Assuntos Estratégicos da Presidência da República. Comunicados do IPEA n ${ }^{0}$ 64. PNAD 2009 - Primeiras Análises: Tendências Demográficas. 2010. Acessado em 29/11/2010, disponível no formato eletrônico em http://www.ipea.gov.br.

BRASIL. Ministério da Saúde. Secretaria de Atenção à Saúde. Departamento de Ações Programáticas Estratégicas. Caminhos para uma política de saúde mental infanto-juvenil / Ministério da Saúde, Secretaria de Atenção à Saúde, Departamento de Ações Programáticas Estratégicas. - 2. ed. rev. - Brasília: Editora do Ministério da Saúde, 2005.72 p. - (Série B. Textos Básicos em Saúde) 2005c.

BRASIL. Ministério da Saúde. Secretaria de Atenção à Saúde. Saúde integral de adolescentes e jovens: orientações para a organização de serviços de saúde / Ministério da Saúde, Secretaria de Atenção à Saúde. - Brasília: Editora do Ministério da Saúde, 44p.: il. - (Série A. Normas e Manuais Técnicos) 2005b. 
BRASIL. Ministério da Saúde. Secretaria de Atenção à Saúde. Núcleo Técnico da Política Nacional de Humanização. Clínica ampliada, equipe de referência e projeto terapêutico singular / Ministério da Saúde, Secretaria de Atenção à Saúde, Núcleo Técnico da Política Nacional de Humanização - 2. ed. - Brasília: Ministério da Saúde, 60 p. : il. color. - (Série B. Textos Básicos de Saúde), 2007.

BRASIL. Ministério da Saúde. 20 anos de pesquisas sobre aborto no Brasil. Brasília, DF: Ministério da Saúde; 2009.

BROCKINGTON, I. Postpartum psychiatric disorders. Lancet, v.363, n.9414, p.1077-1078. 2004.

BRUM, E.H.M. A depressão materna e suas vicissitudes. PSYCHÊ, São Paulo, ano X, n.19, p.95-108, set.-dez. 2006.

BURKE, L. (2003). The impact of maternal depression on familial relationships. International Review of Psychiatry, v.15, n.3, p.243-255, aug. 2003.

CAMACHO, R.S. et al. Transtornos psiquiátricos na gestação e no puerpério: classificação, diagnóstico e tratamento. Rev. Psiq. Clín., São Paulo, v. 33, n. 2, p. 92-102, 2006.

CAMPOS, A. P.; ROMAGNOLI, R. C. Os Encontros Entre os Agentes Comunitários de Saúde e as Famílias dos Portadores de Transtorno Mental. Mental, Barbacena, n.9, ano V, p.79-99, nov. 2007.

CANTILINO, A. et al. Validação da escala de depressão pós-parto de Edimburgh no nordeste do Brasil, 2006. Acessado em 20/08/2010; disponível em http:// www.virtualpsy.org/neurociencia/anais2.html.

CANTILINO, A. et al. Validação da escala de depressão pós-parto de Edinburgh (versão em português) no Nordeste do Brasil. Trabalho apresentado no XXI Congresso Brasileiro de Psiquiatria, 2003, Goiânia, GO. 
CAPUTO, V.G.; BORDIN, I.A. Problemas de saúde mental entre jovens grávidas e não-grávidas. Rev. Saúde Pública, São Paulo, v.41 n.4, p.573-581, ago. 2007.

CARIFETE, N. G. Patologia Afectiva Pós-parto em Mulheres Angolanas. 2009. 131p. Dissertação de mestrado - Faculdade de Medicina da Universidade do Porto, Porto.

DE CARVALHO, M.H.B.; FRANCISCO, R.P.V.; BRIZOT, M.L. Pré-natal. In: ZUGAIB, M. (Ed). Obstetrícia. Barueri: Manole, 2008. p.196.

CHALEM, E. et al. Gravidez na adolescência: perfil sóciodemográfico e comportamental de uma população da periferia de São Paulo, Brasil. Cad. Saúde Pública, Rio de Janeiro, v.23, n.1, p.177-186, jan. 2007.

COSTA R.; PACHECO A.; FIGUEIREDO B. Prevalência e preditores de sintomatologia depressiva após o parto. Rev. Psiq. clín, v.34, n.4, p.157-165, 2007.

COUTINHO, M.P. de L.; SARAIVA, E.R.de A. Depressão pós-parto: considerações teóricas. Estud. pesqui. psicol, Rio de Janeiro, v.8, n..3, p.759773, dez. 2008a.

COUTINHO, M.P.de L.; SARAIVA, E.R.de A. As Representações Sociais da Depressão Pós-parto Elaboradas por Mães Puérperas. PSICOLOGIA CIÊNCIA E PROFISSÃO, v.28, n.2, p.244-259, 2008b.

CREEDY, D.K.; SHOCHET, I.M.; HORSFALL J. Childbirth and the development of acute symptoms: Incidence and contributing factors. Birth; v.27, n. 2, p.104-111, jun. 2000.

CRIVELATTI, M.M.B.; DURMAN, S.; HOFSTATTER, L.M. Sofrimento psíquico na adolescência. Texto Contexto Enferm, Florianópolis, v.15, Ed.Esp, p. 64-70, 2006. 
CRUZ, E.B.S.; SIMÕES, G.L.; FAISAL-CURY, A. Post-partum depression screening among women attended by the Family Health Program. Rev. Bras. Ginecol. Obstet., Rio de Janeiro, v.27, n.4, p.181-88, apr. 2005.

CZARNOCKA J, SLADE P. Prevalence and predictors of post-traumatic stress symptoms following childbirth. British Journal of Clinical Psychology, v.39, p.35-51, 2000.

D'OLIVEIRA, A.F.PL.; DINIZ, S.G.; SCHRAIBER, L.B. Violence against women in health care institutions: an emerging issue. Lancet, v.359, n. 9318, p.1681-1685, may. 2002.

DA SILVA et al. Depressão durante a gravidez no sistema público de saúde. Rev Bras de Psiquiatr. v.32, n.2, p.139-144, jun. 2010.

DAVIES, B.R.; HOWELLS, S.H.; JENKINS, M. Early detection and treatment of postnatal depression in primary care. Journal of Advanced Nursing, v.44, n.3, p.248-255, 2003.

DELL'ÁGLIO, D.D.; HUTZ, C.S. Depressão e desempenho escolar em crianças e adolescentes institucionalizados. Psicol. reflex. crit., Porto Alegre, v.17, n.3, p.345-350, 2004.

DE PAULA, C.S.; DE MIRANDA, C.T.; BORDIN, I.A.S. Saúde mental na infância e adolescência: revisão dos estudos epidemiológicos brasileiros. In: LAURIDSENRIBEIRO, E.; TANAKA, O.Y. (Orgs.). Atenção em saúde mental para crianças e adolescentes no SUS. São Paulo: Hucitec, 2010. p. 87-89.

DENNIS, C.L.; CREEDY, D. Psychosocial and psychological interventions for preventing postpartum depression (Cochrane Review). In: The Cochrane Lybrary, Issue 4, 2006. Oxford: Update Software.

DENNIS, C.L. Can we identify mothers at risk for postpartum depression in the immediate postpartum period using the Edinburgh Postnatal Depression Scale? Journal of Affective Disorders, v.78, n.2, p.163-169, 2004. 
DE ROSA, N.; LOGSDON, M.C.A. Comparison of screening instruments for depression in postpartum adolescents. J Child Adolesc Psychiatr Nurs, v.19, n.1. p.13-20, feb. 2006.

DINIZ, D.; MEDEIROS, M. 0254/2010 - Aborto no Brasil: uma pesquisa domiciliar com técnica de urna. 2010. Acessado em 29/11/210, disponível no formato eletrônico em

http://www.ccr.org.br/uploads/noticias/PesquisaANISAbortonobrasil.pdf

DINIZ, S.G. et al. Empowering women in Brazil. Lancet, v.370, n.9599, p.15961598, nov. 2007.

DINIZ, S.G.; CHACHAM, A.S. O "corte por cima" e o "corte por baixo": o abuso de cesáreas e episiotomias em São Paulo. Questões de Saúde Reprodutiva, n.I, v.1, p.80-9, 2006.

DUTRA, E.M.S. Depressão e suicídio em crianças e adolescentes. Mudanças, v.9, n.15, p.27-35, jan.-jun. 2001.

EMBU GUAÇU - Prefeitura Municipal. 2003, disponível em http://www.embuguacu.sp.gov.br/portal/HOME/tabid/36/language/pt-

BR/Default.aspx; acessado em outubro de 2007.

ENKIN, M. et al. Guia para atenção efetiva na gravidez e no parto. 3 ed. Rio de Janeiro: Guanabara Koogan, 2005.

EVINS, G.G.; THEOFRASTOUS, J.P.; GALVIN, S.L. Postpartum depression: a comparison of screening and routine clinical evaluation. Am J Obstet Gynaecol, v. 182, n.5, p.1080-1082, may. 2000.

FALCONE, V.M et al. Atuação multiprofissional e a saúde mental de gestantes. Rev Saúde Pública, v.39, n.4, p.612-8, ago. 2005.

FELIX, G.M.A.; GOMES, A.P.R. FRANCA, P.S. Depressão no ciclo gravídicopuerperal. Com. Ciências Saúde, v.19, n.1, p.51-60, jan.-mar. 2008. 
FERREIRA, F. M. O.; et al.. Atenção e Reabilitação Psicossocial: uma revisão bibliográfica conceitual. Nursing, v. 85, n. 8, p. 277-281, jun. 2005.

FIGUEIRA, P. et al. Escala de Depressão Pós-natal de Edimburgo para triagem no sistema público de saúde; Rev Saúde Pública, v.43, suppl.1, p. 79-84, 2009.

FIGUEIREDO, B. Maternidade na adolescência: consequências e trajectórias desenvolvi mentais. Análise Psicológica, Lisboa, v.18 n.4, p.485-498, 2000.

FIORATI, R. C.; SAEKI, T.. O Acompanhamento Terapêutico na Internação Hospitalar: inclusão social, resgate de cidadania e respeito à singularidade. Interface comum. saúde, educ, Botucatu. v.12, n. 27, p.763-772, out.-dez. 2008.

FISHER, J.R.W.; WYNTER, K.H.; ROWE, H.J. Innovative psycho-educational program to prevent common postpartum mental disorders in primiparous women: a before and after controlled study .BMC Public Health, v.10, n.432, 2010.

FONSECA, V.R.J.R.M.; DA-SILVA, G.A.; OTTA, E. Relação entre depressão pósparto e disponibilidade emocional maternal. Cad. Saúde Pública, Rio de Janeiro, v.26, n.4, p.738-746, abr. 2010.

FONSECA, M.H.G.; FERREIRA, R.A.; FONSECA, S.G. Prevalência de sintomas depressivos em escolares. Pediatria, São Paulo, v.27, n.4, p.223-232, 2005.

FONTANA, A.M.; FONTANA, M.C.P.S. Transtornos do humor. In: Manual de clínica em psiquiatria. São Paulo: Atheneu; 2005. p.295-316.

FREITAS, G.V.; BOTEGA, N.J. Prevalence of depression, anxiety and suicide ideation in pregnant adolescents. Rev Assoc Med Bras., v.48, n.3, p.245-249, sep. 2002.

FRIZZO, G.B.; KAHL, M.L.F; OLIVEIRA, E.A. F. Aspectos psicológicos da gravidez na adolescência. Psico, v.36, n.1, p.13-20, jan.-abr. 2005. 
GAMA S.G.N. et al. Fatores associados à assistência pré-natal precária em uma amostra de puérperas adolescentes em maternidades do Município do Rio de Janeiro, 1999-2000. Cad Saúde Pública, Rio de Janeiro, v.20, suppl. 1, p.101111. 2004.

GONTIJO, D.T.; MEDEIROS, M. Gravidez / maternidade e adolescentes em situação de risco social e pessoal: algumas considerações. Revista Eletrônica de Enfermagem, v. 06, n. 03, p. 394-399, 2004. Disponível em www.fen.ufg.br, acessado em 13/10/2010.

GOODMAN, J. H. Paternal postpartum depression, its relationship to maternal postpartum depression, and implications for family health. Journal of Advanced Nursing, v.45, n.1, p.26-35, jan. 2004.

GRAHAM, N. et al. Redução da Estigmatização e da Discriminação das Pessoas Idosas com Transtornos Mentais: uma declaração técnica de consenso. Rev Psiq clín, São Paulo. v.34, n.1, p.34-39, 2007.

HALBREICH U, KARKUN S. Cross-cultural and social diversity of prevalence of postpartum depression and depressive symptoms. J Affect Disord, v.91, n.2-3, p.97-111, apr. 2006.

HEAVEY, E. J. et al. Differences in pregnancy desire among female adolescents at a state-funded family planning clinic. J Midwifery Womens Health, v.53, n.2, p.130-137, mar. 2008.

HENDRICK, V. Treatment of postnatal depression. BMJ. v.327, n.7422, p.10031004, nov.2003

HETEM, L.A.B.; GRAFF, F.G. Transtornos de ansiedade. Rio de Janeiro: Atheneu, 2004. 435p.

HODNETT, E. Pain and women's satisfaction with the experience of childbirth: A systematic review. American Journal of Obstetrics and Gynecology, v.186, supp.5, p.160-S172, 2002. 
HOFFBRAND, S.; HOWARD, L.; CRAWLEY, H. Antidepressant treatment for post-natal depression (Cochrane Review). In: The Cochrane Library, Issue 1, 2006. Oxford: Update Software.

HORIMOTO, C.H.; AYACHE, D.C.G.; SOUZA, J.A. Depressão: diagnóstico e tratamento clínico. São Paulo: Roca. 2005.

HOROWITZ J, DAMATO E, DUFFY M, SOLON L: The relationship of maternal attributes, resources and perceptions of postpartum experiences to depression. Res Nurs Health, v.28, n.2, p159-171, 2005.

HOWARD, L.M. Antidepressant prevention of postnatal depression (Cochrane Review). In: The Cochrane Library, Issue 1, 2006. Oxford: Update Software.

IACONELLI, V. Depressão pós-parto, psicose pós-parto e tristeza materna. Rev Pediatria Moderna; vol.41, n.4, jul.-ago. 2005.

IBIAPINA, F.L.P. et al. Depressão pós-parto: tratamento baseado em evidências. FEMINA, v.38, n.3, p.161-165, mar. 2010.

JATOBÁ, J.D.V.N.; BASTOS, O. Depressão e ansiedade em adolescentes de escolas públicas e privadas. J Bras Psiquiatr, v.56, n.3, p.171-179, 2007.

JABLENSKY, A.V. Pregnancy, Delivery, and Neonatal Complications in a Population Cohort of Women With Schizophrenia and Major Affective Disorders. Am J Psychiatry, v.162, p.79-91, jan. 2005.

JOHANSON, R., et al. The North Staffordshire Maternity Hospital prospective study of pregnancy-associated depression. J Psychosom Obstet Gynaecol, v.21, n.2, p.93-97, jun. 2000.

JOSEFSSON, A. et al. Prevalence of depressive symptoms in late pregnancy and postpartum. Acta Obstet Gyneacol Scand, v.80, n.3, p.251-255, mar. 2001. 
LAMOUNIER, J.A.; MOULIN, Z.S.; XAVIER, C.C. Recomendações quanto à amamentação na vigência de infecção materna. Jornal de Pediatr, v.80, suppl.5, p.181-188, 2004.

LANCETTI, A.; AMARANTE, P. Saúde mental e saúde coletiva. In: CAMPOS et al. (Org.). Tratado de saúde coletiva. 2.ed. São Paulo: Ucitec; Rio de Janeiro: Fiocruz, 2009. p. 615, 628-629.

LEAHY-WARREN, P.; McCARTHY, G. Postnatal Depression: Prevalence, Mother's Perspectives, and Treatments. Archives of psychiatric nursing, v.21,n.2, p. 91-100, apr. 2007.

LEONE, C.; GALLO, P.R. Saúde do jovem, início do século XXI, Brasil. In: LAURIDSEN-RIBEIRO, E.; TANAKA, O.Y. (Org.). Atenção em saúde mental para crianças e adolescentes no SUS. São Paulo: Hucitec, 2010. p.37-44.

LIPPINCOTT, W.; WILKINS I. Enfermagem Psiquiátrica- Incrivelmente Fácil. Rio de Janeiro: Guanabara Koogan; 2005. P.157-87.

LUGO,G.F.O.; MONDRAGÓN, V.J. Trastornos afectivos posparto. UNIVERSITAS MÉDICA, v.47, n.2, p.131-139, 2006.

MAGALHÃES, P.V. DA S. et al. Questões críticas para o tratamentofarmacológico da depressão pós-parto. Rev. Psiq. clín., v.33, n.5, p.245-248, 2006.

MASLACH, C.; SCHAUDELI, W.B.; LEITER, M.P. Job burnout: New directions in research and intervention. Current Directions in Psychological Science, v.12, p.189-192, 2003.

MATTHEY, S. et al. Prevention of postnatal distressor depression: an evaluation of an intervention at preparation for parenthood class. J Affect Disord, v.79, n.1, p.113-26, apr. 2004. 
MAZZIERI, S.P.M. O pai acompanhante no processo de nascimento e parto: narrativas sobre a experiência. São Paulo, 2005. 221 p. Dissertação (Mestrado) - Escola de Enfermagem, Universidade de São Paulo.

MENDES A.V.; LOUREIRO, S. R.; CRIPPA, J.A.S. Depressão materna e a saúde mental de escolares. Rev. Psiq. clín, São Paulo, v.35, n.5, p.178-86. 2008.

MENESES, C.R.A.M. Fatores associados a transtornos mentais comuns e desejo de engravidar em gestantes adolescentes. 2008.126p. Tese (doutor em saúde coletiva) Universidade do estado do Rio de Janeiro, Rio de Janeiro.

MILLER, L. J. Postpartum depression. JAMA, v.287, n.6, p.762-65, feb. 2002.

MITSUHIRO, S.;S. et al. Teenage pregnancy: use of drugs in the third trimester and prevalence of psychiatric disorders. Rev. Psiq. clín, v.28,n.2, p.122-125, jun. 2006.

MONTEIRO, J.C.C.; LAGE, A.N.V. A depressão na adolescência. Psicologia em Estudo, Maringá, v.12, n.2, p.257-265, mai.-ago. 2007.

MORAES, I.G. et al. Prevalência da depressão pós-parto e fatores associados. Rev Saúde Pública, São Paulo, v.40, n.1, p. 65-70, fev. 2006.

MOTTA, C.C.L.; CREPALDI, M.A. O pai no parto e apoio emocional: a perspectiva da parturiente. Paideia - Cadernos de Psicologia e Educação, Ribeirão Preto, v.15, n.30, p.105-118, jan.-abr. 2005.

NEWPORT, J. et al. The treatment of postpartum depression: minimizing infant exposures. J Clin Psychiatry, v.63, suppl.7, p.31-44, 2002.

NICE - National Institute for Health and Clinical Excellence. Antenatal and postnatal mental health: Clinical management and service guidance Issue date: February 2007 (reissued April 2007). 
OATES, M. Perinatal psychiatric disorders: a leading cause of maternal morbidity and mortality. British Medical Bulletin, v.67, n.1, p.219-229, 2003.

OMS - Organização Mundial da Saúde. Classificação de transtornos mentais e de comportamentos da CID-10: Descrições clínicas e diretrizes diagnósticas. Porto Alegre: Artes Médicas; 2009.

PADOVANI, F.L.P. et al. Sintomas de ansiedade e depressão em mães de neonatos pré-termo. Rev Bras Psiquiatr, v.26, n.4, p.251-254, dez. 2004.

PANTOJA, A.L. "Ser alguém na vida": uma análise socio-antropologica da gravidez e maternidade na adolescência, em Belém do Pará, Brasil. Cad Saúde Pública, Rio de Janeiro, v.19, suppl.2, p.335-343, 2003.

PAPALIA, D.E.; OLDS, S.W. Desenvolvimento humano. 7ed. Porto Alegre: Artes Médicas; 2000.

PEREIRA, P.K.; LOVISI, G.M. Prevalência da depressão gestacional e fatores associados - revisão de literatura. Rev Psiq clín, São Paulo, v.35, n.4, p.144-153, 2008.

PEROSA, G.B. et al. Sintomas depressivos e ansiosos em mães de recémnascidos com e sem malformações. Rev. Bras. Ginecol. Obstet., v.31, n.9, p.433-9, 2009.

PORTO,J.R.R.; LUZ, A.N.H. Percepções da adolescente sobre a maternidade. Rev. bras. enferm, v.55, n.4, p.384-391, jul.-ago. 2002.

REIS, A.O.A. O discurso da saúde pública sobre a adolescente grávida: avatares. 1993. 192p. Tese (Doutor em Saúde Pública) - Faculdade de Saúde Pública, Universidade de São Paulo, São Paulo.

REIS, A.O.A. et al. Breve história da saúde mental infanto-juvenil. In: LAURIDSEN-RIBEIRO, E.; TANAKA, O.Y. (Org.). Atenção em saúde mental para crianças e adolescentes no SUS. São Paulo: Hucitec, 2010. p. 
RENNÓ, J.; SOARES, C. N. Transtornos mentais associados ao ciclo reprodutivo feminino. In: LOUZÃ NETO, M.R.; ELKIS, H. Psiquiatria básica. 2ª ed. Porto Alegre: Artmed, 2007. p.418-28.

RIGHETTI-VELTEMA, M. et al. - Postpartum depression and mother-infant relationship at 3 months old. J Affect Disord, v.70, n.3, p.291-306, aug. 2002.

ROGERS, N.; GRUNSTEIN, R. Sleep Loss Symposium Report: working and sleeping around the clock. Med J Aust, v.182, n.9 p.444-445, 2005.

RONDÓ, P.H.C.; SOUZA, M.R. Maternal distress and intended breastfeeding duration. Journal of Psychosomatic Obstetrics \& Gynecology, v.28, n.1, p.5560, mar. 2007.

ROWE, H.J.; FISHER, J.R.W. Development of a universal psycho-educational intervention to prevent common postpartum mental disorders in primiparous women: a multiple method approach. BMC Public Health, 2010, v.10, p.499-514, 2010.

RUSCHI, G.E.C. et al. Aspectos epidemiológicos da depressão pós-parto em amostra brasileira. Rev. psiquiatr. Rio Gd. Sul, Porto Alegre, v.29, n.3, p. 274280, dec. 2007.

SABROZA, A.R. et al. Perfil sócio-demográfico e psicossocial de puérperas adolescentes do Município do Rio de Janeiro, Brasil - 1999-2001. Cad. Saúde Pública, Rio de Janeiro, v.20, suppl.1, p.112-120, 2004.

SADOCK, B.J.; SADOCK, V.A. Compêndio de psiquiatria: ciências do comportamento e psiquiatria clínica. Porto Alegre: Artmed; 2007. p.572-629.

SANDÍ L.E. Validación del inventario de depresión para niños (IDN) en Costa Rica. Acta méd. costarric. v.41, p.10-16, mar. 1999. 
SANTOS et al. Validation of the Edinburgh Postnatal Depression Scale (EPDS) in a sample of mothers from the 2004 Pelotas Birth Cohort Study. Cad. Saúde Pública. v.23, n.11, p.2577-2588, nov. 2007.

SANTOS JUNIOR, H.P.O.; SILVEIRA, M.F.A.; GUALDA D.M.R. Depressão pósparto: um problema latente. Rev Gaúcha Enferm., Porto Alegre (RS), v.30, n.3, p.516-524. set. 2009.

SANTOS M. F. S, MARTINS F. C, PASQUALI L. Escala de auto-avaliação de depressão pós-parto: estudo no Brasil. Rev. psiquiatr. clín., São Paulo, v.26, n.2, p.90-95, mar.-abr. 1999.

SANTOS, S.R.; SCHOR, N. Vivências da maternidade na adolescência precoce. Rev Saúde Pública, v.37, n.1, p.15-23, 2003.

SARAIVA, E.R.A.; COUTINHO, M.P.L. O sofrimento psíquico no puerpério: um estudo psicossociológico. Rev. mal-estar subj, Fortaleza, v.8, n.2, p.505-527, jun. 2008.

SCHMID,T E.B.; PICCOLOTO, N.M.; MÜLLER, M.C. Depressão pós-parto: fatores de risco e repercussões no desenvolvimento infantil. Psico-USF, v.10, n.1, p.61-68, jan.-jun. 2005.

SCHMIDT, R.M. et al. Moderate to severe depressive symptoms among adolescent mothers followed four years postpartum. J Adolesc Health, v.38, n.6, p.712-718, jun. 2006.

SCHWENGBER, D.D.S.; PICCININI, C.A. Estud. Psicol., Campinas, v.22, n.2, p. 143-156, abr.-jun. 2005.

SCIVOLETTO S., TARELHO L. G. Depressão na infância e adolescência. RBM, São Paulo, v.59, n.8, p.555-558, 2002. 
SECCO, M.L. et al. Factors affecting postpartum depressive symptoms of adolescent mothers. J Obstet Gynecol Neonatal Nurs, v.36, n.1, p.47-54, jan.feb. 2007.

SENG, J.S. et al. Posttraumatic Stress Disorder and Pregnancy Complications. Obstet Gynecol., v.97, n.1, p.17-22, jan. 2001.

SIAB. Sistema de Informação da Atenção Básica. Disponível em http://siab.datasus.gov.br/SIAB/index.php; acessado em outubro de 2010;

SILVA, M.C.F.; FUREGATO, A.R.F.; COSTA JUNIOR, M.L. Depressão: pontos de vista e conhecimento de enfermeiros da rede básica de saúde. Rev. Latinoam. Enferm, v.11, n.1, p.7-13, jan.-fev., 2003.

SILVA, M.R.; PICCININI, C.A. Paternidade no contexto da depressão pós-parto materna: revisando a literatura. Estud. psicol. (Natal), Natal, v.14, n.1, p.5-12, jan.-abr. 2009.

SILVEIRA, I. P. da. et al. A percepção do pai frente ao nascimento do seu filho. Rev. RENE, v.5, n.2, p.23-27, jul.-dez. 2004.

SMITH, M.; JAFFE, J. Postpartum depression: signs, symptoms, and help for new moms. Available at http://www.helpguide.org/mental/postpartum depression.htm, accessed on 10/14/10.

SOARES, K. et al. Sintomas depressivos entre os adolescentes e adultos de uma amostra populacional de três centros urbanos brasileiros: análise dos dados do "estudo multicêntrico de morbidade psiquiátrica". Rev. Psiquiatr. clín., São Paulo, v.26, n.5, p.218-24, set.out. 1999.

SODERQUIST, J.; WIJMA, K.; WIJMA, B. Traumatic stress in late pregnancy. Anxiety Disorders, v.18, n.2, p.127-142. 2004. 
SOET, J.E.; BRACK, G.A.; DILORIO, C. Prevalence and predictors of women's experience of psychological trauma during childbirth. Birth, v.30, n.1, p.36-46, 2003.

SOUZA, L.D.M.S. et al. Ideação suicida em pré-adolescentes brasileiros: prevalência e fatores associados. Rev. Bras. Psiquiatr. v. 32, n.1, p.37-41, 2010.

SPADINI, L. S.; SOUZA, M. C. B. M.. A doença mental sob o olhar de pacientes e familiares. Rev. Esc. Enferm. USP, São Paulo, v.40, n.1, p. 123-127, mar. 2006.

SPANEMBERG, L. Postpartum depression: terminological considerations. Rev. psiquiatr. Rio Gd. Sul, Porto Alegre, v.30, n.1, apr. 2008. Carta.

STEFANELLI, M. C., FUKUDA, I. M. K., ARANTES, E. C. Enfermagem Psiquiátrica em Suas Dimensões Assistenciais. Barueri: Manole, 2008. p. 58.

STORTI, J. P. L. O acompanhante no trabalho de parto e parto: expectativas e vivências do casal. Ribeirão Preto, 2004. 118 f. Dissertação (Mestrado apresentada à Escola de Enfermagem de Ribeirão Preta/USP).

STUART, G.W.; LARAIA, M. Tratado de Enfermagem Psiquiátrica. $6^{\circ}$ ed. Porto Alegre: Artmed; 2001.p.380-416.

SZIGETHY, E.M.; RUIZ, P. - Depression among pregnant adolescents: an integrated treatment approach. Am J Psychiatry, v.158, n.1, p.22-27, 2001.

TANNOUS, L.; GIGANTE, L.P.; BUSNELO, E.D. Prevalência de depressão pósparto na cidade de Porto Alegre. In. Transtornos do humor/suicídio. Rev Bras Psiquiatr, 2001,v. 24, suppl.2, p.44-62, 2001,

TAYLOR, C.M. Fundamentos de enfermagem Psiquiatria de Mereness. Porto Alegre: Artes Médicas; 1992. p.202-209. 
TOLEDO V. et al. Perfil de salud mental en adolescentes que interrumpen su embarazo con un aborto. Rev. Soc. Chil. Obstet. Ginecol. Infant. Adolesc.,v.6, n.1, p.14-21, 1999.

TOMELERI, K. R. et al. "EU VI MEU FILHO NASCER": vivência dos pais na sala de parto. Rev. Gaúc. Enferm., Porto Alegre, v.28, n.4, p.497-504, dez. 2007.

TOWNSEND M. C. Enfermagem psiquiátrica - conceitos e cuidados. Rio de Janeiro: Guanabara Koogan S.A.; 2002. p.390-427.

VAN SON, M. et al. Prenatal depression, mode of delivery and perinatal dissociation as predictors of postpartum posttraumatic stress: an empirical study. Clinical Psychol. and Psychotherapy, v.12, p.297-312, 2005.

VESGA-LÓPEZ, O. et al. Arch Gen Psychiatry, v.65, n.7, p.805-815, jul. 2008.

WASHINGTON, D. C. Diagnostic and Statistical Manual of Mental Disorders Text Revised. 4th ed.: American Psychiatric Association (DSM-IV-TR); 2000. p.323-329.

WENDER, M.C.O. et al. Depressão puerperal: atualização.Femina, v.30, n.7, p.439-444, 2002.

WHITE, T. Postnatal depression and post-traumatic stress after childbirth: Prevalence, course and co-occurrence. Journal of Reproductive and Infant Psychology, v.24, n.2, p.107-20, 2006.

WHO- World Health Organization - WHO, 2010. Statistical Information System (WHOSIS). Acessado em 01/10/2010, Disponível em: http://apps.who.int/rhl/pregnancy_childbirth/care_after_childbirth/mgccom/en/

ZAMBALDI, C.F.; CANTILINO, A.; SOUGEY, E. B. Sintomas obsessivo-compulsivos na depressão pós-parto: relatos de casos. Rev. psiquiatr. Rio Gd. Sul, v.30, n.2, p.155158, mai.-ago. 2008.

ZAMORA-CABRAL, R. Diagnóstico de los trastornos depresivos en la adolescência. Rev. argent. clín. psicol., v.7, n.1, p.51-59, abr. 1998. 
ZINGA, D.; PHILLIPS, S.D.; BORN, L. Depressão pós-parto: sabemos os riscos, mas podemos preveni-la? Rev Bras psiquiatr., v.27, suppl. II, p.56-64. 2005.

ZINN-SOUZA, L.C.I. et al. Fatores associados a sintomas depressivos em estudantes do ensino médio de São Paulo, Brasil. Rev. Saúde Pública, São Paulo, v.42 n.1 p.34-40, fev. 2008.

ZLOTNICK, C. et al. Postpartum depression in women receiving public assistance: pilot study of an inter-personal-therapy oriented group program. Am J Psychiatry, v.58, p.539-545, 2001. 


\title{
11. CURRÍCULO LATTES DO ORIENTADOR E DA AUTORA
}

\author{
Alberto Olavo Advincula Reis
}

Possui graduação em Psicologia - Universite de Paris VII - Universite Denis Diderot (1971), mestrado em Psicologia - Universite de Paris VII - Universite Denis Diderot (1977) e doutorado em Saúde Pública pela Universidade de São Paulo (1993). Atualmente é professor Livre Docente da Universidade de São Paulo. Tem experiência na área de Saúde Coletiva, com ênfase em Saúde da Criança do Adolescente e do Jovem, atuando principalmente nos seguintes temas: saúde mental, capsi, adolescente, saúde pública e adolescencia. (Texto informado pelo autor)

Última atualização do currículo em 15/09/2010

Endereço para acessar este $\mathrm{CV}$ :

http://lattes.cnpq.br/2335295597324821

\section{Certificado}

pelo autor em

15/09/10

Dados pessoais

Nome

Nome em citações

bibliográficas

Sexo

Endereço profissional
Alberto Olavo Advincula Reis

REIS, Alberto Olavo Advincula; Reis, Alberto OA

Masculino

Universidade de São Paulo, Faculdade de Saúde Pública, Departamento de Saúde Materno-Infantil.

Av. Dr Arnaldo $7152^{\circ}$ andar

Cerqueira Cesar

01246-904 - Sao Paulo, SP - Brasil

Telefone: (11) 30667126 Fax: (11) 30850240

URL da Homepage: $\underline{\text { www.fsp.usp.br }}$ 
Elisabeth Octaviano Kogima

possui graduação em Graduação em Enfermagem e Obstetrícia pela Faculdade Adventista de Enfermagem (1983), graduação em Tecnologia em Processamento de Dados pela Universidade Presbiteriana Mackenzie (1993), Especialização em Obstetrícia pela EEUSP (1996) e mestrado em Saúde Pública pela Universidade de São Paulo (2004). Atualmente é professora de ensino superior do Centro Universitário Adventista de São Paulo U N A S P. Tem experiência na área de Enfermagem, com ênfase em Enfermagem Psiquiátrica, atuando principalmente nos seguintes temas: depressão, puérpera, saúde mental, cuidadores e transtorno afetivo bipolar.

(Texto informado pelo autor)

Última atualização do currículo em 18/04/2010

Endereço para acessar este $\mathrm{CV}$ :

http://lattes.cnpq.br/3162621848880427

Certificado

pelo autor em

18/04/10

\section{Dados pessoais}

Nome

Nome em citações

bibliográficas

Sexo

Endereço profissional
Elisabeth Octaviano Kogima

KOGIMA, E. O.

\section{Feminino}

Centro Universsitário Adventista de São Paulo, Curso de Enfermagem.

Estr. de Itapecirica da Serra, 5859

Jd. IAE

05858-001 - Sao Paulo, SP - Brasil - Caixa-Postal: 12630

Telefone: (011) 58226166 Ramal: 6172 


\section{ANEXOS}

\section{ANEXO I}

Folha de rosto da apresentação da escala conforme será aplicada às puérperas

\section{Escala de Edimburgo}

J. L. Cox, J. M. Holden, R. Sagovsky, 1987

(C) British Journal of Psychiatry

tradução: Maria Fátima S. dos Santos e Célia C. Moraes

supervisão de tradução: Prof. João Dino F. P. Santos

Depto. de Letras _ UnB

validação: Maria Fátima S. Santos, Francisco M. C. Martins e Luis Pasquali _ Depto. de Psicologia _ UnB

Seu nome:

Data de nascimento do bebê:

Você teve há pouco tempo um bebê e nós gostaríamos de saber como você está se sentindo. Por favor, marque a resposta que mais se aproxima do que você tem sentido NOS ÚLTIMOS SETE DIAS, não apenas como você está se sentindo hoje.

Aqui está um exemplo já preenchido:

Eu tenho me sentido feliz:

$\square$ Sim, todo o tempo.

凶Sim, na maior parte do tempo.

$\square$ Não, nem sempre.

$\square$ Não, em nenhum momento.

Esta resposta quer dizer: "Eu me senti feliz na maior parte do tempo" na última semana.

Por favor, assinale as questões seguintes do mesmo modo. 
Texto da EPDS conforme validação no Brasil

\section{Nos últimos sete dias}

1. Eu tenho sido capaz de rir e achar graça das coisas.

$\square$ Como eu sempre fiz.

$\square$ Não tanto quanto antes.

$\square$ Sem dúvida menos que antes.

$\square$ De jeito nenhum.

2. Eu sinto prazer quando penso no que está por acontecer em meu dia-a-dia.

$\square$ Como sempre senti.

$\square$ Talvez menos do que antes.

$\square$ Com certeza menos.

$\square$ De jeito nenhum.

3. Eu tenho me culpado sem necessidade quando as coisas saem erradas.

$\square$ Sim, na maioria das vezes.

$\square$ Sim, algumas vezes.

$\square$ Não muitas vezes.

$\square$ Não, nenhuma vez.

4. Eu tenho me sentido ansiosa ou preocupada sem uma boa razão.

$\square$ Não, de maneira alguma.

$\square$ Pouquíssimas vezes.

$\square$ Sim, alguma s vezes.

$\square$ Sim, muitas vezes.

5. Eu tenho me sentido assustada ou em pânico sem um bom motivo.

$\square$ Sim, muitas vezes.

$\square$ Sim, algumas vezes.

$\square$ Não muitas vezes.

$\square$ Não, nenhuma vez. 
6. Eu tenho me sentido esmagada pelas tarefas e acontecimentos do meu dia-a-dia.

$\square$ Sim. Na maioria das vezes eu não consigo lidar bem com eles.

$\square$ Sim. Algumas vezes não consigo lidar bem como antes.

$\square$ Não. Na maioria das vezes consigo lidar bem com eles.

$\square$ Não. Eu consigo lidar com eles tão bem quanto antes.

7. Eu tenho me sentido tão infeliz que tenho tido dificuldade de dormir.

$\square$ Sim, na maioria das vezes.

$\square$ Sim, algumas vezes.

$\square$ Não muitas vezes.

$\square$ Não, nenhuma vez.

8. Eu tenho me sentido triste ou arrasada.

$\square$ Sim, na maioria das vezes.

$\square$ Sim, muitas vezes.

$\square$ Não muitas vezes.

$\square$ Não, de jeito nenhum.

9. Eu tenho me sentido tão infeliz que tenho chorado.

$\square$ Sim, quase todo o tempo.

$\square$ Sim, muitas vezes.

$\square$ De vez em quando.

$\square$ Não, nenhuma vez.

10. A idéia de fazer mal a mim mesma passou por minha cabeça.

$\square$ Sim, muitas vezes, ultimamente.

$\square$ Algumas vezes nos últimos dias.

$\square$ Pouquíssimas vezes, ultimamente

$\square$ Nenhuma vez. 


\section{ANEXO II}

\section{QUESTIONÁRIO SÓCIO-ECONÔMICO E OBSTÉTRICO}

I - Informações sociodemográficas:

1.1 Idade:

1.2 Estado civil : ( ) solteira ( ) casada ( ) divorciada ( ) mora com companheiro

1.3 Que cor atribui a sua pele: ( ) branca ( ) negra ( ) parda ( ) amarela

1.4 Até que série você estudou?

1.5 Quanto a sua família ganha por mês?

1.6 Você mora com o pai do bebê?

1.7 Você usa algum medicamento diário? Se sim,

qual? ___

1.8 Você usa algum tipo de droga? Se sim, qual?

II - Aspectos relacionados à moradia:

2.1 - Sua moradia é: ( ) casa ( ) apartamento ( ) cômodo

2.2 - O material usado na construção é: ( ) alvenaria ( ) madeira ( ) outro:

2.3 - Quantos cômodos têm na moradia?

2.4 - Quantas pessoas moram na casa?

2.5 - Quem é o dono da moradia?

2.6 - A moradia possui água encanada?

2.7 - A moradia possui esgoto ou fossa? 
2.8 - O lixo é coletado diariamente ou jogado em terreno vizinho?

2.9 - A moradia tem eletricidade? ( )sim ( ) não

2.10 - Na moradia têm: ( ) fogão a gás ( ) geladeira ( ) televisão )máquina de lavar roupa ( ) computador ( ) telefone ( ) filtro de água

III - Aspectos relacionados à adolescente e à maternidade:

3.1 - Qual foi sua reação quando descobriu que estava grávida? 3.2 - $\quad$ E a reação da sua família? 3.3 - E a reação do seu companheiro?

3.4 - Parou de estudar durante a gravidez ou após o parto? Se sim, quais os motivos?

3.5 - Qual a sua idade do pai do bebê?

3.6 - Quantos filhos você tem? Qual a idade deles, inclusive a do bebê?

3.7 - Quais foram os tipos de parto que você já teve? Quem ficou com você durante o parto?

3.8 - Qual o tipo de parto que você preferia ter tido?

3.9 - Você fez quantas consultas de pré-natal?

3.10 - Se você faltou a alguma consulta de pré-natal, quais foram os motivos?

3.11 - Quem ajudou ou ainda ajuda você nos cuidados com o bebê? Como está seu lazer, alimentação, sono e seu cuidado com a aparência e higiene? 
IV - Aspectos relacionados Unidade de Saúde da Família:

3.1 - A Unidade de Saúde é longe da sua casa? 3.2 - Você já teve dificuldade para marcar consulta alguma vez?

3.3 - Você acha que as consultas de pré-natal esclareceram as suas dúvidas?

3.4 - Você já teve algum problema em receber os remédios na Unidade de Saúde?

3.5 - Com quem você teve mais contato na Unidade Básica de Saúde durante o pré-natal?

3.6 - Esse contato continuou igual após o parto? 


\section{ANEXO III}

\section{TERMO DE CONSENTIMENTO LIVRE E ESCLARECIDO}

Você está sendo convidada como voluntária a participar da pesquisa: "Depressão puerperal na adolescência: descobrindo o olhar da puérpera adolescente". O motivo que nos leva a estudar o problema da depressão na adolescência é estarmos percebendo que muitas adolescentes apresentam sintomas de depressão após o parto que muitas vezes passam despercebidos pelo companheiro, pela família e até pela própria adolescente. Desta forma a pesquisa se justifica no sentido de buscar conhecer melhor quais as melhores formas de amenizar as dificuldades neste período pós-parto, incluído as sugestões da própria mãe adolescente. O objetivo desse projeto é conhecer que proporção de adolescentes enfrenta sintomas depressivos após o parto e quais são suas sugestões quanto à ajuda necessária que este período seja mais prazeroso para a mãe, para o bebê e familiares. Se você sentir necessidade de acompanhamento quanto a sintomas emocionais de depressão será agendado o seu atendimento pela equipe da Unidade.

O procedimento de coleta de material dados será através de um questionário que pode ser respondido tanto por você, mãe adolescente ou, se preferir, com a ajuda da pesquisadora. Serão respeitadas suas possibilidades de dia e horário de forma a não prejudicar sua rotina.

Você será esclarecida sobre a pesquisa em qualquer aspecto que desejar. Você é livre para recusar-se a participar, retirar seu consentimento ou interromper a participação a qualquer momento. A sua participação é voluntária e a recusa em participar não irá acarretar qualquer penalidade ou perda de benefícios. Em caso de você apresentar algum gasto com transporte a pesquisadora se compromete em arcar com essa despesa.

A pesquisadora irá tratar a sua identidade com padrões profissionais de sigilo. Os resultados dos questionários permanecerão confidenciais. Seu nome ou o material que indique a sua participação não será liberado sem a sua permissão. Você não será identificada em nenhuma publicação que possa resultar deste estudo. Uma cópia deste consentimento informado será arquivada no Curso da Pós-Graduação da Faculdade de Saúde Pública da Universidade de São Paulo e outra será fornecida a você. 
$\mathrm{Eu}$, fui informada (o) dos objetivos da pesquisa acima de maneira clara e detalhada e esclareci minhas dúvidas. Sei que em qualquer momento poderei solicitar novas informações e motivar minha decisão se assim o desejar. A pesquisadora Elisabeth Octaviano Kogima certificou-me de que todos os dados desta pesquisa serão confidenciais. Em caso de dúvidas poderei chamar a pesquisadora Elisabeth Octaviano Kogima no telefone (11) 58165834 ou o Comitê de Ética em Pesquisa da Faculdade de Saúde Pública da Universidade de São Paulo, sito à Av. Dr. Arnaldo, 715, Cerqueira César - São Paulo, SP.

Declaro que concordo em participar desse estudo. Recebi uma cópia deste termo de consentimento livre e esclarecido e me foi dada a oportunidade de ler e esclarecer as minhas dúvidas.

\begin{tabular}{lll}
\hline Nome & Assinatura do Participante & Data \\
\hline Nome & Assinatura do Pesquisador & Data \\
\hline Nome & Assinatura do Responsável & Data
\end{tabular}




\section{ANEXO IV}

\section{VARIÁVEIS UTILIZADAS}

As variáveis sócio-demográficas analisadas foram: idade da puérpera, "1419 anos" e "20 anos"; idade do companheiro, categorizado em "17-19 anos", "2025 anos" e "26-31 anos"; idade do filho, como "1-5 meses" e "6 ou mais meses"; estado civil, "mora com companheiro", "solteira" e "casada"; cor de pele, caracterizada "em branca", "negra", "parda" e "amarela"; escolaridade, categorizado em "médio incompleto", "médio completo", "fundamental incompleto", "fundamental completo" e "superior incompleto"; renda familiar, categorizada em "100-550 reais", "600-800 reais", "ignorados", "1800-2000 reais"; morar com o pai do bebê, uso de medicamento diário e uso de droga, categorizados em "sim" e "não".

Quanto à condição de moradia, as variáveis foram: tipo de moradia, casa, apartamento e cômodo; material usado na construção categorizado em "alvenaria" e "madeira"; número de cômodos com corte em 5 cômodos; número de pessoas que moram na casa, categorizados em "menos que três", "três" e "mais"; dono da moradia categorizado em "alugada", "cedida" e "própria"; presença de água encanada, presença de esgoto, categorizados em "sim" e "não"; coleta do lixo diariamente categorizado em coletado pela prefeitura "1 vez por semana", "2 vezes por semana" e "não coletado"; posse de fogão a gás, geladeira, televisão, máquina de lavar roupa ou tanquinho, computador, telefone e filtro de água, categorizados em "sim" e "não".

Quanto aos aspectos obstétricos, as variáveis foram: reação da puérpera ao descobrir que estava grávida, reação da família ao descobrir que a adolescente estava grávida e reação do companheiro ao descobrir a gravidez da companheira, categorizadas em "boa", "ruim" e "indiferente". Interrupção dos estudos relacionada à maternidade, categorizado em "sim" e "não"; número de filhos tido; tipo de parto que teve "normal" e "cesárea"; tipo de parto que você preferia ter tido "normal" e "cesárea"; número de consultas de pré-natal; faltou a alguma consulta de pré-natal, categorizado em "não" e "sim"; quem ajudou ou ainda ajuda você nos cuidados com o bebê, categorizado em "mãe ou pai", "dois ou mais familiares", "sogra ou amiga" e "ninguém". 
Quanto aos aspectos relacionados à ESF, as variáveis foram: unidade de saúde é longe da sua casa, dificuldade em marcar consulta, esclarecimento de dúvidas durante o pré-natal, dificuldade em receber medicamentos, categorizados em "sim" e "não"; contato mais presente durante o pré-natal "médico", "enfermeira", "2 ou mais profissionais" e "agentes comunitários"; esse contato continuou igual após o parto categorizada em "sim" e UBS, categorizada em "progresso", "sapateiro" e "penteado".

$\mathrm{O}$ estudo restringiu-se as adolescentes com probabilidade ou risco de apresentarem os sintomas depressivos. Adotou-se a Escala de Depressão Pósparto de Edimburgo (anexo II), utilizando-se o ponto de corte 12. Assim, todos os adolescentes que apresentam a escala igual ou maior a 12 foram considerados com risco de apresentar os sintomas depressivos. 


\section{ANEXO V}

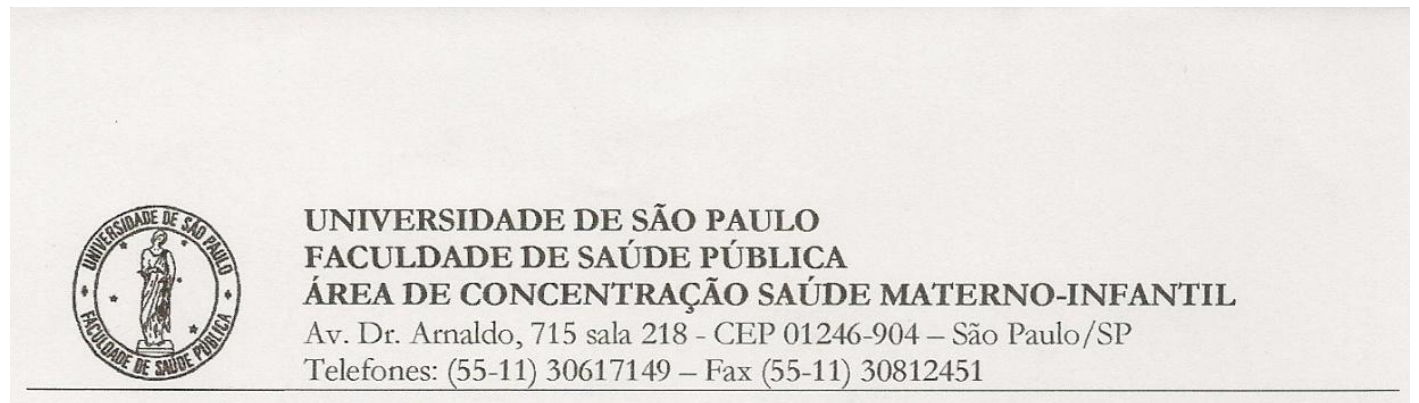

RELATÓRIO DO EXAME DE QUALIFICAÇÃO DA CANDIDATA AO TÍTULO DE "DOUTOR EM SAÚDE PÚBLICA", ÁREA DE CONCENTRAÇÃO SAÚDE MATERNO-INFANTIL ELISABETH OCTAVIANO KOGIMA

Aos vinte e sete dias do mês de novembro de 2008 às 9h30, na sala Diógenes Augusto Certain da Faculdade de Saúde Pública da USP, reuniu-se a Comissão Julgadora composta pelos membros Doutora Diva Maria Faleiros de Camargo Moreno, Professora Carmen Simone Grilo Diniz - Departamento de Saúde Materno-Infantil e Professor Alberto Olavo Advincula Reis - Departamento de Saúde Materno-Infantil da FSP/USP (Orientador e Presidente da Comissão), para a realização do Exame de Defesa do Projeto da candidata ao título de "Doutor em Saúde Pública" área de concentração Saúde Materno-Infantil - ELISABETH OCTAVIANO KOGIMA, de acordo com as Normas e Instruções dos Cursos de PósGraduação da Faculdade de Saúde Pública da Universidade de São Paulo. A candidata apresentou o projeto de tese intitulado: "DEPRESSÃO PUERPERAL NA ADOLESCÊNCIA: DESCOBRINDO O OLHAR DA PUÉRPERA ADOLESCENTE". A Comissão Julgadora passou à argüição pública da candidata. Encerrados os trabalhos de argüição, os examinadores deram o parecer final:

Doutora Diva Maria Faleiros Camargo Moreno

Aprovado(a) $₫ \quad$ Reprovado $\square$

CPF: 000.612.968-48

Professora Doutora Carmen Simone Grilo Diniz

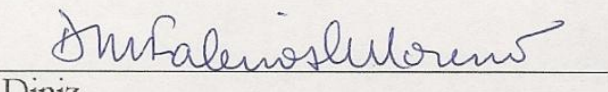

Aprovado(a) \& Reprovado $\square$

CPF: 297.227.134-34

Professor Alberto Olavo Advincula Reis

Aprovado(a) \ Reprovado $\square$

CPF: $131.614 .586-72$

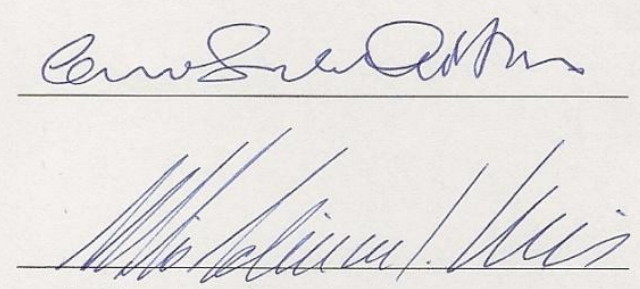

Presidente da Comissão Examinadora

- Orientador - 